\title{
REFERENCE
}

Al1106 6906】?

NBSIR 74-479

Analysis of Cost-Sharing Programs

for Pollution Abatement of

Municipal Wastewater

Harold E. Marshall and Rosalie T. Ruegg

Buslding Economics Section

Institute for Applied Technology

National Bureau of Standards

Washington, D. C. 20234

September, 1974

Final Report

Prepared for

Office of Research and Monitoring

U.S. Environmental Protection Agency

Washington, D. C. 20460

100

.456

$\# 74-479$

1974 



\section{ANALYSIS OF COST-SHARING PROGRAMS FOR POLLUTION ABATEMENT OF MUNICIPAL WASTEWATER}

Harold E. Marshall and Rosalie T. Ruegg

Building Economics Section

Institute for Applied Technology

National Bureau of Standards

Washington, D. C. 20234

September, 1974

Final Report

Prepared for

Office of Research and Monitoring

U.S. Environmental Protection Agency

Washington, D. C. 20460

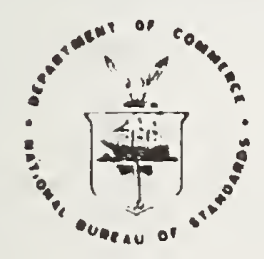

U. S. DEPARTMENT OF COMMERCE, Frederick B. Dent, Secretan

NATIONAL BUREAU OF STANDARDS, Richard W. Roberts. Director 
Abstract iv

Figures $\quad$ v

Exhibits v

Tables vi

Acknowledgments vil

\section{$\underline{\text { Sections }}$}

I Executive Summary 1

II Introduction 7

$\begin{array}{ll}\text { Purpose } & 7\end{array}$

$\begin{array}{lr}\text { Scope and Approach } & 8\end{array}$

$\begin{array}{lr}\text { General } & 9\end{array}$

$\begin{array}{ll}\text { Organization } & 15\end{array}$

III Description of Existing Cost-Sharing Programs and 19

Institutional Constraints

$\begin{array}{ll}\text { Construction Grant Program } & 19\end{array}$

Eligibility for Grants as Defined in 23 Legislation

Eligibility for Grants in Practice 26

Cost Sharing By Other Agencies $\quad 32$

Institutional Constraints to Abatement 34

IV Theoretical Relationships 39

Selective Survey of the Literature $\quad 39$

Derivation of Demand $\quad 43$ 
CONTENTS-continued

$\underline{\text { Page }}$

$\begin{array}{ll}\text { Conditions for Efficlency } & 48\end{array}$

$\begin{array}{ll}\text { Techniques } & 49\end{array}$

$\begin{array}{ll}\text { Scale } & 55\end{array}$

$\begin{array}{ll}\text { Characteristics of Equity } & 64\end{array}$

V Efficlency Implications of Existing and Alternative 70 Cost Sharing Programs

$\begin{array}{ll}\text { Techniques } & 70\end{array}$

$\begin{array}{lr}\text { Scale } & 81\end{array}$

VI Effects of User Fees on Cost Shares 90

Leglslated User Fees $\quad 91$

Alternative Interpretations 93

$\begin{array}{ll}\text { Interest Charges in User Fees } & 102\end{array}$

User Fee Implications $\quad 104$

VII Summary, Findings, and Suggestions for Further 112

Research

$\begin{array}{ll}\text { Summary } & 112\end{array}$

$\begin{array}{ll}\text { Findings } & 114\end{array}$

$\begin{array}{ll}\text { Suggestlons for Further Research } & 121\end{array}$

$\begin{array}{ll}\text { Appendix } & 123\end{array}$

$\begin{array}{lr}\text { Blbliography } & 135\end{array}$ 
This study evaluates existing cost-sharing programs for wastewater pollution abatement as described in the Federal Water Pollution Control Act Amendments of 1972, describes alternative cost-sharing programs that provide improvements in terms of national efficiency and equity criteria as defined herein, and suggests related areas for further research. Emphasis is on how Federal cost sharing biases communities in favor of certain kinds of techniques. The approach is to describe the current cost-sharing programs for both plant and nonplant techniques; to examine cost-sharing, legal, and other institutional biases against certain techniques; to analyze efficiency and equity effects of alternative cost-sharing programs; and to describe the incentive effects of cost sharing on nonfederal interests with respect to their choices among abatement techniques. Findings of the study are that more efficient abatement will result if the same percentage cost share applies to all plant and nonplant techniques of abatement; the same percentage also applies to all categories of cost (e.g., capital, land, operation and maintenance) for a given technique; the same percentage applies to large and small communities; institutional constraints on the selection of nonplant techniques are removed; and if the program provides for Federal cost sharing of every abatement technique that is technically viable.

This report was submitted in fulfillment of Program Element PE $1 B A 030$ and Work Order Number EPA-IAG D4 H 374 by the National Bureau of Standards, Bullding Economics Section. 


\section{FIGURES}

No.

Page

1 Combined and Separate Municipal Sewer Systems

2 Alternative Approaches to Reduction of Wastewater Pollution

Indifference Curves and Budget Constraints

Demand for Pollution Abatement

5 Demand for Pollution Abatement, With and Without Enforcement

6 Insufficient Demand for Pollution Abatement

Cost Share for Efficient Technique(s)

Cost Share for Efficient Scale

9 Average Cost and Efficient Scale of Pollution Abatement

10 Efficient Scale with Regional Abatement

\section{EXHIBITS}

1 Alternative Techniques for Abating Wastewater Pollution

Allowable and Unallowable Project Costs Under the Construction Grant Program 
No.

$\underline{\text { Page }}$

1 Cost of Some Alternative Techniques for

Meeting the Dissolved Oxygen Objective

of 4 PPM in the Potomac Estuary

2 Eligibility for EPA Construction Grants of

Alternative Techniques, by Cost Cateogry

Grants by EPA and Other Federal Agencies as a

Share of Eligible and Total Project Costs as of

December 31, 1972

4 Maximum Federal Cost Shares for Sewer Facilities

Provided by HUD, FHA, and EDA

Impact on Local Project Cost of Different Cost-

Sharing Rules: An Illustration

Impact on Choice of Techniques of a Cost-Sharing

Rule Which Does Not Apply Equally to All

Categories of Cost

Determination of a Cost-Sharing Constraint to

Reduce Potential Bias in Selection of Abatement

Techniques

$8 \quad$ Federal and Nonfederal Expenditure Requirements of Alternative Cost-Sharing Rules Viewed Historically

Illustration of a Grantee's Costs for a

Application of Pollution Abatement Techniques To Major Problems of Municipal Waste Treatment Systems 


\section{ACKNOWL.EDGMENTS}

The authors wish to thank the project monitor, Dr. Marshall Rose, and Dr. Roger Shull, both in the Implementation Research Division, for help in defining the bounds of this research effort. We also acknowledge the many persons in the Environmental Protection Agency and in state agencies who patiently explained to us many 1ssues concerning waste treatment and discussed with us the potential impacts of alternative cost-sharing programs. Finally, we are indebted to those persons in the National Bureau of Standards, especially Dr. Vartkes Broussallan and Dr. Peter Colwe1l, who gave helpful comments in the course of the in-house review process. The responsibility for all errors and shortcomings in the paper, however, rests with the authors. 



\section{SECTION I}

\section{EXECUTIVE SUMMARY}

The Environmental Protection Agency (EPA) administers the Construction Grant Program for the abatement of wastewater pollution. The Federal Water Pollution Contro1 Act Amendments of 1972 (1972 Act) describe to some extent the eligibility requirements for a community to apply for EPA grants and the percentage Federal cost shares that can be awarded for community abatement projects.

The Construction Grant Program, as enacted by the 1972 Act and administered by EPA, has been criticized for being inefficient in that it encourages a misallocation of resources in wastewater pollution abatement. The purpose of this study, undertaken at the request of EPA, is to evaluate the existing and alternative cost-sharing programs primarily with respect to efficiency and to some extent equity (see Section IV for definitions of efficiency and equity). Cost sharing affects efficiency through its incentive effects on the choices by local communities for one kind or size of abatement program over another. Cost sharing affects equity in abatement through its differential treatment of participating communities. The existing cost-sharing program as described in the 1972 Act and implemented by Agency regulations is discussed. Theoretical relationships between cost sharing and its incentive effects on community decisions regarding the size of abatement projects and the kind of techniques used therein are Identified. Case examples 1llustrate the biasing effects on communities of current rules that apply different cost-sharing percentages to different techniques and to different cost categories. Local communities have incentives to pick techniques which cost them the least money, but under 
existing rules, these are not necessarily the least-cost techniques to the nation. Equity in the sense of falrness to parties particlpating in abatement seems violated in that cost sharing is not directly related to or varied with benefits received. Finally, legal and other institutional constraints appear to play a significant role in affecting what techniques, plant or nonplant, are chosen by communities seeking assistance in pollution abatement. Specific findings of the study are summarized below:

(1) Application of the same percentage cost share to all plant and nonplant techniques for the purpose of abating wastewater pollution will encourage nonfederal interests to simultaneously select the combination of techniques which is least costly to the nation as well as to themselves. Applying the same share (regardless of what that share 1s) across all techniques will eliminate the potential cost-sharing bias for some techniques over others (e.g., for plant over nonplant techniques) that exists under the current rules. (See Sections IV and $V_{.}$)

Granting of cost-sharing eligibility to all technically viable alternatives would encourage consideration of new technologles. Where only part of a multiple-purpose project is abatement, sharing only those costs that could properly be allocated to abatement per se would encourage the efficient scale of abatement. Thus a lower Federal cost share would apply to techniques that provide other benefits in addition to abatement; than to techniques which provide abatement on $1 \mathrm{y}$, and the cost share would decrease as the cost of providing those other benefits increases relative to the cost of abatement.

(2) Application of the same percentage cost share to all categorles of project costs (1.e., to capital; to land for both site and process; "for operation and malntenance; and to planning) wil1 encourage community selection of the nationally least-cost technique(s) of providing abatement. Because operation and maintenance costs are not currently shared at all by the Federal government, while capital costs are shared, grant recipients are blased towards capital-intensive techniques even though all techniques may be eligible for the same percentage share of capital cost. (See Sections IV and $V_{\text {. }}$ ) 
Where only one category of cost (e.g., capltal) can be shared, two alternative approaches for encouraging local selection of the least-cost technique(s) might be considered in lieu of the same percentage for all categories. The first approach is to vary the share of the single cost category to be subsidized so that the local share as a percentage of total project costs ( $1 . e$, the effective cost share) w1ll be uniform across all techniques. A second approach, still providing a Federal share for one category only, would impose a constraint on the percentage of total costs that the Federal agency could bear. The cost-sharing bias would be reduced to a degree dependent on how low the constraint is, and in some cases would be completely eliminated.

(3) Nationally efficient scales of abatement would be encouraged by reducing the effective Federal cost share.

The legislation governing the Construction Grant Program does not specify nationally efficient scales of abatement (1.e., the maximization of national net benefits) as an objective of the'program (see Section III). If, however, this were an objectlve, the Association Rule (see Section IV) could accomplish it by encouraging grant reciplents to choose a scale of abatement that is nationally as well as locally efficient. For most projects, existing Federal cost shares probably exceed those that would be obtained from applying the Association Rule (see Section V). Lower Federal shares would tend to encourage more efficient scales of abatement, but could nevertheless be set large enough to provide some incentive for communities to expand their abatement activities. Since adequate information regarding the incidence of abatement benefits is not avallable, further research is needed before speciflc percentage cost shares can be selected. (4) Varying cost shares in proportion to community size, other things being equal, may lead to inefficient scales of abatement.

Over some range of abatement levels, the average cost of abatement 1s likely to fall as a result of economies of scale. Assuming that this range of decreasing average cost extends to large scales of abatement, big cities with large demands for abatement would be expected to have lower average costs than small cities with less demand for abatement. 
One way of encouraging small cities to demand higher levels of abatement and thereby profit from economies of scale is to ralse the percentage cost share for small citles above that of big citles. However, the efficlent scale of abatement for a small city may be much less than that scale at which average costs are minimized (see Section IV). Thus, applying preferential Federal cost shares to small cities to encourage them to take advantage of economies of scale may result in oversized projects from the standpoint of maximizing net benefits from abatement. Achleving efficient levels of abatement is not necessarily incompatible with taking advantage of economies of scale, however. For example, it might be advantageous to individual cities as well as the nation for cities to join in the construction of reglonal treatment plants that would lower the average cost of abatement to all while at the same time providing the efficient level of abatement.

(5) Returning all industrial user fees collected against the Federal grant to EPA for redistribution through the Construction Grant Program w111 eliminate the problems described below, without reducing the amount of funds avallable to municipalities.

Existing Federal user fee practice allows grantees to retain part of the user fees collected from industry to repay industry's share of the Federal grant. Retention of these user fees by the grantee increases the Federal subsidy and reduces the effective cost share to the grantee. The more industrialized the community, the larger this additional subsidy and the lower the effective cost share of the grantee. This practice has the following effects: (a) the tendency towards construction of larger-thanefficlent scales of abatement is increased because the grantee's effective share of cost is thereby reduced; (b) the bias towards capital-intensive and eligible land-intensive projects is increased, because the grantee's effective cost share is inversely related to the amount of capital and eliglble land costs that are attributable to industry; (c) a larger Federal subsidy is provided to Industrialized communities than to residential communitie:s, because the amount of retained user fees is dependent on the construction cost of facilities provided to industry. (See Section VI.) 
(6) Including an interest charge in user fees collected from industry against the Federal grant would help assure that industry pald its full share of costs. Under existing arrangements, Industrial users tend to be substantially undercharged for their part of the costs of facilities because they pay no interest on their part to reflect the time value of money. Hence, the user fee revenue is much less than it would be if industry repaid the full cost of treating its wastewater. (See Section VI.)

(7) Legal and other institutional constraints exist which bias against the selection of efficient abatement techniques.

The following steps might be considered for ellminating these blases: (a) educational and promotional efforts to encourage planners to consider nonplant techniques; (b) encouragement by grant officials of applicants to consider fully abatement alternatives during the initial project planning stages; (c) establishment of architects'/engineers' fees based upon operation and maintenance costs, as well as capital costs, to avoid bias towards capital-intensive techniques; (d) encouragement of regional management of wastewater abatement to reduce the inefflciencies resulting from the narrow view taken by smal1 jurisdictions; and (e) the same treatment of all abatement techniques in the law, the regulations, and the program. (See Section III.)

In summary, this study has identified action that would increase the local share of abatement costs; reduce the cost-sharing bias toward capitalIntensive and eligible land-intensive projects; reduce the cost-sharing bias for some plant over nonplant techniques; increase the Federal and local expenditures on nonplant techniques relative to plant techniques; Increase the community demand for nonplant techniques; increase the degree of abatement per national dollar spent, and in general result in more efficient and equitable profects.

Additional areas of research were identified that might be of value to EPA in meeting its objectives of encouraging efficient abatement and of treating cost-sharing parties equitably. One type of research needed is an Investigation of how institutional requirements affect communities' selections of techniques of abatement. A second research problem is the 
determination of the optimal points in time for reducing and/or eliminating pollution abatement grants. A third potential area ts the analysis of the link between levels of local performance in abatement and rewards or grants based on good performance. A loan program for capital that reduces the amount to be pald back as performance improves should be studled. A fourth area of research should be the determination of community objective functions in pollution abatement to see if communities are really concerned with collection and disposal. A fifth area of research would be to investigate the responsiveness to varying cost shares of communfty demand for nonplant techniques. Additional perspective that is needed to analyze the potential biases against nonplant techniques might be obtained through these areas of research. 
SECTION II

INTRODUCTION

PURPOSE

The Environmental Protection Agency (EPA) was directed by Section 317 of the 1972 Amendments to the Federal Water Pollution Control Act, ${ }^{1}$ hereafter referred to as the $1972 \mathrm{Act}$, to continue to investigate and study the feasibility of alternative financing methods for preventing, controlling, and abating pollution. Implicit in this directive is a responsibility to examine cost-sharing programs for nonplant* control and treatment of sewage as well as for conventional plant treatment techniques. The purpose of this study is to provide EPA with an evaluation of alternative costsharing programs both for plant and nonplant prevention, control, and treatment, hereafter referred to as abatement.

The study will evaluate exlsting cost-sharing arrangements for their national efficiency and equity effects and will recommend alternative practical cost-sharing programs that will lead to more nationally efficient profects and more equitable dealings with communities seeking assistance in water pollution abatement. Cost-sharing rules will be proposed that (1) will promote selection by local communties of the nationally least-cost techniques for providing pollution abatement, (2) will promote selection by local communities of the nationally efficient scale of abatement, and (3) will treat each local community in the same manner with respect to certain defined conditions of fair treatment, 1.e., equity.

* Nonplant control and treatment here refer to all processes "outside the fence" (see Figure 1). 
SCOPE AND APPROACH

Because EPA's Construction Grant Program is the major program through which cost-sharing rules set forth in the 1972 Act are implemented, it is the focus of this study. The incentive effects of cost sharing under the Construction Grant Program are emphasized. "Cost sharing" as used in this report refers to the rules for sharing project costs between Federal and nonfederal participants in a pollution abatement project. "Incentive. effects" refers to the way in which cost-sharing programs might encourage, or blas, local communitles to pick one kind or size of abatement program over another.

The incentive effects of cost sharing are examined from the standpoint of two efficiency problems that might arise from a cost-sharing bias. One problem is that nonfederal interests may be induced to choose a technique for abating pollution that is not cost effective from the viewpoint of society (i.e., the nation), although it may be least costly for nonfederal interests. Another arises in terms of the scale of abatement to be considered (regardless of the technique(s)' chosen for a particular project. Local communities will be influenced by cost sharing in deciding how large a project to build. If Federal grants are too large, local communities will be encouraged to opt for projects that are overdeveloped in the national sense, $1 . e .$, too many resources are allocated to abatement at the expense of other types of investment projects. If Federal grants are too low, local communities will be encouraged to opt for projects that are underdeveloped in the national sense, i.e., too few resources are allocated to abatement relative to competing investment profects.

In addition to the examination of biasing effects in the cost-sharing rules per se, the report also examines user fee arrangements for their impact on effective* cost shares. By changing the effective cost shares, user fees are found to influence the community government's choice of abatement programs.

*The effective cost share is the actual percentage of total abatement costs that a project participant must bear after taking into consideration the cost-sharing rule and other factors which affect the ultimate cost share. 
The two types of efficiency issues--the least-cost technique(s) and the efficlent scale--are examined in the theoretical discussion. However, the emphasis is placed on cost-sharing incentives as they relate to encouraging the selection of the nationally least-cost technique(s), as this appears to be the more prevalent problem and the one for which corrective measures could be implemented most easily in practice.

In its focus on cost sharing, the study does not review other economic tools which could be used to encourage polluters to control their wastes in a particular manner. For example, selective payments to waste dischargers for waste reduction, low-interest loans for pollution control equipment, and grants for research and development are forms of subsidies which would encourage desired behavior. Likewise, penalties in the form of effluent charges, fines, excise taxes on polluting products, charges for discharge permits, and required insurance coverage would discourage undesirable behavior.

GENERAL

Financial requirements to meet pollution abatement goals expressed in the 1972 Act are immense. The 1972 Act authorized $\$ 18$ billion to be spent in flscal years 1973 to 1975 under EPA's Construction Grant Program. ${ }^{2}$ (OF the $\$ 18$ billion authorized, $\$ 9$ billion have been ordered by the President to be spent; the remaining $\$ 9$ billion have been impounded.) ${ }^{3}$ Costs of waste treatment plants, pumping stations, and other facilities necessary to meet clean water requirements through 1990 have been estimated at about $\$ 60$ billion by a recent survey, ${ }^{4}$ but it is thought that costs may run much higher. 5 In any case, extensive Federal financial support to local jurisdictions is expected to continue through the Construction Grant Program. Given the large expenditures, both required and authorized, the importance of an efflcient allocation of resources to pollution abatement is apparent. And, indeed, there are provistons in the 1972 Act which indicate legislative concern for promoting efficiency in the abatement program.

Sec. 212 (2)(c) of the 1972 Act, for example, requires that grant applications be made for "the most cost-effective alternative... ." 
Nevertheless, the existing cost-sharing rules have been criticlized for Inefficiently allocating resources to abatement.*

The central problem of existing rules examined here -- that of biasing selection against the most efflcient abatement technlques -- results from the varlation In Federal cost sharing among abatement techniques. Although the leglslation implies that Federal cost sharing for construction costs is now avallable for a variety of techniques, historically there has been 11 ttle Federal cost sharing available for nonplant techniques. Moreover, some nonplant techniques continue to be ineligible for construction grants (see Section III). In addition, for those techniques which are eligible, grants vary as percentages of the total costs (i.e., capital plus operation and maintenance ( $O \& M$ ) plus land costs) associated with the different techniques. Hence, the share of total costs assumed by the Federal government may vary considerably depending upon the abatement technique adopted by the municipality. Other things equal, grant reclpients will favor those techniques which cost them the least.

The importance of considering a variety of techniques has been demonstrated by studies of river basins** which have shown that nonplant techniques and combinations of plant and nonplant techniques may offer improvements in efficiency over conventional plant approaches alone. Consider, for example, Table 1, which shows the costs of alternative abatement techniques analyzed for water quality improvement in the Potomac estuary. To meet the dissolved oxygen performance objective of $4 \mathrm{ppm}$, combinations of plant and nonplant processes (shown under item 2 of the table) are less costly than plant processes alone (shown under items 3 and 4 of the table). But while there may appear to be a number of viable alternatives from both a technical and cost standpoint, from the standpoint of implementation under existing cost-sharing and institutional conditions, there may be few alternatives.

With respect to the kinds of alternative abatement techniques which are avallable, two general categories are delineated in this report: plant,

*Some efflciency defects of existing rules have been documented in other studies, among them, Richard Raymond, "The Impact of Federal Financing Provisions in the Federal Water Pollution Control. Act Amendments of 1972," Public Policy, Vol. XXII, Winter 1974, pp. 109-110, and Urban Systems Research and Englneering Inc., Methods for Financing Water Pollution Abatement from Polnt Sources, a research paper prepared for the Water Quality Office of the Environmental Protection Agency, August, 1971, p. 39.

**See, for example, Robert K. Davis, The Range of Cholce in Water Management (Baltimore: The Johns Hopkins Press, 1968). 


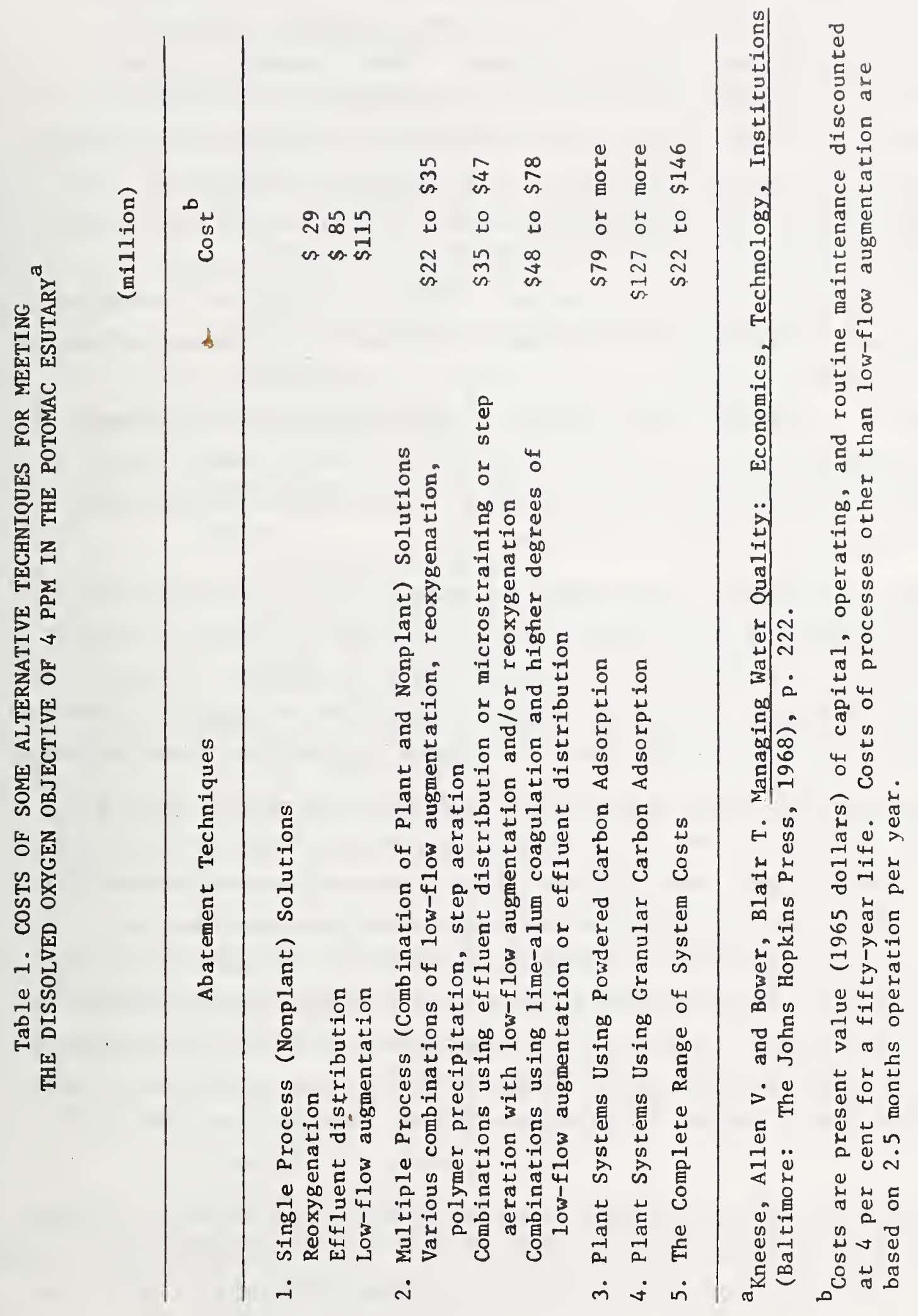


those techniques concerned with waste treatment in a plant facility; and nonplant, those techniques concerned with waste control, prevention, reduction, or treatment outside the plant. Waste treatment in plant facilities is the conventional approach to abatement of pollution of our rivers and streams from inflows of wastewater. However, the nonplant techniques for treating wastewater, for preventing its generation, for eliminating some of its detrimental characteristics, and for controlling 1t, may be used in lieu of or in confunction with plant treatment to combat water pollution from wastewater. Examples of nonplant techniques are wastewater-flow-reduction programs, active use of the sewage collection system, in-stream aeration, community septic systems, and low-flow augmentation. Exhibit 1 lists these and additional pollution abatement techniques which are considered in this study. A description of each, as well as an Indication of the type of pollution problem to which they may be applied, is provided in the Appendix.

The term "alternatives" is not meant to imply that these techniques are necessarily equal to plant treatment or to each other in their cost or in their ability to reduce or treat a specific kind of sewage, nor that all are sultable in every situation. These alternatives are simply a nonexhaustive 1 ist of technologically viable techniques for reducing water pollution. Attention should perhaps be called to the distinction between plant and nonplant techniques. The distinction is somewhat confusing because many of the treatment processes used in a plant could also be used outside the plant. Making the distinction on the basis that plant treatment is capital intensive, whereas nonplant abatement is not, is also confusing, because nonplant techniques may likewise involve large capital expenditures. Thus we have chosen a classification scheme based on whether the abatement technique is applied inside or outside of the treatment plant and the main interceptor sewer leading into the plant, i.e., "inside or outside the fence."

The distinction made here between plant and nonplant techniques is illustrated by Figure 1, which shows two versions of a typical municipal sewer system. To the left of the river on the figure is a "combined system," and to the 


\section{Exhibit 1}

Alternative Techniques for Abating Wastewater Pollution

I. Wastewater Prevention, Control, and Reduction Techniques

A. Prior to Discharge into Waterway

1. Reduction In Water Use

2. Active Control and Modification of the Sewer Collection System

a. Injection of High Molecular Welght Polymers into the Collection System

b. Selective Retention and Control of Flow in the Collection System

c. Pretreatment in the Collection System

d. Controlled Flushing of Sewers

3. Enhancement of New and Rehabilitation of Existing Collection Sewers

a. Enlargement of Sewers

b. Separation of Storm and Wastewater Collection Systems

c. Design and Construction of Collection System to Prevent Infiltration and Inflows

4. Control of and Restrictions. on Release of Certain Substances into the Sewer System

5. Influence on Decisions of Households and Industry to Connect to the Municipal Sewer System

B. During and After Discharge into Waterway

1. Selective Routing of Effluent Discharge

2. Low-Flow Augmentation of Recelving Waters

II. Wastewater and Effluent Treatment Techniques

A. Prior to Discharge into Waterway

1. Treatment In Conventional and Advanced Waste Treatment Plants

2. Land Treatment of Wastewater

3. Community Septic Tanks

4. Raw Sewage Lagoons

B. During and After Discharge into Waterway

1. In-stream Aeration

2. Treatment of Overflow 

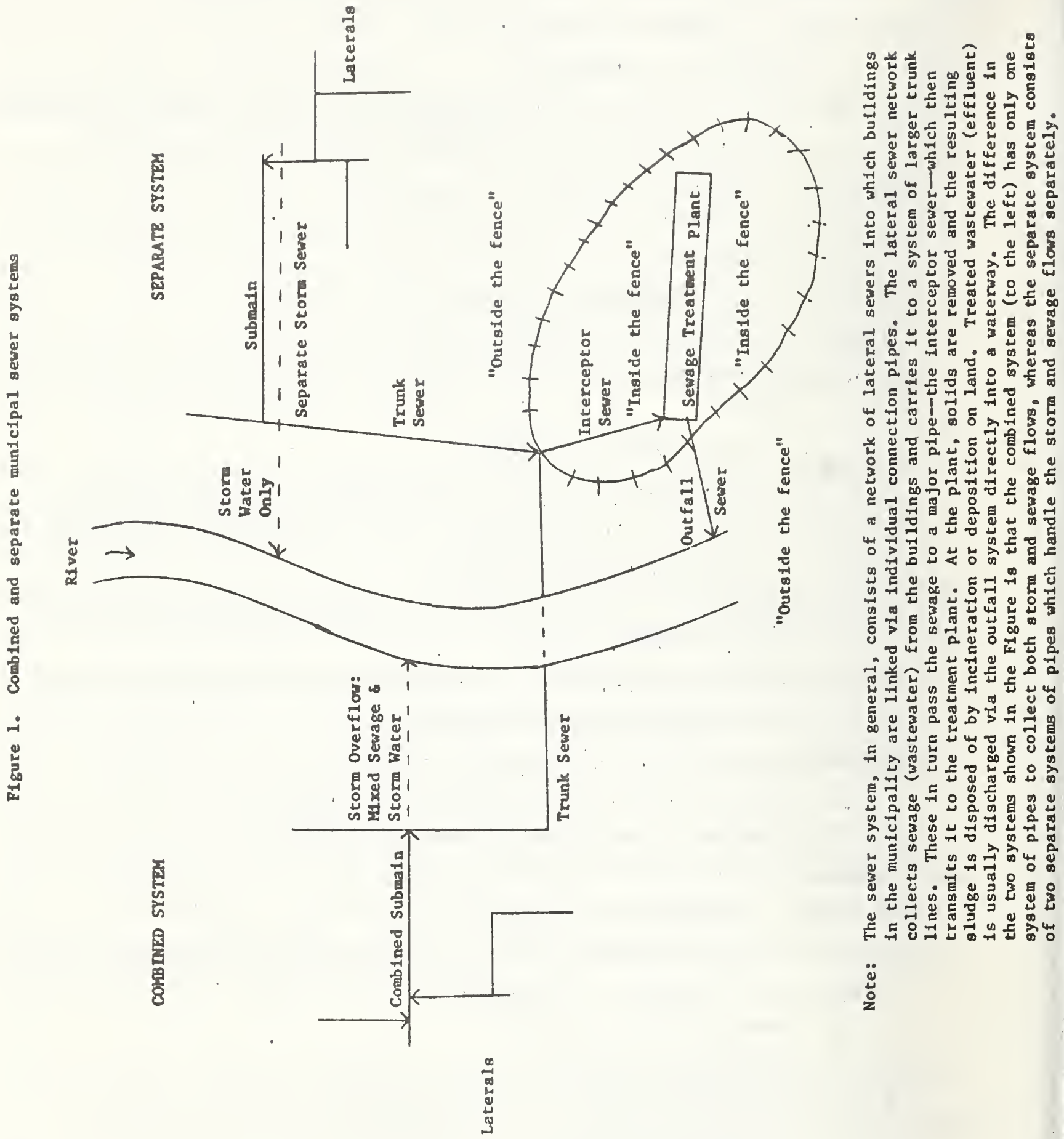
right is a "separate system." For either system, techniques or processes which would be applied within the interceptor sewer and/or the treatment plant (i.e., "Inside the fence," as shown in Figure 1), are here defined as "plant techniques." Those techniques which would be applied "outside the fence" are here defined as "nonplant techniques."

Flgure 2 illustrates the application of some of the techniques listed in Exhlbit 1. Note that the nonplant techniques Include actions taken completely outside the municlpal sewage collection system and treatment plant.

\section{ORGANIZATION}

A description of existing cost-sharing programs is given in Section III. The procedure for obtaining grants from EPA is outlined. The eligibility for and size of EPA grants are discussed, both in terms of leglslative authority and in terms of actual practice. In addition to EPA, the programs of other Federal agencles which provide cost-sharing assistance to municipalities for collection and/or treatment of wastewater are brlefly described. These other agencies are the Farmers Home Adminlstration, the Department of Housing and Urban Development, and the Economic Development Administration. Legal, administrative, and other institutional conditions affecting the selection of nonplant techniques are also evaluated in Section III to see what changes might be made to provide additional incentives for local interests to select techniques that are nationally efficient.

In Section IV the theoretical relationships between cost sharing and the selection of techniques are derived and discussed. The demand for pollution abatement is shown to depend on the level of Federal cost sharing. Necessary conditions for encouraging local communities to select the nationally least-cost technique(s) for pollution abatement and the nationally efficient scale of pollution abatement are derived. Characteristics of equity, 1.e., fairness, of cost-sharing rules are presented and applied to existing rules.

In Section $V$ the efficiency implications of existing and alternative cost-sharing programs are considered. Case examples are given of 


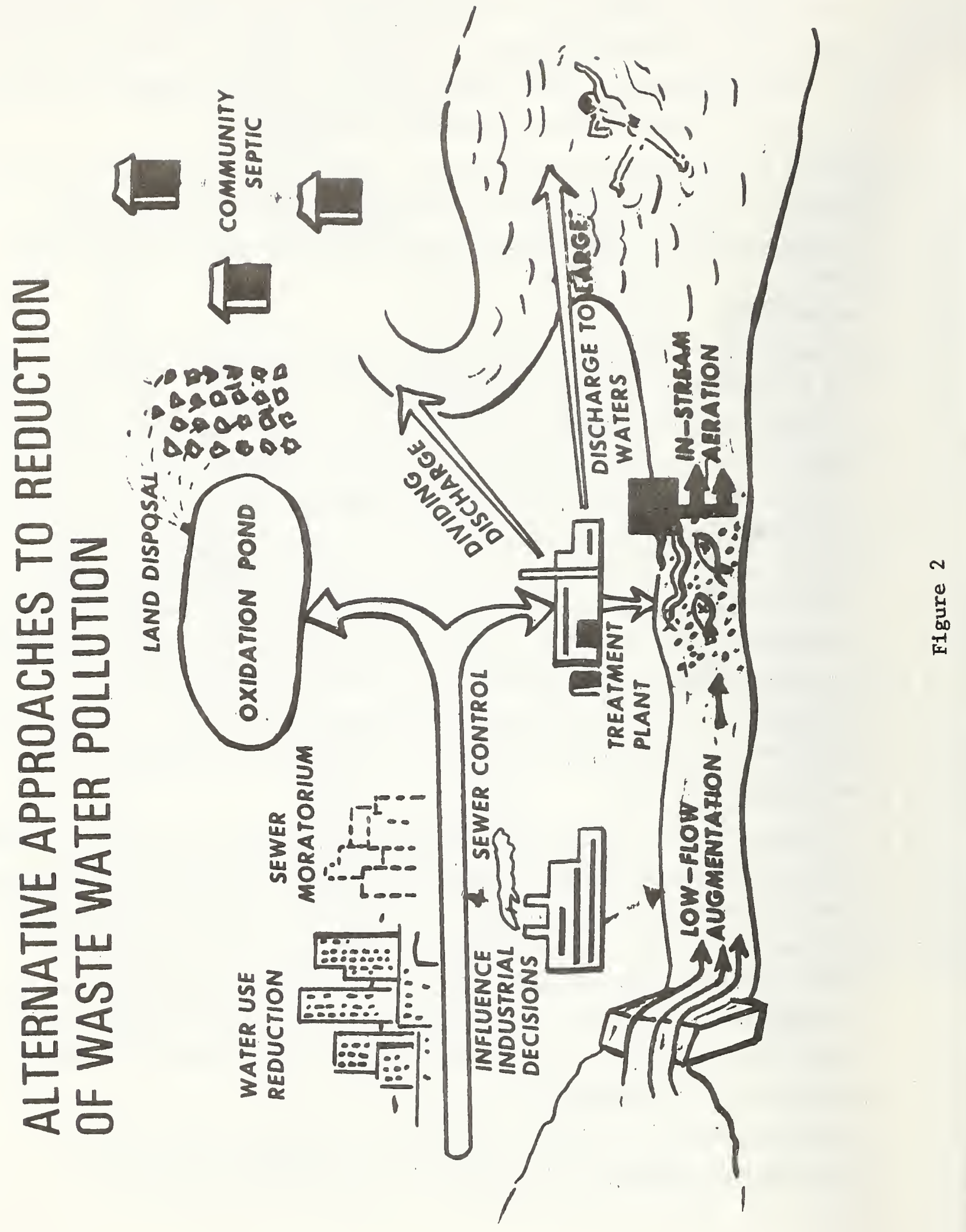


cost-sharing biases for certain abatement techniques. The relative costs to Federal and nonfederal participants of alternative cost-sharing programs as applied to historical abatement are compared.

Section VI explores the effects of user fees on the Federal and grant recipients' cost shares. User fee requirements as legislated and as set forth in grant program regulations are discussed. The effective change in cost shares attributable to user fee arrangements is determined. The resulting impacts on decisions regarding abatement programs, and on residential as compared with industrial communities, are assessed. The study is summarlzed in Section VII. Findings of the study regarding the existing EPA Construction Grant Program and alternative programs are described. Suggestions are made for further research. 
1. Federal Water Pollution Control Act Amendments of 1972, PL 92-500, 92nd Congress, S. 2770 , Oct. 18, 1972.

2. Sec. 207, PL 92-500.

3. "Rivers Cleanup Aid Cut," The Washington Post, January 11, 1974, Pp. A-1, A-4.

4. Costs of Construction of Publicly-Owned Wastewater Treatment Works: 1973 Needs Survey. Environmental Protection Agency, Washington, D.C. November 1973.

5. Waste Treatment Fund Allocations. Senate Committee on Public Works. 93rd Congress, 1st Session, Calendar No. 604, Report No. 93-630, December 13, 1973. p. 6. 


\section{SECTION III}

\section{DESCRIPTION OF EXISTING COST-SHARING PROGRAMS AND INSTITUTIONAL CONSTRAINTS}

This section is divided into three parts. The first provides background information on the grant program and discusses the grant eligibility of the various abatement techniques. The cost shares awarded by EPA are shown. The second part provides a brief description of cost-sharing programs of other agencles for wastewater pollution abatement. The third part describes institutional constraints on the selection of various techniques.

\section{CONSTRUCTION GRANT PROGRAM}

Grants for construction of treatment works are authorized under Title II of the 1972 Act. According to Sec. 201(g)(1), "The administrator is authorized to make grants to any state, municipality, or intermunicipal or interstate agency for the construction of publicly owned treatment works." In addition to the enabling legislation, the grant process is further governed by regulations codified in the Code of Federal Regulations under Title 40 , Sec. 35.900 et seq. ${ }^{1}$

The objective of the Construction Grant Program as expressed in EPA literature is "to assist and serve as an incentive in construction of publicly owned treatment works which are required to meet State and Federal water quality standards." 2 The objectives of the program are carried out by the sharing of construction costs of wastewater treatment facilities with municipalities (i.e., cities, towns, boroughs, counties, parishes, districts -- except school districts), associations, management agencies, and other public bodles created by or pursuant to state law and having jurisdiction over disposal of sewage. 
The EPA Grant Program wakes awards for any or all of the following three steps: (1) Facilities Planning, during which the applicant's problem is investigated in detail, existing facilities are assessed, alternative approaches to problem solving are evaluated, and environmental impact and cost-effectiveness studies are made; (2) Preparation of Detailed Construction Plans and Specifications, during which the facilities are planned, public hearings are held, and blueprints are prepared; and (3) Construction, during which the facilities are built.

According to Sec. 202(a) of the 1972 Act, the share of cost to be borne by EPA $1 \mathrm{~s} 75 \%$ of the cost of construction of a treatment works. This appears to be the current legal maximum Federal cost share.*

It may also be asked if this is the minimum legal cost share. The answer hinges on the definition of "treatment works." Unt11 recently, as reflected in the interim grant program regulations, it was required that a fundable Step 3 project result in an operable treatment works. Thus, under former interpretation, the legal minimum, as well as maximum, Federal cost share was $75 \%$ of total eligible construction costs of a completed facility.

However, program requirements for a minimum grant of $75 \%$ of total construction costs were criticized, and have since been changed. According to the Senate Committee on Public Works, ${ }^{3}$ this requirement did not allow a state the flexibility
- . to use its annual allocation of grant funds among as many projects on its priority list as it wishes, on the basis of what can be accomplished in a given year, rather than to tie up all its funds in a few large projects at the top of a state's priority list.

The Committee further stated that "phased funding," whereby a portion of a total facility would be approved for a grant, would not under the 1972 Act commit the grant program to eventual funding of the total factlity, nor create a pool of reimbursable claims against the grant program for an ultimate grant of $75 \%$ of the full construction costs of the completed facility.

*The effective or real cost share borne by the Federal government may exceed $75 \%$ of the costs of construction because local interests can retain some of the industrial user fees collected agalnst the Federal share. This additional Federal subsidy is explained in Section VI. 
Section 203 of the 1972 Act has since been Interpreted to allow states to divide Individual treatment works into separate parts for the purpose of funding. This new interpretation is reflected in the final program regulations which provide for grants of $75 \%$ of the construction cost of segments of treatment works. "Segment" is defined as "any portion of an operable treatment works" and 1ts completion need not result in an operable treatment works.

It appears, in summary, that the Federal share must comprise a minimum $75 \%$ share of the eligible construction costs of an approved project, but that the approved project no longer need result in a completed facility.

Avallable funds for grant awards are allocated among the states in the ratio of the estimated cost of constructing al1 needed publicly owned treatment works in each state to the estimated cost of construction of all needed publicly owned treatment works in all of the states. 4 Computation of the ratios are based on a "Needs Survey," biennially revised, for public waste treatment works.* The specific allocation formula ${ }^{5}$ recently developed by Congress and used to allocate the 1975 allotment of Federal funds is the following: Half of each state's share is based on the rat 10 of the individual state's total construction needs to the total of all states' total construction needs. The other half is based on the ratio of the Individual state's costs to all states' costs for the following three specific categories of pollution control facilities: secondary waste treatment plants; advanced waste treatment facllities to meet water quality standards; and new interceptors, force mains, and pumping stations. In addition, the formula provides that no state w11l receive less than $1 t$ recelved in fiscal year 1972.

Eligible public bodies apply for grants through their state water pollution control office. The state office reviews each application, coordinates the plans outlined with other relevant projects in the state, makes recommendations for changes, and if approving of the plan, places the application

*The most recent survey was conducted in 1973 and the results reported in Environmental Protection Agency, Costs of Construction of Publicly-Owned Wastewater Treatment Works; 1973 "Needs" Survey. 
on a priority 1ist which it then sends to the EPA regional administration. The EPA administration, one of ten regional EPA offices, makes the grant award. The total amount of grants made to applicants in a state is limited by the state's allocation of grant funds.

Applicants recelve grants according to their order of priorlty as determined by the state priority ranking criteria. Evaluations and priority line-ups made by the state water pollution control offlces are based on EPA guidelines and state guidelines which have been approved by the EPA regional administration. Provisions of the $1972 \mathrm{Act}$ and EPA regulations and guidelines establish some mandatory criteria for project approval and certification of priority for grants by state offices, allowing other criterla to be determined by the state with EPA concurrence. For the most part, the state options are intended to allow for environmental or other relevant differences among areas.

The application and award process works as follows: After determining that a problem exists, the applicant, say a town represented by a town mayor, makes initial inquiry to its state water pollution control agency. (The title of the state office varies from state to state; e.g., in Alabama it is the Water Improvement Commission; In Kansas, the Division of Environmental Health, State Department of Health; and in Washington, the Washington State Department of Ecology.) The state office hears the inquiry and suggests that the applicant make a formal application for a Step 1 grant. Upon approval, the town assesses its existing wastewater disposal facilities, present and projected waste loads, and alternative approaches which it might take to deal with its problem -- typically alternative plant processes and facilfties. The plans are submitted to the state agency, which evaluates the plans and tries to mesh them with other wastewater disposal efforts in the area. Grants for subsequent steps can be made elther as amendments to the original grant application or separately. The state office and/or the EPA regional office may follow up the award process with an investigation of the functioning of the facilities which were constructed.*

*Information on the grant process was obtained from the following sources: Interviews with EPA staff; EPA, Federal Assistance Programs of the Environmental Protection Agency, Reprinted from the Catalog of Federal Domestic Assistance, Washington, D.C., June 1973, Sec. 66.015; and from Final Regulations, Federal Register, February 11, 1974. 
Eligibility for Grants as Defined in Legislation

Much difference in opinion appears to exist regarding eligibility of nonplant techniques for construction grants. For this reason, we first explore the 1972 Act for statements regarding eligibility and then examine eligibility practice under the existing program.

A review of the Act reveals a number of passages which suggest inclusion of nonplant techniques for grant consideration. Recalling that the Act authorizes grants for construction of publicly owned treatment works, consider how it defines "treatment works" in Sec. 212(2)(A):

The term 'treatment works' means any devices and systems used in the storage, treatment, recycling, and reclamation of municipal sewage or industrial wastes of a liquid nature.. . or necessary to recycle or reuse water at the most economical cost over the estimated life of the works, including intercepting sewers, outfall sewers, sewage collection systems, pumping power, and other equipment, and their appurtenances; extensions, improvements, remodeling, additions, and alterations thereof; elements essential to provide a reliable recycled supply such as standby treatment units and clear well facilities; and any works, including site acquisition of the land that will be an integral part of the treatment process or is used for ultimate disposal of residue resulting from such treatment.

Section $212(2)(B)$ adds the following items to the definition of treatment:

- . any other method or system for preventing, abating, reducing, storing, treating, separating, or disposing of municipal waste, including storm water runoff, or industrial waste, including waste in a combined storm water and sanitary sewer systems.

This is indeed a very broad definition which would appear to include practically any technique imaginable by which water pollution from municipal waste and storm water could be abated. Similarly, the definition of construction, as given in Sec. 212(2), does not limit grants to a particular kind of "treatment works."

Other passages of the Act emphasize that projects for which grants are awarded should use the most cost-efficient alternatives. 6 The intent appears to be to encourage the most efficient technique, regardless of whether it be "plant" or "nonplant." 
There are, however, other passages in the Act which might be interpreted to prohibit consideration of certain of the nonplant techniques. Most important to the restrictive interpretation of eligibility are the requirements in the law for a non-polluting discharge and proviston of the best practicable waste treatment technology (BPT) (now generally defined as secondary treatment) before any discharge into recelving waters. For examples, Sec. 201(a)(1) states that". . It Is the national goal that the discharge of pollutants into the navigable waters be eliminated by 1985... ." Section 201(b) states the following: "Waste treatment management plans and practices shall provide for the application of the best practicable waste treatment technology before any discharge into recelving waters . . . "Finally, Sec. 301(b)(1) states that:

There shall be achieved . . . for publicly owned treatment works in existence on July 1, 1977, or approved . . prior to June 30,1974 . . . effluent limitations based upon secondary treatment... .

"Before any discharge Into recelving waters" is sometimes interpreted as disallowing grants for techniques whose application is after the sewer outfall system. Accordingly, low-flow augmentation and in-stream aeration would be ruled ineligible for grants.

The above sections may also be interpreted as placing decided emphasis on treatment as opposed to other forms of abatement. Such an interpretation might result from the fact that a specified level of treatment is explicitly required by the law and that attention is on improving the quality of the effluent discharge. The focus on treatment before discharge might tend to lessen attention to techniques almed at prevention, control, and reduction of wastewater, as well as treatment techniques applied in the stream.

An alternative interpretation of eligibility as defined in the Act, and one which we think is more defensible, is the following: Emphasis on treatment techniques is inherent in the legislation, insofar as goals and requirements are stated in terms of achievement of nonpolluting discharges and minimum treatment standards. Likewise, emphasis is on action prior to effluent 
discharge. Nonetheless, the legislation does not appear to exclude from grant eligibility any of the nonplant techniques discussed in this report.*

For one thing, we could find no requirement in the law that the BPT be plant treatment, nor that secondary treatment be provided in plants. Furthermore, we do not see that the requirement that the best practicable treatment technology be applied before discharge necessarily rules out grants for techniques to reduce, control, or pretreat wastewater prior to BPT treatment. Neither do we see that the law prohibits grants for techniques which are applied after discharge, so long as they are used in conjunction with treatment prior to discharge and not in lieu of it. To the contrary, there are sections of the law which appear to suggest use of such nonplant techniques. Consider, for example, Sec. $302(a)$ :

Whenever . . discharges of pollutants from a point source. . . with the application of effluent limitations required under Section 301(b)(2) of this Act, would interfere with the attainment or maintenance of that water quality . . , effluent limitations (including alternative effluent control strategies) . . shall be established... .

In conclusion, under one interpretation wilch might be given to the 1972 Act, all of the nonplant techniques appear eligible for grants. In particular, techniques such as land disposal and community septic tanks, which can provide the equivalent of secondary treatment with no direct discharge into a waterway, appear especially to satisfy the tenets of the 1972 Act. Techniques which prevent or reduce the generation of wastewater also appear to comply with the law by reducing the discharge of pollutants into waterways. Nonplant treatment techniques, which alone or in combination with each other or plant techniques, are able to fulfill water quality standards likewise appear compatible with the law.

With respect to types of costs, 1.e., capital cost, 1and, 1abor, and management costs, made eligible for funding under the law, the main indication of eligibility appears in the definition of construction, which is defined in Sec. $212(1)$ as follows:

*An exception might be techniques requiring expenditure for collection systems in new communities, grants for which are implicitly prohibited by Sec. 211 of the 1972 Act. 
- . preliminary planning to determine the feasib1lity of treatment works, engineering, architectural, legal, fiscal, or economic investigations or studies, surveys, designs, plants, working drawings, specifications, procedures, or other necessary actions, erection, bullding, acquisition, alteration, remodeling, improvement, or exterfor of treatment works, or the Inspection or supervision of any of the foregoing items.

Thus, while the law is not specific with respect to cost eligibility by type of costs, eligible costs would appear to include labor, equipment, materlals, and management necessary to obtain the treatment works. There appears, however, no intent in the 1972 Act to fund operation and maintenance of the facility once constructed.

\section{E11g1bility for Grants in Practice}

Let us now examine eligibility of alternative techniques and costs under the grant program as set forth in policy documents, publications, and as described by EPA grant officials.

First, it appears that the general philosophy of the program is centered quite heavily on treatment per se, and the term "treatment," as used in program literature, appears devold of the additional meanings given it in the 1972 Act, where the definition was extended to include control, prevention, and other forms of abatement. It also appears that the term "works," broadly defined in the Act to include any method or system for pollution abatement, Is of ten translated in program 11terature to "fac1lities," and thence to "plant." 7

The emphasis on the treatment plant and its Immediate appurtenances (1.e., the interceptor and outfall sewers) appears in the following statement of project eligibility set forth in an EPA program brochure:

- . (eliglble costs include) those to construct new treatment plants, to expand or improve existing plants, to construct Interceptor and outfall sewer lines or to provide pumping, power, and other equipment necessary to operate a sewage treatment system. Under certain conditions, sewage collection systems and projects to control pollution from combined sewers may also recelve Federal assistance. 8 
Allowable and unallowable project costs as further defined in the U.S. Code of Regulations are listed in Exhibit 2.

Let us now examine eligibility specifically in terms of plant and nonplant techniques. Table 2 shows for some of the techniques listed earlier in Exhibit 1 the current maximum Federal percentage share of costs which would, in principle, apply. From the Table, 1 appears that (a) 14 of the 19 techniques are eligible for a Federal grant covering $75 \%$ of capital cost; (b) only 4 of the 19 techniques involve land costs which are interpreted as an integral part of the treatment process, and, therefore as eligible for a grant equal to $75 \%$ of these costs; and (c) none of the techniques is eligible for Federal grants for land site acquisition (land not an integral part of the treatment process) or for 0 \& M Costs. In-stream aeration, low-flow augmentation, publicly-owned individual septic tanks on private property, water-use and waste-reduction programs, and controlled flushing of sewers (which is regarded as part of $0 \& M$ ), are the techniques currently considered ineligible for Federal cost sharing of capital costs. These, together with all the other techniques except land treatment, community septic tanks, and treatment of wastewater overflows, are also ineligible for Federal cost sharing of any land costs. In contrast, all of the 19 techniques would be eliglble for a planning grant, provided they related to the particular facility under consideration.

While most of the nonplant techniques appear in principle eligible for a grant for capital costs, few appear actually to have been funded to any significant degree. It is, however, difficult to determine to what extent the general paucity of grant awards to nonplant techniques is attributable to a more restrictive practice of cost sharing than is indicated by Table 2. Techniques other than plant treatment only became eligible for cost sharing under the 1972 Act, and few grants of any kind have as of this time been made under this law.

Let us now look at Federal cost sharing from a historical standpoint. We can see from Table 3, which shows cumulative grants by EPA and other Federal agencies from the Inception of the Construction Grant Program through 1972, that EPA grants have averaged only about $36 \%$ of eligible construction 


\section{Allowable and Unallowable Profect Costs Under the Construction Grant Program}

\section{Allowable Costs:}

Costs of the grantee which are reasonable and necessary are allowable. Necessary costs may include but are not limited to:

(a) Costs of salartes, benefits, and expendable material incurred by the grantee for the project.

(b) Costs under construction contracts.

(c) Professional and consultant services.

(d) Facility planning directly related to the treatment works.

(e) Sewer system evaluation.

(f) Project feasibility and engineering reports.

(g) Relocation and land acquisition costs required pursuant to the Uniform Relocation Assistance and Real Property Acquisition Policies Act of 1970, 42 U.S.C. 4621 et seg., 4651 et seq., and regulations issued thereunder.

(h) Costs of complying with the National Environmental Policy Act, including costs of public notices and hearings.

(1) Preparation of construction drawings, specifications, estimates, and construction contract documents.

(j) Landscaping.

(k) Supervision of construction work.

(1) Removal and relocation or replacement of utilities, for which the grantee is legally obligated to pay.

(m) Materials acquired, consumed, or expended specifically for the project.

(n) A reasonable inventory of laboratory chemicals and supplies necessary to Inftiate plant operations.

(o) Development and preparation of an operation and maintenance manual.

(p) Project Identification signs. 
Unallowable Costs:

Costs which are not necessary for the construction of a treatment works project are unallowable. Such costs include, but are not limited to:

(a) Basin or areawide planning not directly related to the project. ${ }^{\text {a }}$

(b) Bonus payments not legally required for completion of construction in advance of a contractual completion date.

(c) Personal injury compensation or damages arising out of the project, whether determined by adjudication, arbitration, negotiation, or otherwise.

(d) Fines and penalties resulting from violations of, or failure to comply with, Federal, state, or local laws.

(e) Costs outside the scope of the approved project.

(f) Interest on bonds or any other form of indebtedness required to finance the grantee's share of project costs.

(g) Ordinary operating expenses of local government, such as salaries and expenses of a mayor, city council members, or city attorney; except as provided in \$35.940-4 for allowance of indirect costs of the grantee in accordance with an indirect cost agreement negotiated and incorporated in the grant agreement.

(h) Site acquisition (for example, sewer rights-of-way, sewer treatment plant sites, santtary landf111s and sludge disposal areas); except as provided in \$35.950-3(a) for land which will be an integral part of the treatment process or that will be used for ultimate disposal of residues resulting from such treatment, if approved by the Administrator.

(1) Costs for which payment has been or w11l be received under another Federal assistance program.

(j) Costs of equipment or material procured in violation of $\$ 35.938-4$ (b), which provides for award to the low responsive, responsible bidder.

Source: "Final Construction Grant Regulations," Federal Register, XXXIX, No. 29, February 11, 1974, p. 5268.

${ }^{a}$ Grants for areawide waste treatment management planning are provided for under Sec. 208 of the 1972 Act. For fiscal years through June 30, 1975, these grants are to be $100 \%$ of the costs; beyond that time, $75 \%$ of the costs are allowed. 


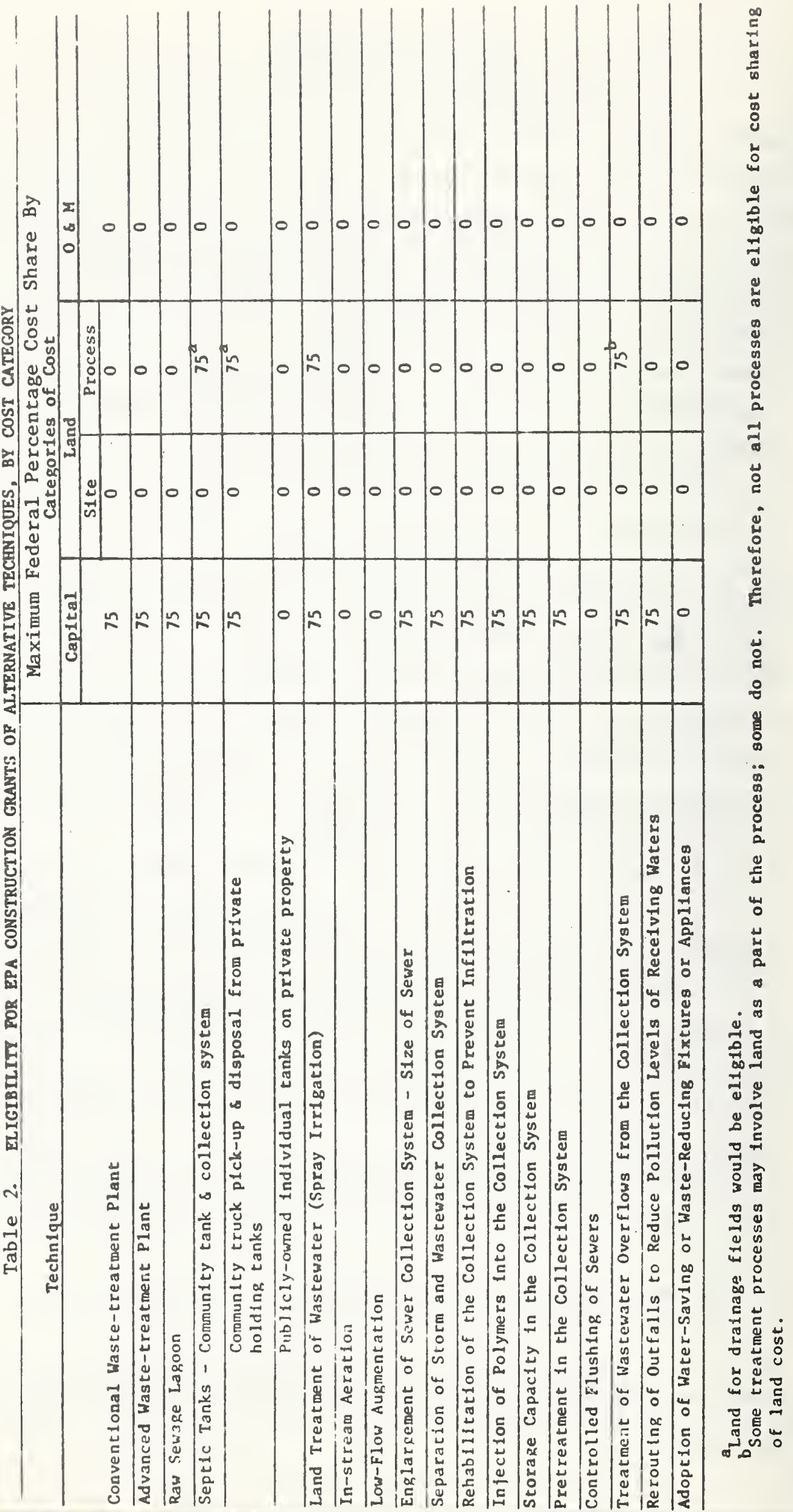




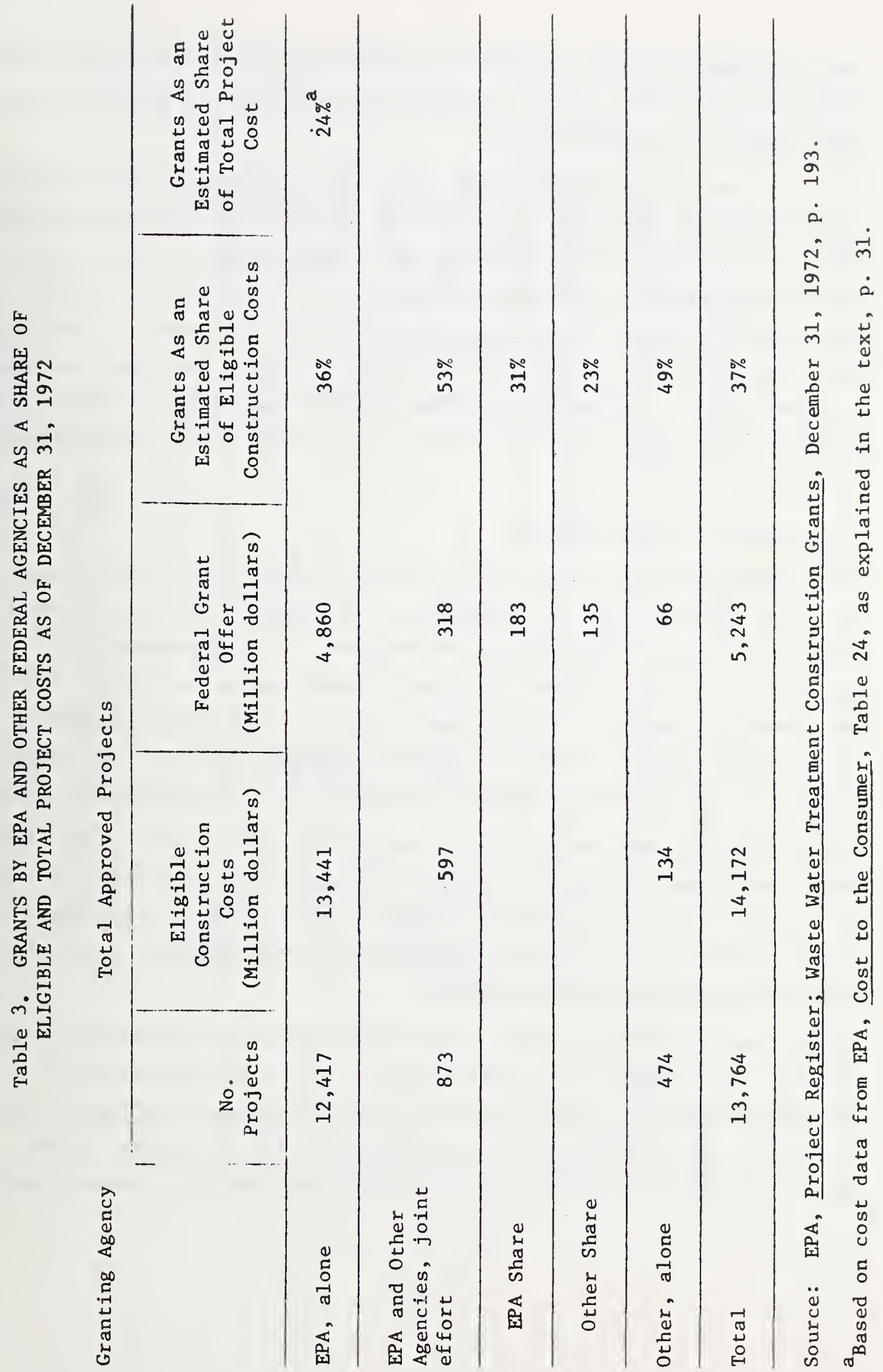


cost. During this period, the legal maximum cost share was $50-55 \%$, rather than the present $75 \%$. Thus to average $36 \%$, many projects must have been funded below the maximum levels.

Note that the effective cost share, i.e., the percentage of total (construction plus $0 \& M$ ) costs, is lower than the $36 \%$ share of construction costs since $0 \& M$ costs were not shared by EPA. An EPA share of $24 \%$ of total costs was estimated by dividing EPA grants by estimated total project costs, which included construction plus estimated 0 \& $M$ costs. The 0 \& $M$ costs were estimated on the basis of eligible construction costs as shown In Table 3 and on the assumptions that construction on the average comprises $65 \%$ of total costs and $0 \& M$ comprises $35 \%$ of total costs of wastewater treatment plants. 9

COST SHARING BY OTHER AGENCIES

Other Federal agencles which cost share with nonfederal groups in water pollution abatement are the Department of Housing and Urban Development (HUD), the Farmers' Home Administration (FHA) in the Department of Agriculture, and the Economic Development Administration (EDA) In the Department of Commerce. The maximum percentage cost shares of these agencles are shown in Table 4. It should be noted, however, that these agencies do not always actively fund projects, due to insufficient funds. HUD's grant program provides ald to municipalities in construction of new sewer factlities. Eligible projects are construction of sewers for the collection, transmission, and discharge of sanitary wastes, and storm sewer systems for collection, transmission, and discharge of storm water. Sewage treatment works are excluded.

FHA provides grants to public, quasi-public, or non-profit organizations serving rural areas for the installation, repair, improvement, and expansion of a rural waste disposal system, including sewer lines, waste collection, and treatment of all wastes. In addition, guaranteed or Insured loans are made for profect costs not covered by the money grant. 


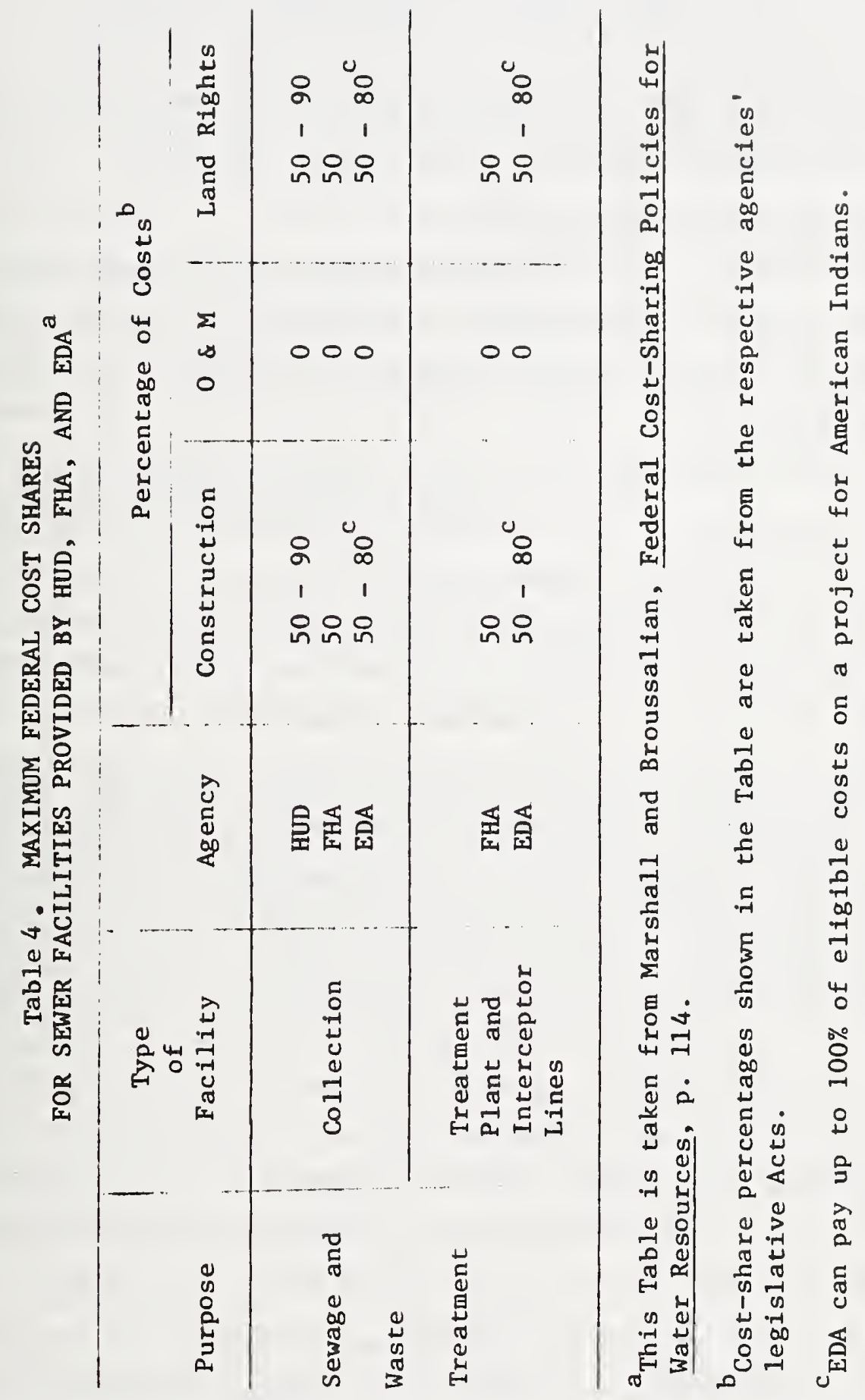


EDA makes grants to private or public nonprofit organizations representing redevelopment (depressed) areas for construction of sewer systems, including collection, transmission, and treatment facilities. In addition, direct loans are made if local matching funds are not avallable.

Thus, all three of the agencies provide grants for collection of sewage, whereas only two, FHA and EDA, provide funds for treatment.

\section{INSTITUTIONAL CONSTRAINTS TO ABATEMENT}

The purpose of this section is to identify and discuss characteristics of existing institutions or grant program arrangements -- other than costshare eligibility -- which may bias municipalities against efficient cholces in pollution abatement.

One aspect of the grant program which may influence municipalities in their selection of techniques is the influence of state and EPA design standards, guidelines, and technology transfer manuals. If these are conservative and emphasize the well-established processes, which nearly always are processes to be used in treatment plants, they may direct municipalities away from consideration of more innovative techniques.

Another related characteristic of the grant process which may cause bias in choice of techniques is the fact that the training and experience of many state and EPA officials who review applications are often geared towards plant engineering. Any preference at that level for traditional plant/engineering solutions may exert a strong bias on the local applicant whose objective is to achieve a high priority ranking for his project. Another factor, which may be in part attributable to state and EPA program operations, is the apparent widespread fallure of municipalities fully to consider abatement alternatives. Greater emphasis by state and EPA officials on plans which consider a wide range of alternatives would contribute to adequate identification of the cost-effective abatement approach.

It is customary practice to base architects'/engineers' fees for design of a facility on the amount of capital costs. This practice may give them incentive to design capital-intensive facllities. Thus the designs 
for abatement faclities provided to municipalities may be biased against nomplant and/or low capital techniques, and, consequently, the municipality may not give adequate consideration to these techniques.

The municipality's relative ability to fund the different kinds of costs comprising its share of pollution abatement may also cause a bias at the local level. Municipalities may find it easier to allocate funds to capital costs than to current operations. When funds are short and expenditures must be cut, servicing the debt issue normally takes precedence over current maintenance and operating requirements. Hence a municipality may be better able to sustain funding of capital-intensive techniques than non-capital-intensive techniques, and may, therefore, tend to have its abatement activities biased towards capital-intensive techniques, apart from any Federally-induced bias.

Limits to the area of jurisdiction or authority of municipalities may restrict the choice of techniques. As has been pointed out in studies of wastewater management, ${ }^{10}$ implementation of certain types of abatement systems, collective facilities, and integrated operation of systems requires flexibile area-wide institutional arrangements. Moreover, studies have shown potential cost savings achievable through integrated systems as compared with conventional treatment. But in many places, regional water quality management systems are still in the planning stages despite the fact that current law supports regional planning. Institutional arrangements are generally not sufficiently flexible to allow deliberate variation in quality of discharge at one point to be compensated for at another point, or by another method where treatment costs are less. Thus, decisionmaking bodies may not have the legal authority to plan and coordinate the use of techniques in all areas of relevant concern and may, therefore, be forced to accept less than best solutions.

Another problem which may interfere with efficient choice of size or kind of techniques is the use of sewerage systems as growth management tools. Some communities are using their authority with respect to sewage disposal as a substitute method of controlling other community developments, such 
as the rate of population growth. In the words of the chairman of the Falrfax County, Virginia, Board of Supervisors, "We've used sewers as a growth management tool. It's a bad one but it is the only one we 've had."11 Another example is provided by the Northern Virginia Conservation Council which recently requested EPA to halt any further expansion at four of the Washington, D.C. area's major sewage treatment plants. According to the council, a major reason for its action was that "their enlargement would lead to more growth in the area, which they consider undesirable."12

Local decision makers may also resist a tie-in with a regional treatment system or other solutions which would eliminate their basis for control. It was reported recently, for example, that the Prince William County, Virginia, Board of Supervisors was considering building its own treatment plant rather than participate in a regional effort now underway, despite estimates that costs would thereby be quadroupled. The reported rationale was that "the reglonal plant would remove control of sewer line construction and operation -- and thus of growth -- from the county."13

A very powerful institutional barrier to unbiased consideration of techniques may be found in the 1972 Act itself. Short of a major change, the high cost and relatively short time horizon for compliance with the high effluent standards set in the law, together with the emphasis on plant treatment, may preclude avallability of Federal grants for other kinds of techniques, such as waste-flow reduction, active use of the collection system, and in-stream aeration. These and other techniques might otherwise be used alone or in combination with plant treatment to achieve similar levels of water quality at lower cost.

There are likely a host of additional special circumstances which cause techniques to be favored or disfavored. Examples of techniques which appear to have been disfavored by circumstances are those for correcting the problem of storm overflow. Both separation of combined sewers and other applicable techniques, it may be recalled, meet criterla of eligibility for program grants. Yet construction grant funds generally have not been available for correcting storm overflow. 14 This "backburner" attitude at 
the program level, conveyed to local communities, means fewer project applications to deal with the problem. One reason for such a position is a practical one -- immense cost of correction. EPA has estimated the capital cost of solving the storm overflow problem by sewer separation at $\$ 70$ billion in 1973, and by alternative methods such as storage and treatment at $\$ 25$ billion. (And some communities, if given the choice, may opt for sewer separation since separation generally requires a lower proportion of $0 \& M$ cosls.j $15 \quad$ Another reason may be that there are differences in opinion as to what should be done to correct the problem. But in any case the cost involved is so great that little has been done from the standpoint of cost sharing. A similar bias has existed until recently against raw sewage lagoons, but for a different reason. In this case, the problem has been doubt within the grant program as to the degree of treatment achievable by lagoons. 
1. Final Construction Grant Regulations, Construction Grants for Waste Treatment Works. Federal Register, XXXIX, No. 29, February 11, 1974.

2. Federal Assistance Programs of the Environmental Protection Agency.

Reprinted from the Catalog of Federal Domestic Assistance, Washington, D.C. June 1973, Sec. 66.015.

3. Waste Treatment Fund Allocations. Senate Committee on Publlc Works. p. $9-11$.

4. PL 92-500, Sec. (205)(a).

5. Environmental News. Environmental Protection Agency, January 10, 1974, p. 2 .

6. PL 92-500, Sec. $212(\mathrm{~s})(\mathrm{c})$.

7. The Federal Water Pollution Control Act Amendments of 1972, Highlights. Environmental Protection Agency, Washington, D.C. December 1972.

8. Federal Grants for the Construction of Municipal Waste Water Treatment Facilities. Environmental Protection Agency, Washington, D.C.

9. Cost to the Consumer for Collection and Treatment of Wastewater. Environmental Protection Agency. Washington, D.C., Government Printing Office. Water Pollution Research Series, No. 17090. July 1970. Table 24.

10. Kneese, Allen and Blair Bower. Managing Water Quality: Economics, Technology, Institutions. Baltimore, The Johns Hopkins Press, 1968. p. 97-179, and Davis, Robert $K$. The Range of Choice in Water Management, A Study of Dissolved Oxygen in the Potomac Estuary. Baltimore, The Johns Hopkins Press, 1968. p. 124-126.

11. "Fa1rfax Sewage Plan Set," The Washington Post, March 27, 1974, p. C-1, col. 1 .

12. "Sewage Plant Work Halt Sought," Washington Star-News, January 27, 1974, p. B-4, Col. 3 .

13. "Prince William Tables Funds for Sewer Plant," The Washington Post, February 5, 1974, Sec. C.

14. Research and Demonstration Program to Achieve Water Quality Goals: What the Federal Government Needs to Do. General Accounting Office. Washington, D.C., Government Printing Office. Volume 1, No. B-166506. Report to Congress. January 1974. p. 339.

15. Ib1d. 


\section{SECTION IV \\ THEORETICAL RELATIONSHIPS}

This section begins with a selective survey of the theoretical literature pertaining to cost sharing pollution abatement specifically and water projects in general. The demand for pollution abatement by grant recipients is shown to depend on the percentage cost shares borne by grant recipients. Cost-sharing conditions are derived for encouraging the efficient techniques and scales of pollution abatement projects.

SELECTIVE SURVEY OF

THE LITERATURE

This survey provides a brlef overview of some of the work that has been done in relating cost sharing in water projects to the selection of the least-costly techniques and of the efficient scale. Equity considerations are also discussed. The survey starts with an examination of what has been done specifically in the wastewater area. The rest of the survey deals with the theory of cost sharing as it has been developed for water resources in general.

Robert Davis, in his study of alternative approaches to water quality management in the Potomac estuary, noted some of the biasing effects of existing Federal financing arrangements. ${ }^{1}$ He illustrated how differences In the ellgibility of techniques for grants may make the most'expensive system in terms of total cost become the least expensive system as viewed by the local sector. He also pointed out that differences in the kinds of costs associated with the various techniques, e.g., relatively high operating and low capital costs for treatment by polymers compared with relatively high capital and low operating costs for microstraining, can result in a larger Federal cost share for, and hence a local bias towards, 
the more capital-intensive technique under current cost sharing rules. Richard Raymond has taken a direct look at the cost-sharing bias in pollution abatement. 2 Using estimated costs of selected wastewater treatment alternatives in the Cleveland-Akron area, he showed that if a cost-sharing rule does not cover all cost categorles equally, when applled to alternative techniques having different compositions of cost (i.e., different proportions of capital relative to operation and malntenance relative to land costs), profects with higher national costs may appear cheaper to a community than profects with lower national costs. He developed a method of measuring the maximum increase in total cost to the nation ("maximum blas") generated by unequal cost shares among cost categorles. (See Chapter V for a case example taken from Raymond's work.)

In its final report, the National Water Commission (NWC) has commented on the efficiency and equity of the EPA grant program. ${ }^{3}$ It criticizes Federal subsidies in general as belng unfalr, promoting inefficiency, and falling to achieve desired results. It criticlzes the 1972 Act specifically for 1 ts inequjty in deflecting $75 \%$ of capital costs from local users to national taspayers; $i . e .$, for providing a $75 \%$ Federal cost share for a project that benefits essentlally a local area. The Report also dispenses with redistribution as an equity rationale for high Federal cost sharing, saying that full sewer charges represent small proportions of family budgets, and furthermore, that redistribution and abatement goals should be decided independently. ${ }^{4}$ With respect to efficient techniques, the NWC again criticizes the grant program on the grounds that it has not stimulated the search for least-cost solutions. 5 The NWC recommends that the grant program be continued until the backlog of needed facllities has been eliminated. It recommends a grant cutoff date within 10 years, hoping that cities will be induced to expedite their abatement programs to fall within the grant period. ${ }^{6}$ Both on economic and equity grounds, the NWC further recommends municipal waste treatment as an "Ideal" enterprise to put on a self-sustalning basis through use of user fees and service charges. 7 . 
More theoretical work has been devoted to cost sharing in the general area of water resource development (i.e., flood protection, recreation, fish and wildife, navigation, irrigation, hydroelectric power, municipal and industrlal water, and shoreline protection) than in pollution abatement per se. The survey that follows covers cost sharing as it has been applied to some of the purposes mentioned above. However, only those applications that have relevance to the pollution abatement problem are Included. 8

Mark Regan was an early advocate of cost sharing of water projects by local interests in proportion to their benefits. 9 He recognized that local interests had different objective functions than the nation and that these differences, if not compensated for by cost sharing might encourage local support of projects that were not nationally efficient. Edward Renshaw, another leader In recognizing the significance of cost sharing, Investigated the economic efflciency effects of having different cost-sharing rules for alternative techniques of providing a given water resource project. 10 For flood protection, for example, he pointed out that local interests would pick that alternative with the highest ratio of Federal to local costs, other things equal, even though that selected alternative might not be the cheapest for the nation.

James Loughlin has also examined cost sharing in water resource development. 11 He concludes that differences in cost-sharing policies within an agency and among agencies lead to national inefficiencles and inequities. Loughlin recommends a uniform approach to sharing the costs of flood protection to bring about greater efflclency and equity.

Harold Marshall has derived the necessary conditions in cost sharing for encouraging local interests to select the least-cost combination of techniques and the nationally efficlent project scale for providing any given water resource project. ${ }^{12}$ The condition for encouraging the selection of the least-cost combination of techniques is that local groups be charged the same percentage cost share for each technique available to them. The necessary condition (called the Association Rule) for 
encouraging local support of the nationally efficient scale is that local groups be charged according to the benefits that they receive. ${ }^{13}$ Marshal1 shows that current cost-sharing rules for many of the water programs do not meet these conditions. (These conditions will be discussed in detail later in this section.)

Marshall and Broussalian have extended the conventional evaluation of cost sharing, which centers on efficiency effects, to examine the equity implications, where equity is consldered both in terms of fairness and redistribution of income. 15 In the same study the general cost-sharing programs of the grant agencies (EPA, EDA, FHA, and HUD) are evaluated on efficiency grounds and compared to those programs of the construction agencies (Corps of Engineers, Bureau of Reclamation, and Soil Conservation Service). 16

Rafuse and Sherman have taken a somewhat unique approach to determining cost shares for flood protection projects. They maintain that the net benefits from a flood control project are not additive among benefiting districts, and therefore that local cost-sharing requirements should not be based on an addition of these benefits. 17 They introduce the "net fiscal benefits criterion" as an alternative method for determining what local interests should be willing to pay. The criterion requires that local interests be required to pay a share of the project cost that is equal to the net fiscal benef1ts (e.g., increased tax revenues minus increased local government expenses) that they expect to realize from the project. 18 Rafuse and Sherman recognize that their criterion will not necessarily achieve efficient project decisions, but they emphasize that it has merit in achleving equity among cost-sharing participants. 19

Chapters 15 and 16 of the NWC Report, entitled "Paying the Costs of Water Development Projects" and "Financing Water Programs," deal directly with Federal financing programs. 20 The Report concludes that cost-sharing policies should be consistent among alternative techniques for accomplishing a given purpose. The Report further concludes that Federal financial assistance should be clearly identifiable and not obscurred by subsidized repayment schemes. $^{21}$ Finally, the NWC provides the following general rule on subsidies: "Direct beneficiaries of water projects who can be Identifled and reached should ordinarily be obliged to pay all 
project costs that are allocated to the services from which they benefit." 22 However, the cost-sharing decision to charge direct beneficiaries is more complex in pollution abatement than in other water programs, such as flood control, because pollution abatement is a project purpose which often aims to reduce the costs imposed by one group of people on another. That is, the polluters are not necessarily the beneficiaries. The "polluter pays" principle need not be in conflict with the "beneficiary pays" principle on efficiency grounds. On equity grounds, however, either of these principles may be considered superior, depending upon the decision maker's value system. Marshal 1 has described this particular problem in relation to the cost sharing of salinity control in the Colorado River Basin, where those who cause salt pollution are not necessarily those who benefit from desalting. 23 A 1ocal community which benefits from sewage treatment could be required to contribute a large percentage of abatement costs. It could in turn charge user fees and effluent charges on local residential and industry groups that may both benefit from abatement and/or cause the pollution that requires abatement.

DERIVATION OF DEMAND

Implicit in the analysis of the incentive nature of cost sharing is the assumption that the level of cost sharing does affect grant recipients in their demand for pollution abatement. Other things being equal, we can expect the demand for pollution abatement by local communities to depend on the price to them of that abatement and the value that they place on that abatement. Furthermore, the relationship between the quantity demanded by grant recipients of pollution abatement and the local cost share is hypothesized to be an inverse relationship. This hypothesis is explained with the model below.

Assume that the grant recipient's benefit or welfare function can be expressed as

$$
B_{R}=B_{R}(\Omega, M) \text {, }
$$

where $\mathrm{B}_{\mathrm{R}}$ = benefits accruing to the grant recipient,

$Q=$ unit measure (i.e., quantity) of pollution abatement, and

$M=$ all other goods and services available to the grant recipient, measured in dollars. 
'The grant rectpient is constrained in his purchase of $M$ and $Q$ by the amount of wealth, 1.e., his budget, avallable to him. Therefor: the reciplent will maximize his welfare (other things being equal) subject to the budget constraint which satisfies the relationship

$$
\mathrm{R}=\mathrm{M}+\mathrm{CPQ} \text {, }
$$

where $R$ = budget of the recipient,

$c=$ proportion that the nonfederal cost share bears to total project cost (i.e., nonfederal percentage cost share),

$P=$ national price per unit of $Q$,

$\mathrm{cP}=$ recipient's price per unit of $\mathrm{Q}$, and

$C P Q=$ total costs of $Q$ to recipient.

A1.l functions are considered continuous. To isolate the effect of cost sharing on demand, we shall assume that the percentage cost share (c) changes and that the national prices (P) remain constant.*

Figures 3 and 4 show graphically the derivation of demand for pollution abatement as a function of cost sharing. An indifference curve (I) represents combinations of $M$ and $Q$ to which the grant recipient is indifferent. For higher levels of $M$ and $Q$, the local group achieves higher levels of satisfaction as represented by $\mathrm{I}_{2}$ and $\mathrm{I}_{3}$ being located up and to the right of $\mathrm{I}_{1}$, in Figure 3. The slope of these indifference curves represents the marginal rate of substitution (trade-off) of $M$ for $Q$ that the grant recipient is willing to make, based on his judgment of the value of benefits from extra units of $M$ and $Q$. These indifference curves are derived from the welfare function in equation (1).

The lines $\mathrm{C}_{1}, \mathrm{C}_{2}$, and $\mathrm{C}_{3}$ represent the local budget constraints for different local cost shares $c_{1}, c_{2}$, and $c_{3}$ where $c_{1}>c_{2}>c_{3}$. The slope of the budget constraints is equal to the negative value of the grant recipient price, $1 . e .,(c P)$. As the local cost share of $Q$ diminishes, the budget constraint pivots at point $R$ and intersects the horizontal $Q$ axis at points farther to the right. The points of tangency between the

*This assumption is made for convenience of illustration. In practice the purchase of extra units of pollution abatement might even decrease the national price through economies of scale. Thus the local demand curve would still be downward sloping. 


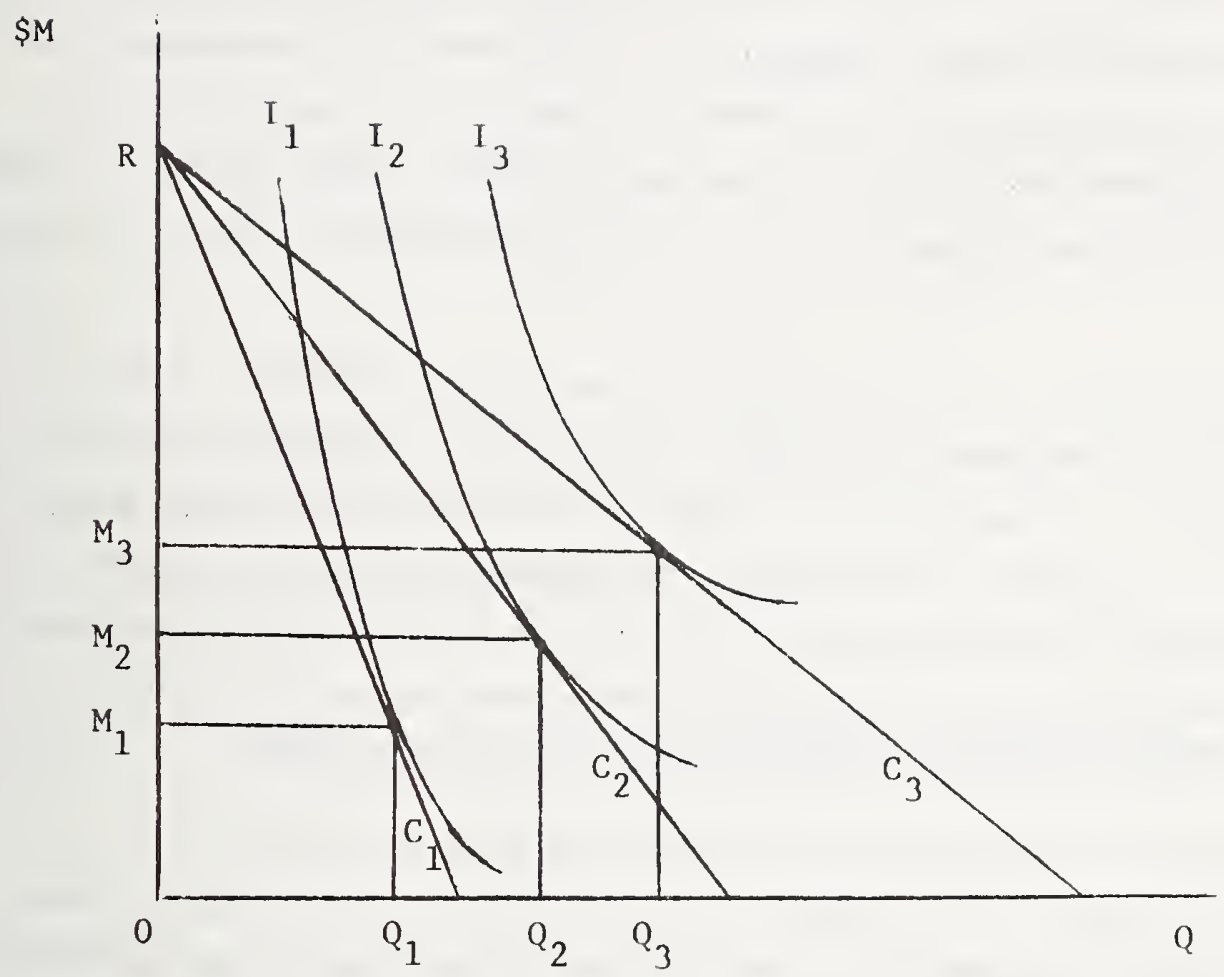

Figure 3. Indifference curves and budget constraints

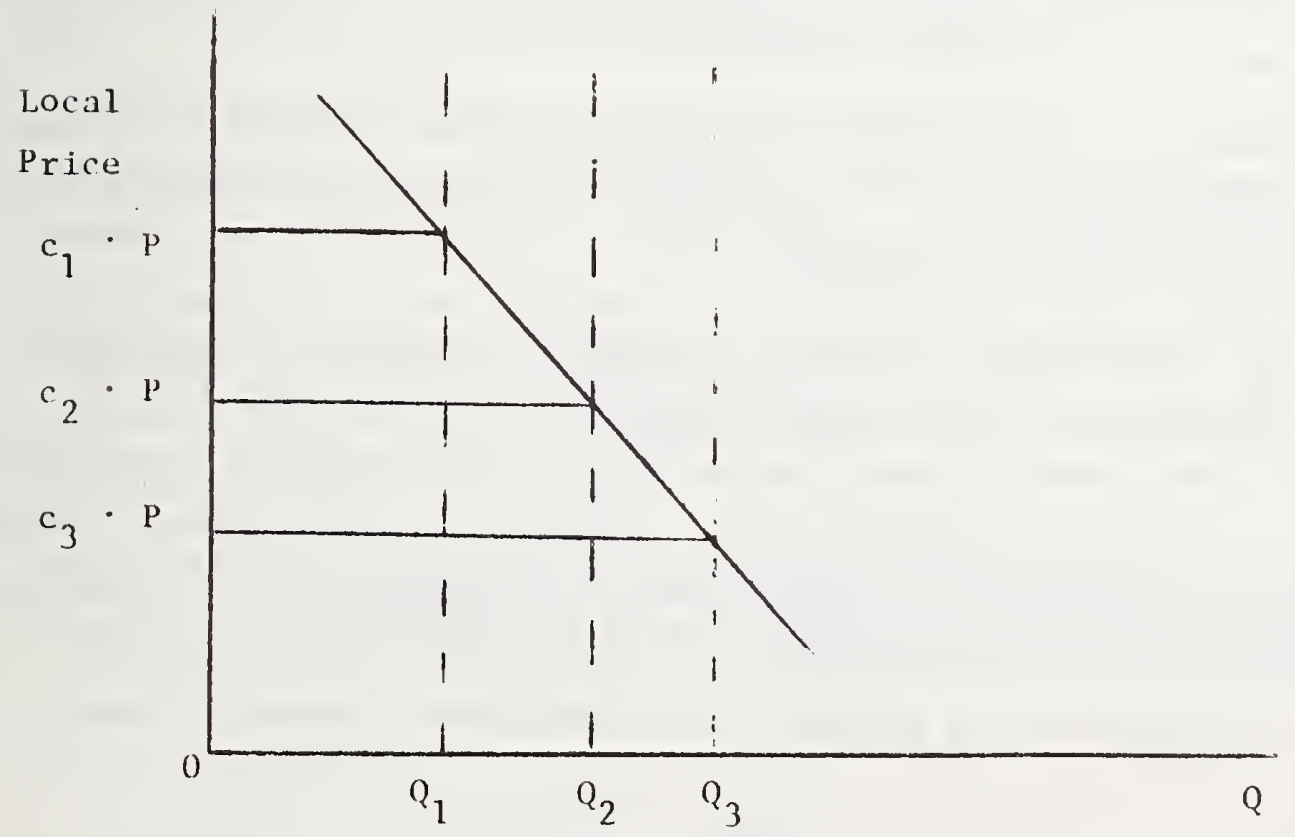

Figure 4. Demand for pollution abatement 
Indifference curves and the budget constraints indicate the economically efficient combinations. Hence, as the grant recipient's cost share decreases from $c_{1}$ to $c_{2}$ to $c_{3}$, the rociplent's absolute price per unit of Q decreases, and the grant reciplent will increase his purchases from $Q_{1}$ to $Q_{2}$ to $Q_{3}$ respectively, as shown in Figure 4. Thus, the grant reciplent's demand for pollution abatement, other things equal, is shown graphically to depend inversely upon the percentage cost share that he must pay.

If the sole purpose of cost sharing for pollution abatement were to encourage local interests to provide more and more abatement, then it follows from this demand analysis that reducing the local cost share would help serve that purpose. But since the Federal budget is limited and there are other projects competing for scarce Federal funds, we know that it may be inefficient to simply allocate Federal money for $100 \%$ of abatement costs to the exclusion of other types of projects.

An alternative to cost sharing for inducing greater abatement is to require a high level of abatement. Let us assume, for example, that Federal abatement standards or controls are imposed on local communities and that they are enforced. Figure 5 shows the resulting kinked demand function (DD) for abatement where $Q_{0}$ is the enforced level.

At least $Q_{0}$ level of abatement will be demanded regardless of the cost share, and the quantity demanded of additional levels of abatement will vary inversely with the local cost share.

If the standards or controls were not enforced, then the effective demand function would be $\mathrm{dD}, 1 . e .$, it would take on the general downward slope of the function derived in Figure 4.

This type of demand analysis might be extended to explain in part why with the 75\% Federal capital grants provided for in the 1972 Act, or even with a $100 \%$ Federal grant, the abatement levels that are considered needed may be greater than those levels demanded by the nonfederal sector. For example, some aspects of higher levels of abatement (e.g., community growth) might be considered as costs to the community but not to the nation. In addition, some aspects (e.g., downstream abatement benefits 


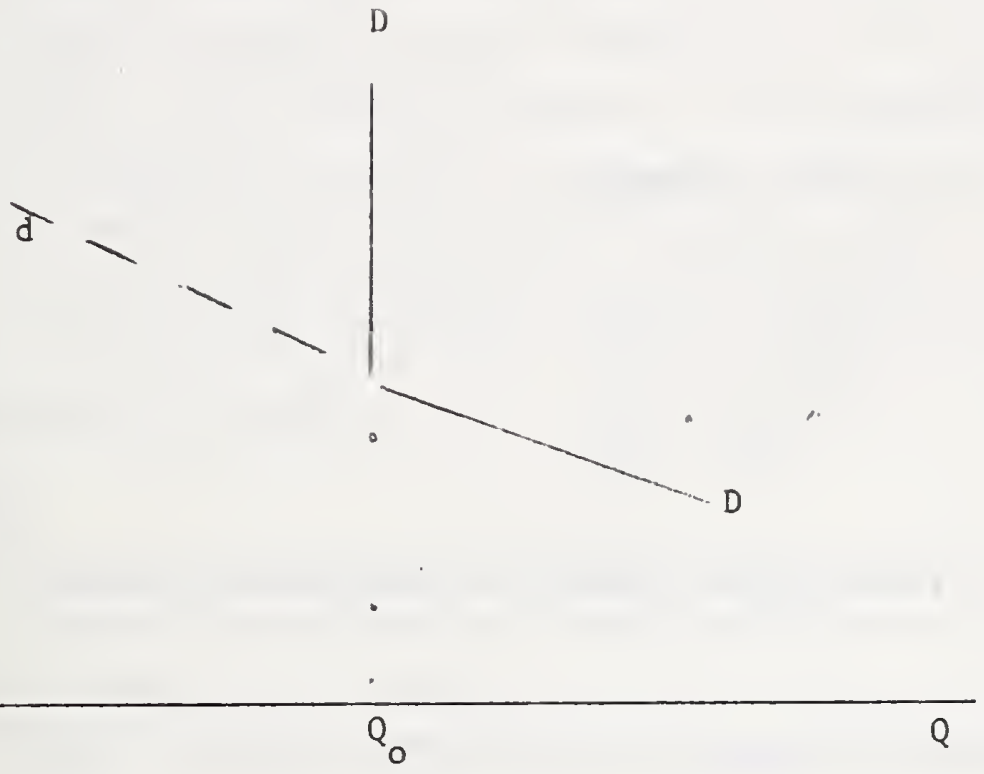

Figure 5. Demand for pollution abatement, with and without enforcement

external to the abating community) are considered as benefits to the nation but not to the comminity. Finally, the community recipient may put up all of the nonfederal cost share and yet receive only a part of the nonfederal benefits. Thus it is quite possible that the optimal level of abatement to the nation may be greater than what the community will provide even with a $100 \%$ Federal subsidy.

Consider Figure 6, where $Q_{0}$ has been designated as some nationally desirable target level of abatement, but where no enforcement exists for compelling the community to implement $Q_{0}$. Even where the local cost share approaches zero percent of total project costs, the community will implement less than $Q_{1}$, leaving a gap of $Q_{0}-Q_{1}$ between what is regarded as needed (optimal from a national standpoint) and what the community is willing to build.

It is quite conceivable that a community might exhibit such a demand function when it takes the narrow viewpoint that the only benefits and 


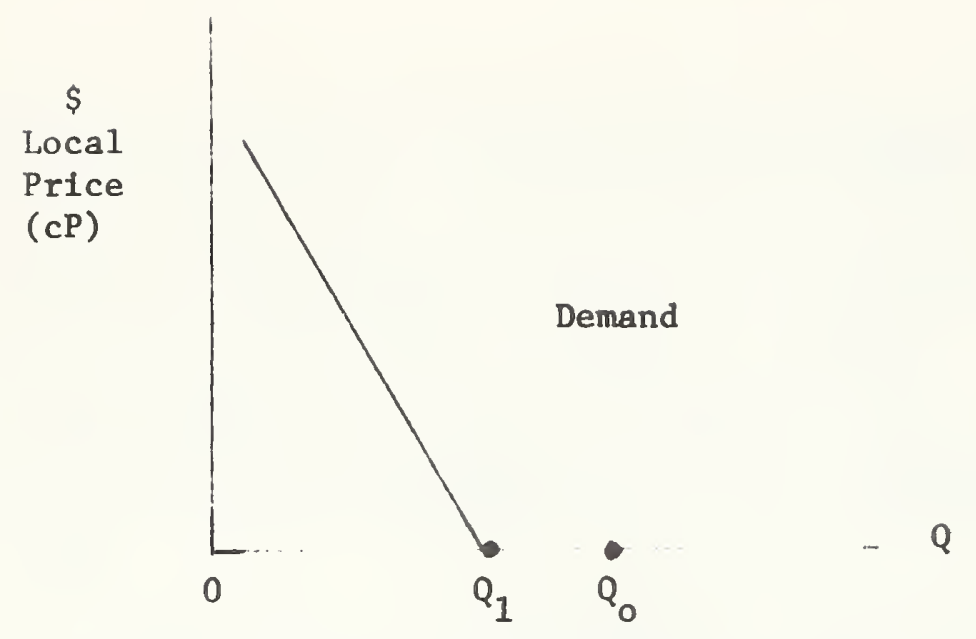

Figure 6. Insufficient demand for pollution abatement

costs of pollution abatement are those accruing directly to it.* CONDITIONS FOR EFFICIENCY

Two kinds of efficiency are discussed in this paper. The first is efficiency in production, which is reached when the least-cost combination of techniques has been chosen for providing pollution abatement. The second is effictency of scale, which is reached when the level of pollution abatement is such that no addition to or subtraction from that level could yield positive net benefits. The efficient mix of techniques and efficient scale can be determined simultaneously. However, local community decisions on techniques and scale may not be made simultaneous $1 \mathrm{y}$, and therefore the two cases are handled separately.

The following assumptions are made. A grant reciplent (e.g., local or state government) and a Federal agency (In this case EPA) share the costs of a project providing water pollution abatement. The grant recipient and the Federal donor agency may apply different criteria for evaluating the project. Grant reciplents would be expected to be most interested in benefits that accrue locally to them and the Federal agency must

*If the situation depicted in Figure 6 were to exist, a $100 \%$ Federal cost share might even be ineffective as an Inducement to encourage $Q^{\circ}$ A subsidy in excess of $100 \%$ or enforced standards would, theoreticaliy, be alternative means of inducement. 
consider benefits that accrue nationally, $1 . e$. , benefits that accrue locally as well as spill over local boundaries. Both the grant reciplent and the nation as a whole are assumed to have downward sloping demand functions for project outputs. That is, the higher their respective cost shares, other things being equal, the less output they will demand. Finally, the production function for abatement is assumed to be characterized, at least after an initial stage, by diminishing marginal returns to successive input units.

\section{Techniques}

The purpose of this section on techniques is not to identify those leastcostly techniques, but to determine what conditions cost sharing must meet to encourage grant reciplents to seek techniques for abating pollution that are least costly to the nation (a recognized objective of the 1972 Act $^{25}$ ), as well as to themselves.

A necessary condtion for least-cost production to the nation is that

$$
\frac{\partial \mathrm{Q}}{\partial \mathrm{T}_{1}} / \frac{\partial \mathrm{Q}}{\partial \mathrm{T}_{2}}=\frac{\mathrm{P}_{1}}{\mathrm{P}_{2}},
$$

where $\quad Q=$ units of output of pollution abatement,

$\mathrm{T}_{1}, \mathrm{~T}_{2}=$ are units of techniques 1 and 2 ,

$P_{1}, P_{2}=$ national cost or price per unit of techniques 1 and 2.

$P_{1}$ and $P_{2}$ are assumed to be constant*in the relevant range of demand for techniques 1 and 2 . This assumption seems reasonable in that the prices would not be expected to vary much with the slze of one project.

This necessary condition (3) is derived as follows. Assume that benefits to the nation (B) from pollution abatement are a function of $Q$ and that $Q=Q\left(T_{1}, T_{2}\right)$. Assume further that the nation has some budget constraint for pollution abatement $(S)$. To find the maximum of $B\left[Q\left(T_{1}, T_{2}\right)\right]$ subject to the constraint that $\mathrm{S}=\mathrm{P}_{1} \mathrm{~T}_{1}+\mathrm{P}_{2} \mathrm{~T}_{2}$, we make the problem unconstrained by use of the Lagrange multiplier $(\lambda)$ and maximize the new expression

$$
\mathrm{W}=\mathrm{B}(\mathrm{Q})+\lambda\left(\mathrm{S}-\mathrm{P}_{1} \mathrm{~T}_{1}-\mathrm{P}_{2} \mathrm{~T}_{2}\right),
$$

where $W$ now is a function of $T_{1}, T_{2}$, and $\lambda$.

*This assumption is essential for the derivation. 
A necessary condition for optimization 18 that the partial derivatives of W with respect to each varlable must equal zero. By doing this for the two techniques we have

$$
\begin{aligned}
& \frac{\partial W}{\partial T_{1}}=\frac{\partial B}{\partial Q} \cdot \frac{\partial Q}{\partial T_{1}}+\lambda\left(-P_{1}\right)=0, \text { and } \\
& \frac{\partial W}{\partial T_{2}}=\frac{\partial B}{\partial Q} \cdot \frac{\partial Q}{\partial T_{2}}+\lambda\left(-P_{2}\right)=0 .
\end{aligned}
$$

Placing the negative terms to the right side of the equations and dividing the first expression by the second ylelds

$$
\frac{\partial \mathrm{B}}{\partial \mathrm{Q}} \cdot \frac{\partial \mathrm{Q}}{\partial \mathrm{T}_{1}} / \frac{\partial \mathrm{B}}{\partial \mathrm{Q}} \cdot \frac{\partial \mathrm{Q}}{\partial \mathrm{T}_{2}}=\frac{\lambda \mathrm{P}_{1}}{\lambda \mathrm{P}_{2}} \cdot
$$

Simplifying equation (7) results in the condition to be demonstrated,

$$
\frac{\partial Q}{\partial \mathrm{T}_{1}} / \frac{\partial Q}{\partial \mathrm{T}_{2}}=\frac{\mathrm{P}_{1}}{\mathrm{P}_{2}} \text {. }
$$

This means that each technique w111 be used up to that level at which the extra output realfzed per extra dollar spent is equal for the two techniques. The Federal agency, as an agent for soclety as a whole, is expected to select techniques according to this least-cost principle. To 111 ustrate how a grant reclpient w111 choose among techniques, we examine his behavior under the assumption that he attempts to maximize his benefits from abatement subject to his budget constraint. A necessary condition for his least-cost production is that

$$
\frac{\partial Q}{\partial T_{1}} / \frac{\partial Q}{\partial T_{2}}=\frac{c_{1} P_{1}}{c_{2} P_{2}} \text {, }
$$

where $c_{1}, c_{2}=$ grant reciplent's cost shares (proportions) of techniques 1 and 2 respectively.

This condition 18 derlved as follows. ${ }^{26}$ Assume that recipient benefits $\left(B_{R}\right)$ are a function of $Q$ and that the reclplent has some budget constraint $R$. To find the maximum of $B_{R}\left[Q\left(T_{1}, T_{2}\right)\right]$ subject to the constraint that $R=c_{1} P_{1} T_{1}+c_{2} P_{2} T_{2}$, we can make the problem unconstrained by use of the Lagrange multiplier and maxtmize the expression 


$$
V=B_{R}(Q)+\lambda\left(R-c_{1} P_{1} T_{1}-c_{2} P_{2} T_{2}\right),
$$

where $\mathrm{V}$ is now a function of $\mathrm{T}_{1}, \mathrm{~T}_{2}, \lambda, \mathrm{c}_{1}$, and $\mathrm{c}_{2}$.

By setting the partial derivatives of $\mathrm{V}$ with respect to $\mathrm{T}_{1}$ and $\mathrm{T}_{2}$ equal to zero, we obtain

$$
\begin{aligned}
& \frac{\partial V}{\partial T_{1}}=\frac{\partial B_{R}}{\partial Q} \cdot \frac{\partial Q}{\partial T_{1}}+\lambda\left(-c_{1} P_{1}\right)=0 \text { and } \\
& \frac{\partial V}{\partial T_{2}}=\frac{\partial B_{R}}{\partial Q} \cdot \frac{\partial Q}{\partial T_{2}}+\lambda\left(-c_{2} P_{2}\right)=0
\end{aligned}
$$

Placing the negative terms to the right side of the equations and dividing the first expression by the second yields

$$
\frac{\partial B_{R}}{\partial Q} \cdot \frac{\partial Q}{\partial T_{1}} / \frac{\partial B_{R}}{\partial Q} \cdot \frac{\partial Q}{\partial T_{2}}=\frac{\lambda c_{1} P_{1}}{\lambda c_{2} P_{2}} .
$$

Simplifying equation (12) results in the condition to be demonstrated,

$$
\frac{\partial Q}{\partial \mathrm{T}_{1}} / \frac{\partial Q}{\partial \mathrm{T}_{2}}=\frac{\mathrm{c}_{1} \mathrm{P}_{1}}{\mathrm{c}_{2} \mathrm{P}_{2}} \cdot
$$

Note that identical cost shares $\left(c_{1}=c_{2}\right)$ must apply to each technique if cost sharing is to induce the grant recipient to select the nationally efficient combination of techniques. If $c_{1}>c_{2}$, the recipient will be biased by cost sharing to choose less of technique 1 and more of technique 2 than is nationally efficient. If $c_{2}>c_{1}$, he will be biased to choose less of technique 2 and more of technique 1 than is nationally efficient. Only when $c_{1}=c_{2}$ does the recipient's maximizing condition (8) become equivalent to the least-cost condition for society (3). This condition for equal cost shares can be extended to as many techniques as are reasonable substitutes for providing a given leve1 of output.*

*The $c_{1}=c_{2}$ does not apply under all situations because the $\mathrm{B}=\mathrm{B}\left[\mathrm{Q}\left(\mathrm{T}_{1}, \mathrm{~T}_{2}\right)\right]$ formulation is not completely general. For example, taking the narrow view that the nonfederal group is represented by a single city that might apply for a grant, locational differences of an abatement project might affect the distribution of benefits and therefore the choice of techniques. Whereas society's benefits from abatement of a given city's sewage might be the same whether it is produced by a given combination of abatement techniques upstream or downstream of the city, (continued on next page) 
Rather than assume the grant recipient attempts to maximize his benefits from abatement subject to his budget constralnt, we can adopt an alternative assumption regarding his behavior in the case where water quality standards are enforced. In such a case, we can assume that he regards as given, a level of abatement that must be met.

The necessary condition under the new assumptions is derived as follows. The recipient attempts to minimize his costs $\left(C_{R}\right)$ subject to the constraint that the level of abatement meets a specified level $\left(Q_{0}\right)$. Making the problem unconstrained by the Lagrange multiplier, we can minimize the expression

$$
C_{R}=c_{1} P_{1} T_{1}+c_{2} P_{2} T_{2}+\lambda\left[Q_{0}-Q\left(T_{1}, T_{2}\right)\right]
$$

By setting the partial derivatives of $\mathrm{C}_{\mathrm{R}}$ with respect to $\mathrm{T}_{1}$ and $\mathrm{T}_{2}$ equal to zero, we obtain

$$
\begin{aligned}
& \frac{\partial C_{R}}{\partial T_{1}}=C_{1} P_{1}-\lambda \frac{\partial Q}{\partial T_{1}}=0 \text {, and } \\
& \frac{\partial C_{R}}{\partial T_{2}}=c_{2} P_{2}-\lambda \frac{\partial O}{\partial T_{2}}=0 .
\end{aligned}
$$

Dividing the first expression by the second and simplifylng, we find the same condition derived earlier,

$$
\frac{\partial Q}{\partial T_{1}} / \frac{\partial Q}{\partial T_{2}}=\frac{c_{1} P_{1}}{c_{2} P_{2}} \text {. }
$$

Thus identical cost shares is a necessary condition for encouraging grant recipients to select the nationally efficient technique both under conditions of constrained budgets and of enforced levels of abatement.

(continued from previous page) the benefits recelved by that city will vary with the location of the treated effluent. If the abatement is above the city, more benefits will accrue locally than if the abatement occurs below the city. Thus the necessary condition that $c_{1}=c_{2}$ might not apply under these assumptions because the distribution of benefits may vary by technique. By taking the broader view of the nonfederal group, which includes cities below and above the particular city applying for a grant, the nonfederal benefits as a collection of regional benefits will be relatively unchanged by the kind of locational differences described in the example. 
Th1s mathematical derivation of equal cost sharing by technique is based on differentiable, convex, curvilinear isoquants that do not intersect the horizontal and vertical axes, thereby eliminating the possibility that one technique alone would be the efficlent choice. The following graphical analysis in Figure 7 allows for corner solutions, which are likely to occur in pollution abatement under some circumstances.

Assume that ? 1 level of pollution abatement can be produced with those combinations of techniques 1 and 2 indicated by the isoquant abc. Assume further that the recipient's share of benefits is the same for output $Q_{1}$ for any combination of techniques 1 and 2 on abc. Isocost $R$ depicts the locus of quantity combinations of techniques 1 and 2 that will be of equal cost to the grant recipient with Federal cost sharing. Isocosts $\mathrm{S}_{1}$ and $\mathrm{S}_{2}$ depict the locus of quantity combinations of techniques 1 and 2 that will be of equal cost (to the nation) in producing $\Omega_{1}$ solely with techniques 2 and 1 , respectively, where $\mathrm{S}_{2}>\mathrm{S}_{1}{ }^{*}$ The recipient and Federal isocosts are not parallel because $c_{1} \neq c_{2}$. In this case, the slope of $R$, $-c_{2} P_{2} / c_{1} P_{1}$, is steeper than the slope of $s_{1}$ and $S_{2},-P_{2} / P_{1}$. Because the recipient's cost share of technique 2 is considerably higher than his share of technique 1 , he will choose a production process using more of technique 1 than will the Federal agency seeking national efficiency. If the absolute value of the slope of $\mathrm{R}$ is less than that of line segment bc, the grant recipient chooses technique 2 on $1 y$. The recipient will stop choosing technique 2 alone and pick the combination of techniques 1 and 2 indicated at $b$ if the absolute value of the slope of $R$ exceeds that of line segment bc but is less than that of $a b^{* *}$. The corner solution

*For any given price ratio, a family of isocosts exists for the nation. The same holds true for the grant recipient for any given cost-sharing proportion and price ratio. Three isocost lines ( $R, S_{1}$ and $S_{2}$ ) are focused upon here out of the families of isocosts to 11lustrate the impact of cost sharing on the selection of least-cost techniques.

**If $\mathrm{R}$ becomes parallel to $\mathrm{bc}$ or $\mathrm{ab}$, the grant recipient would find any combination of techniques 1 and 2 on those respective line segments to be of equal cost in obtaining $Q_{1}$. 


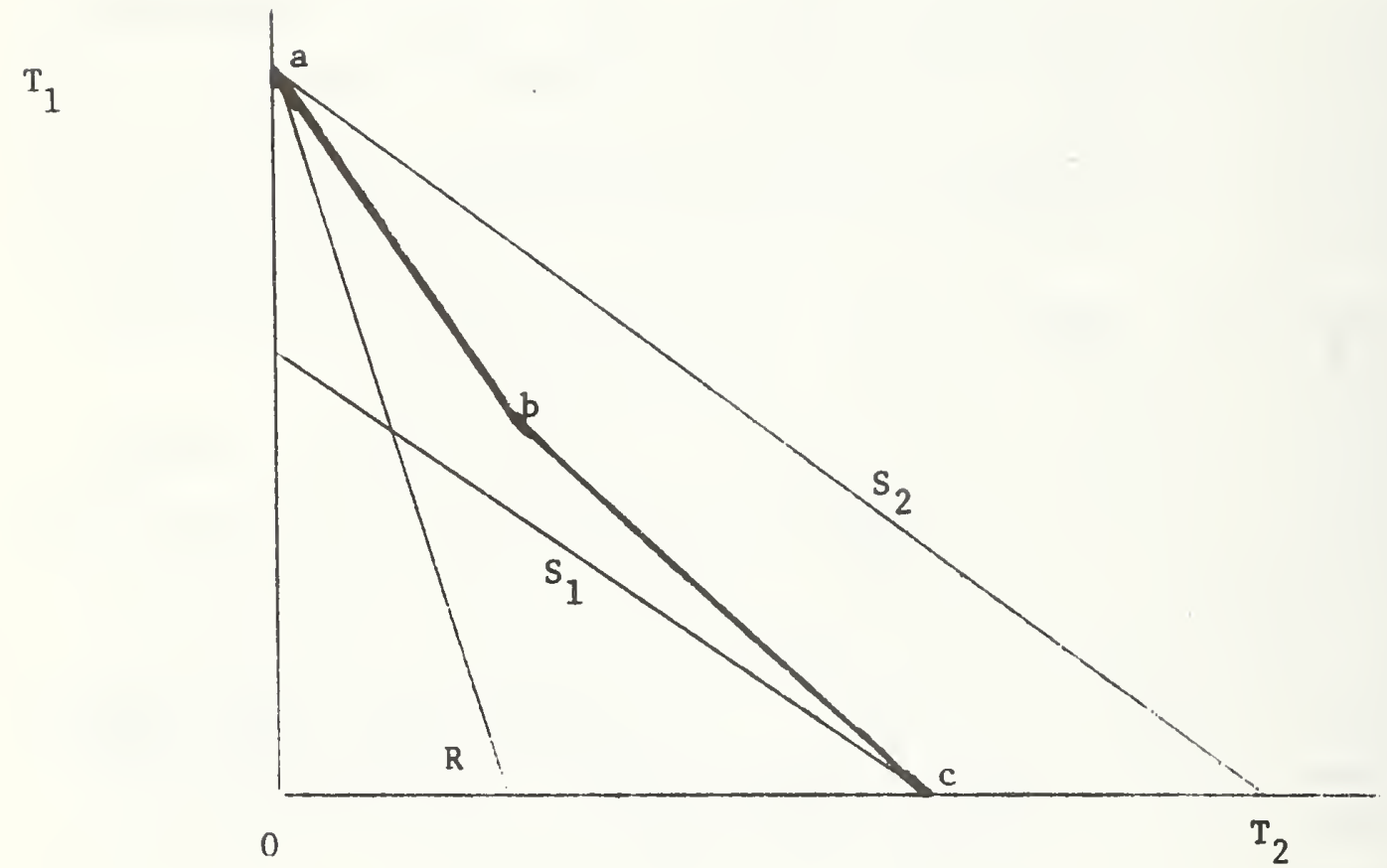

Figure 7. Cost share for efficient technique(s) 
at a, picking only technique 1, will become least cost to the recipient only when the absolute vilue of the slope of $\mathrm{R}$ exceeds that of line segment ab. 'lhus, with this lsoquant that meets the axes, there are ranges of cost shares that might induce grant recipients to select the nationally efficient technique(s).

Figure 7 shows that under the assumed conditions the least-cost technique(s) for the grant recipient is technique 1. The cost to the nation of producing $Q_{1}$ with technique 1 is $S_{2}$. Yet society can realize $Q_{1}$ at a lower cost, $\mathrm{S}_{1}$, by using only technique 2. The grant recipient will select the same technique(s) as the Federal faction for producing $Q_{1}$ only when the slopes of both factions' isocosts are more nearly equal. If $\mathrm{R}$ were to have $\mathrm{a}$ slope with an absolute value less than that of line segment bc, then both the Federal agency and the recipient will choose to produce with technique 2 exclusively, and the savings to the nation (net efficiency gain) from producing $\mathrm{Q}_{1}$ with technique 2 instead of 1 would be the difference in the costs represented by $\mathrm{S}_{2}$ minus $\mathrm{S}_{1}$. The implication of this analysis is that where one technique alone is nationally efficient, a limited range of cost shares might encourage the grant recipient to choose the nationally efficient technique. But to handle all possible configurations of isoquants and be assured that the local cost share is in the proper range, it would seem pragmatic to make $c_{1}=c_{2}$ the general rule for all pollution abatement projects.*

The implications of existing cost-sharing rules for efficiency in production are evaluated in Section $V$, where percentage cost shares are displayed by technique and category of cost for various approaches to pollution abatement.

\section{Scale}

The necessary condition for determining the nationally efficient scale of a water project has traditionally been to equate marginal benefits to

*In addition to the kinked isoquant shown in Figure 7, curv1linear, convex isoquants or straight-line isoquants, both of which touch the axes, might also be representative of the $\mathrm{mix}$ of techniques that would provide $\mathrm{Q}_{1}$ level of abatement. The shape of the isoquant depends on the productivity relationships of the particular techniques examined. The $c_{1}=c_{2}$ rule is appropriate for all of these isoquants. 
marginal costs, i.e., to maximize net benefits, ${ }^{27}$ where benefits represent the change in value of goods and services that result from having a project as compared to not having $i t$, and where costs include all expenses of construction; interest; and of operation, maintenance, and replacement. Construction agencies such as the Army Corps of Engineers, the Bureau of Reclamation, and the Sol1 Conservation Service traditionally were supposed to plan all projects to that scale or size where net benefits are maximized. Additional objectives such as environmental quality and regional development are considered today in the planning of water projects by these construction agencies.

The grant agencies that are most important in providing financial assistance for sewage treatment and collection facilities-EPA, HUD, EDA, and FHAhave objectives that are less specific than the construction agencies in terms of a benefit and cost criterion. Their objectives are more mission oriented, and without detalled criteria regarding the efficient scale or size of a project. For EPA, for example, Title II of the 1972 Act, Sec. 201(a), states that "it is the purpose of this title to require and to assist the development and implementation of waste treatment management plans and practices which will achieve the goals of this Act." In terms of scale, Section 204 (a)(5) states the following:

- . that the size and capacity of such works relate directly to the needs to be served by such works, including sufficient reserve capacity. The amount of reserve capacity provided shall be approved by the Administrator on the basis of a comparison of the cost of constructing such reserves as a part of the works to be funded and the anticipated cost of providing expanded capacity at a date when such capacity will be required.

Needs, as a basis for determining scale, is more ambiguous than a net benefits criterion. The 1972 Act does not provide a clear description of the nationally efficient scale of abatement.

The nationally efficient scale of pollution abatement, $1_{\bullet e}$, where net benefits are maximized, is emphasized in this study. Economies of scale, i.e., where the average cost of abatement decreases at larger levels of abatement, will be examined from the standpoint of how it relates to maximizing net benefits. 
A strong argument on efficiency grounds (to be discussed below) can be made for planning abatement projects to the scale where net benefits are maximized. Even where some target level of abatement is established, to ensure the efficient scale the target level should ultimately be based on a net benefits criterion. Thus the following discussion of the Association Rule (AR) ${ }^{28}$ is provided to demonstrate the cost-sharing condition (i.e., the AR) which will encourage grant recipients to seek the efficient scale of pollution abatement from their standpoint as well as from the nation's standpoint, where maximizing net national benefits from abatement is assumed to be the national objective.

Assume the following:

$$
\begin{array}{rlrl}
\mathrm{B} & =\mathrm{B}(\mathrm{Q}) & \mathrm{C}=\mathrm{C}(\mathrm{Q}) \\
\mathrm{B}_{\mathrm{R}}=\mathrm{B}_{\mathrm{R}}(\mathrm{Q}) & \mathrm{C}=\mathrm{C}_{\mathrm{R}}+\mathrm{C}_{\mathrm{F}} \\
\mathrm{B}_{\mathrm{F}}=\mathrm{B}-\mathrm{B}_{\mathrm{R}} & \mathrm{c}=\overline{\mathrm{c}} \\
\mathrm{b}=\frac{\mathrm{dB}}{\mathrm{dQ}} / \frac{\mathrm{dB}}{\mathrm{dQ}} & (16) & \mathrm{c}=\frac{\mathrm{d} C_{\mathrm{R}}}{\mathrm{dQ}} / \frac{\mathrm{dC}}{\mathrm{dQ}}
\end{array}
$$

where $B=$ total benefits accruing to the nation, $*$

$$
\begin{aligned}
\mathrm{B}_{\mathrm{R}} & =\text { benefits accruing to grant recipient, } \\
\mathrm{B}_{\mathrm{F}} & =\text { widespread benefits not assignable to grant recipients, } \\
\mathrm{b} & =\text { proportion of } \mathrm{B} \text { accruing to grant recipient at the margin, } \\
\mathrm{C} & =\text { total costs accruing to the nation, } \\
\mathrm{C}_{\mathrm{R}} & =\text { costs borne by grant reciplent, } \\
\mathrm{C}_{\mathrm{F}} & =\text { costs borne by the Federal government, } \\
\mathrm{C} & =\text { proportion of } \mathrm{C} \text { paid by grant recipient at the margin, and } \\
\overline{\mathrm{C}} & =\text { constant cost share exogenously determined in legislation. }
\end{aligned}
$$

For national economic efficiency, pollution abatement should be provided at that scale where net national benefits are maximized. Assuming continuous

*Examples of potential benefits from pollution abatement are the following: value of recreational opportunitles gained; reduced costs of purifying water supplies to meet drinking water or other standards; value of gains from enhanced commercial and sport fișheries; and reduced costs of processing water for production purposes. 
and smooth functions, this condition is

$$
\frac{\mathrm{dB}}{\mathrm{dQ}}=\frac{\mathrm{dC}}{\mathrm{dQ}}
$$

The last increment in scale adds benefits fust equal to the marginal costs of production. If a pollution abatement project is underbuilt or overbuilt with respect to the scale that is nationally efficient, then too few or too many resources respectively have been allocated to that project.

To maximize their net benefits, grant recipients w111 choose, if possible, that scale where

$$
\frac{\mathrm{dB}_{\mathrm{R}}}{\mathrm{dQ}}=\frac{\mathrm{dC}_{\mathrm{R}}}{\mathrm{dQ}}
$$

Grant recipients cannot gain net benefits by altering the size of the project when this condtion is satisfied. Rearranging equations (16) and (17), we have

$$
\frac{\mathrm{dB}_{\mathrm{R}}}{\mathrm{dQ}}=\mathrm{b} \cdot \frac{\mathrm{dB}}{\mathrm{dQ}}
$$

and

$$
\frac{\mathrm{dC}_{\mathrm{R}}}{\mathrm{dQ}}=\mathrm{c} \cdot \frac{\mathrm{dC}}{\mathrm{dQ}}
$$

By substitution into equation (19), we obtain the following condition:

$$
b \cdot \frac{d B}{d Q}=c \cdot \frac{d C}{d Q}
$$

This maximization condition for local interests shows, by comparing it with condition (18), that the scale desired by grant recipients will equal that plcked by the Federal agency only if $b=c$. This condition, i.e., that costs are shared in the same proportion as benefits at the margin, is called the Association Rule (AR). If $b>c$, grant recipients will choose a scale larger than the nationally efficient level and $\mathrm{dB} / \mathrm{dQ}<\mathrm{dC} / \mathrm{dQ}$.

*For a derivation of this condition and of the condition for maximizing efficiency in the presence of a budget constraint, see Stephen A. Marglin, "Objectives of Water-Resource Development: A General Statement," Design of Water Resource Systems, Mass, et. a1. (Cambridge, Massachusetts: Harvard University Press, 1962), pp. 31-36. 
If $b<c$, they will choose a scale smaller than the nationally efficient level and $\mathrm{dB} / \mathrm{dQ}>\mathrm{dc} / \mathrm{dQ}$.*

Figure 8 illustrates the AR graphically. Demand functions MNB and MRB represent the willingness-to-pay for pollution abatement by the nation and by grant recipients respectively.** The downward slopes depict diminishing marginal benefits to each faction for extra units of abatement. Assume for 1llustrative purposes that $75 \%$ of MNB accrues 1oca11y, as measured by MRB. Assume further than the marginal national cost curve, MNC, represents the least-cost combinations of techniques for providing each level of output. Net national benefits are maximized at $Q_{0}$ because $d B / d Q=d C / d Q, 1 . e$. , MNB = MNC. Grant recipients will be encouraged to select up to Q。 only when they pay a cost share of $75 \%$, which makes $\mathrm{dB}_{\mathrm{R}} / \mathrm{dQ}=\mathrm{dC}_{\mathrm{R}} / \mathrm{dQ}$ at $\mathrm{Q}_{0}$ (1.e., $\mathrm{MRB}=.75 \mathrm{MNC}=\mathrm{MRC}) . * * *$ If the grant recipients are charged $50 \%$ of costs, they will choose up to $\mathrm{Q}_{2}$. The national efficiency loss would amount to abc if the project were built to this scale. A $90 \%$ share to grant recipients would induce them to choose up to $Q_{1}$. If the project were buflt to this scale, an efficiency loss of area aed would result, equal to the foregone amount by which extra national benefits would have exceeded extra national costs up to $Q_{0}$.

The mathematical and graphical analyses show that the AR meets the necessary condition for encouraging grant recipients to choose the nationally

* It is recognized that there may be other policies than cost sharing that would encourage grant reciplents to seek the nationally efficient scale. However, since this study is focused on cost sharing, we are evaluating in detail only cost sharing policies as incentives for encouraging local behavior that is nationally efficient.

$* * M N B$ and MRB are respectively $\frac{d B}{d Q}$ and $\frac{\mathrm{dB}_{\mathrm{R}}}{\mathrm{dQ}}$.

$\star * t$ These results are not affected if non-linear marginal functions replace the stipulated linear ones, since both MRB and MRC will still coincide at $Q_{0}$. 


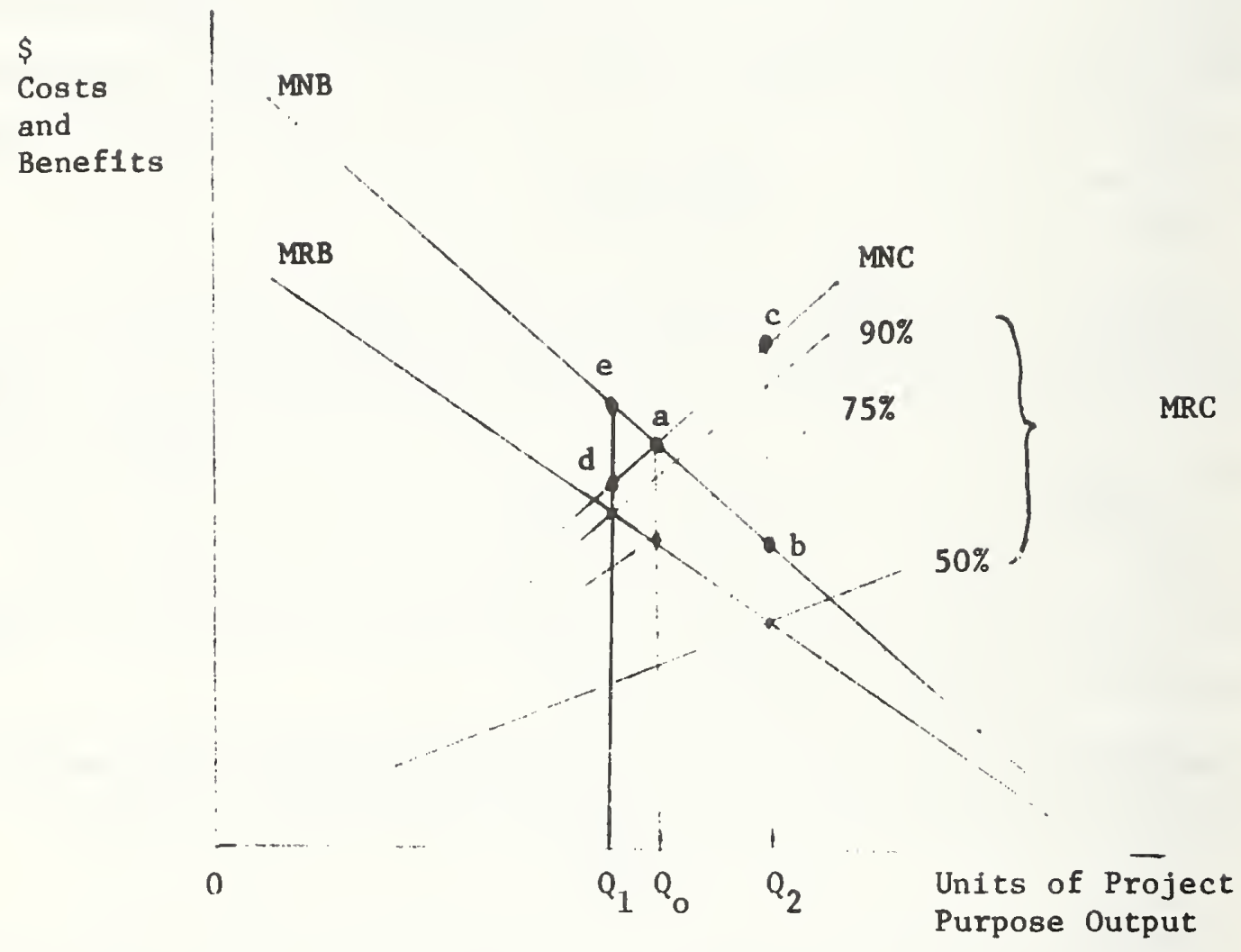

F1gure 8. Cost share for efficlent scale 
efficient project scale.* Implementation of the AR, however, might be considered difficult in that information on benefits that accrue to the grant recipients and to the nation at large is necessary in order to apply the rule. Alternatives to the AR will be evaluated in Section $V$. Now let us examine economies of scale in abatement as they relate to maximfing net national benefits. As the level of abatement increases, the average cost per unit of abatement will decrease under certain conditions. Thus large cities with large abatement profects may benefit from economies of scale, whereas small cities with small abatement projects may pay higher unit costs. This part of the study examines the efficiency implications of varying local cost shares in proportion to community size to encourage nonfederal interests to take advantage of economies of scale. As the size of pollution abatement facilities increases, it is reasonable to expect that the average cost (AC) to the nation per unit of abatement** will first decrease and ultimately increase, as shown in Figure 9.

The characteristic "U"-shaped AC curve demonstrates economies of scale from increasing abatement $(Q)$ up to $Q_{m}$, the minimum $A C$ point, and diseconomies of scale from increasing abatement beyond $Q_{m} * * *$ (Note that marginal cost (MC) always intersects $\mathrm{AC}$ at its minimum point).

*Application of the Association Rule is not inconsistent with the application of the same percentage share to all cost categories and techniques, as discussed earlier in this section. Cost shares could vary by project according to the Association Rule; but to encourage selection of least-cost techniques, the selected percentage for any given project must be applied equally among techniques to satisfy the same percentage rule.

**The average cost function is assumed here to represent the least-cost combination of techniques.

$\star * *$ There is some controversy as to whether or not AC does ultimately bend upwards. Data on the operation of plants seem to support the contention that, in the relevant range of demand for abatement, AC declines. The analysis presented in this section applies to either type of AC situation, the "U"-shaped curve we describe on a priori grounds, or the decreasing AC curve that operators have suggested. 


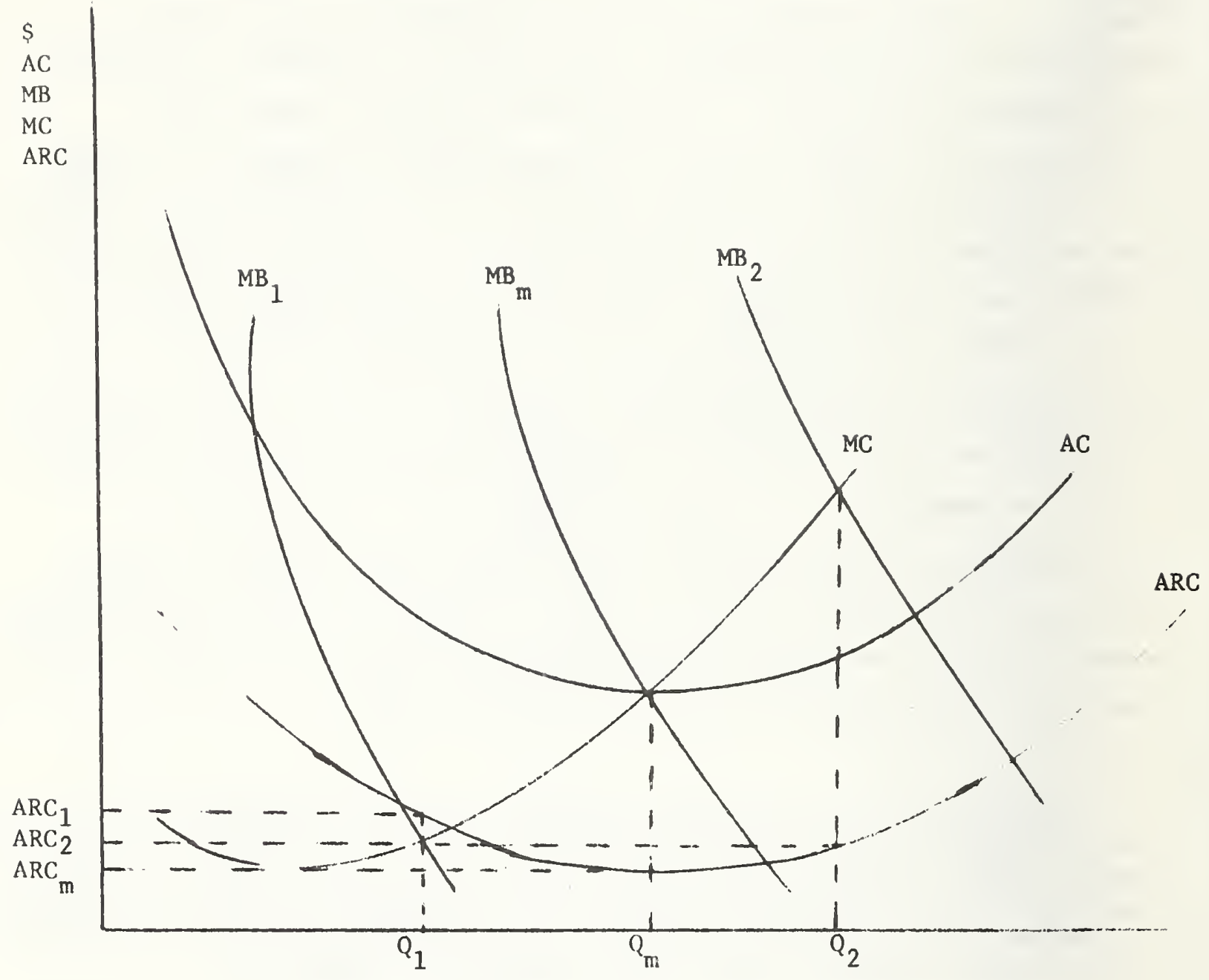

Figure 9. Average cost and efficient scale of pollution abatement 
Several factors contribute to the economies of scale that are reflected in the decreasing portion of the AC function. Increased specialization and more efficient utilization of management occurs with larger operations; more efficient equipment can be utilized in large scale operations; and finally, partial neutralization of wastes by mixing from different sources may reduce treatment costs. Eventually, however, the following factors will tend to push the AC for abatement up. With a large labor force, plants may become unionized, causing higher wage costs. Disposal of sludge becomes more and more costly with greater quantities, particularly in a heavily urbanized area with limited disposal areas. Because collection is an expensive part of total abatement costs, routing from sources at greater and greater distances from a central plant becomes prohibitively expensive.

It was stated earlier that the efficient scale of abatement would be that level where marginal benefits (MB) to society from abatement just equaled marginal costs. This efficient level of abatement could be to the left of $Q_{m}$, say at $Q_{1}$; at $Q_{m}$; or to the right of $Q_{m}$, say at $Q_{2}$. There is no economic efficiency argument for providing $Q_{m}$, for example, unless ${ }^{M B}{ }_{m}$ happens to be society's marginal benefit function.

An abatement program for a small city might have a benefits function such as $\mathrm{MB}_{1}$; that is, extra benefits from abatement become small at relatively low levels of $Q$ once the pollution load requirements of that city have heen met. A large clty, on the other hand, might show a benefits function such as $\mathrm{MB}_{2}$, lllustrating greater marginal benefits at all scales of abatement than the small city。

If the grants for construction to the cities are $75 \%$, this means that the grant reclpient cities would incur $25 \%$ of the abatement costs, as indicated by their average cost (ARC) function in Figure 9 (ARC =.25AC). Note that due to economies of scale, the large city pays less in absolute amount $\left(\mathrm{ARC}_{2}\right)$ per unit of abatement than does the small city $\left(\mathrm{ARC}_{1}\right)$. With the MB function in different positions, however, the small city might pay less per unit of abatement than the large city (assuming that AC rises over the relevant range). The significant finding of this analysis 
is that there is no economic efficiency rationale for giving one city more in percentage terms than to another simply because the absolute AC of abatement differs between the two. In fact, varying cost shares in relation to city size, other things being equal, may lead to inefficient scales of abatement. The analysis does indicate that under some circumstances it might be advantageous to cities and to the nation for cities to join in the contruction of regional treatment plants that will yield economies of scale, thereby reducing the absolute cost per unit of abatement to the individual participating cities and to the nation. For example, in Figure 10 the efficient scale of abatement for city 1 and city 2 would be $Q_{1}$ and $Q_{2}$ respectively when they operate singly. But, If they were to combine their efforts in a regional facility at a joint level of abatement of $\mathrm{Q}_{3}$, the cost to the nation per unit would be $\mathrm{AC}_{3}$, which is lower than what would have been paid for separate facilities, $\mathrm{AC}_{1}$ and $\mathrm{AC}_{2}$. Joint operation would also reduce each city's share of the costs under a fixed Federal grant program.

\section{CHARACTERISTICS}

OF EQUITY

In economics equity is given two meanings: one is fairness, and the other is redistribution of income. Both concepts of equity are discussed here but the emphasis in this study is to determine characteristics of equity by which to evaluate existing and alternative cost-sharing rules to see if they assure fair treatment to communities seeking financial assistance for pollution abatement.

Shoup $^{29}$ has defined six characteristics of a fair fiscal policy from which we have selected three that seem pertinent to the evaluation of grants for pollution abatement.* The selected characteristics are relevancy, continuity, and certainty.

*Others (e.g., Richard Musgrave, The Theory of Public Finance, McGraw Hi11: New York, 1959) besides Shoup have examined equity. However, Shoup's equity characteristics are defined in such a way that they can be applied to existing and alternative cost sharing rules for pollution abatement. Thus his characteristics of fair treatment were chosen in making this evaluation of equity. 


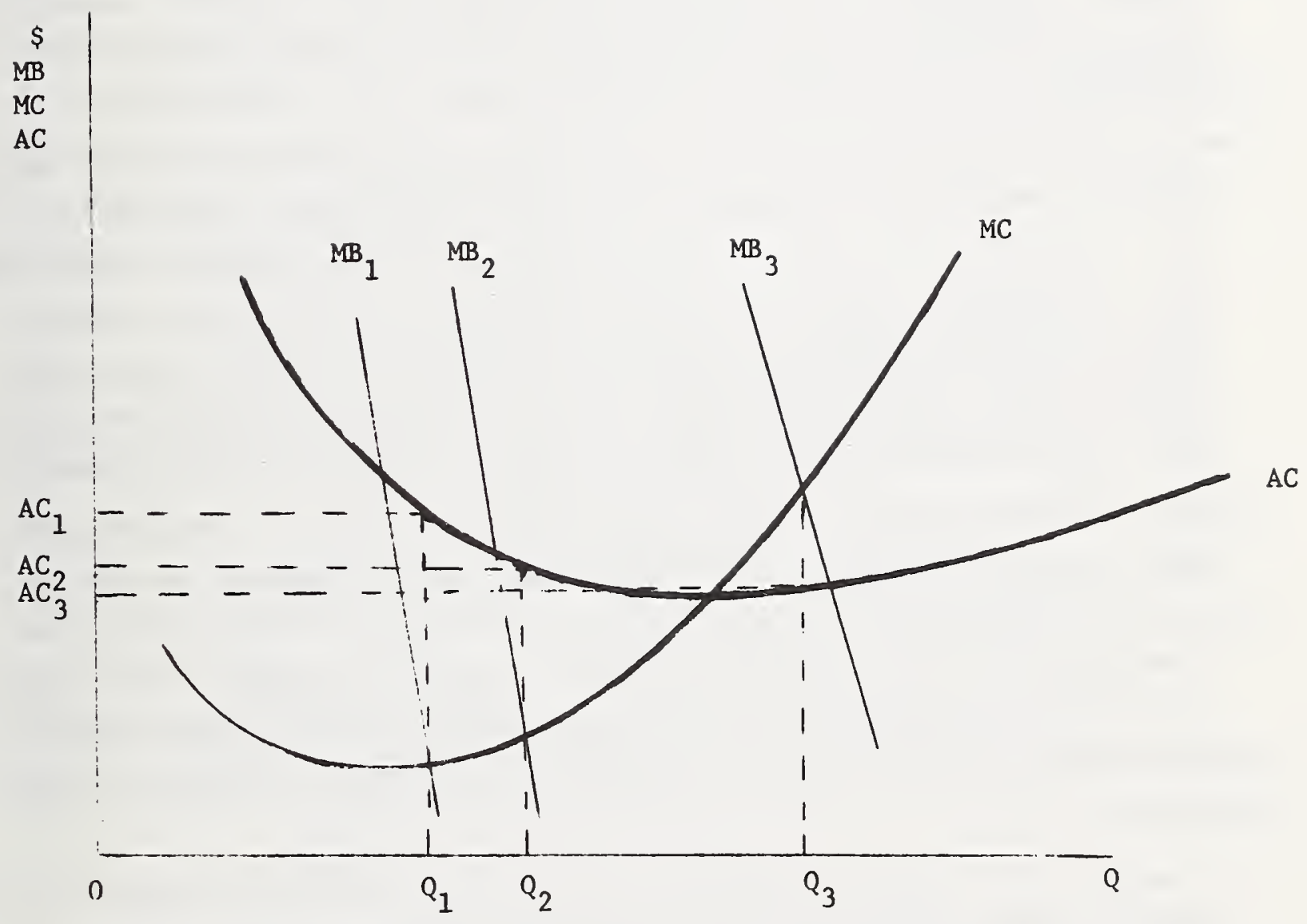

Figure 10. Efficient scale with regional abatement 
For a cost-sharing rule to satisfy the characteristic of relevancy, it must treat all project participants equally with respect to the relevant circumstances affecting them. What are regarded as relevant circumstances may vary with one's point of view. The grant recipient, for example, might consider only the benefits that accrue to him as being relevant, whereas the Federal agency that administers a grant would be expected to consider all benefits, local and widespread, as relevant in planning a project. A different group, such as a development agency, might suggest ability to pay as a relevant circumstance on which to base cost sharing. In this study "benefits received" are assumed to be the relevant circumstance. Accordingly, grant recipients would have to contribute a cost share in proportion to the benefits that they recelve from pollution abatement in order to meet the relevancy characteristic of equity.*

For a cost-sharing rule to satisfy the continuity characteristic, no major change in the relative share of costs borne by the Federal grantor and the local grantee would result from a small change in the relevant circumstances, i.e., the benefits they receive. Thus, given an increase in the ratio of local to national benefits, the resulting change in the local cost share will not differ greatly from the change in the local cost share that would result from adding the next, equal increment of local to national benefits. To satisfy the characteristic of certainty, a cost-sharing rule must treat grant recipients equally at different points in time whenever the same relevant circumstances occur so that the cost-sharing responsibility can be anticipated with reasonable certainty. The grant program should specify the relevant circumstances on which cost-sharing rules are based in order to eliminate any confusion as to whether the relevant circumstances change over time.

It appears that existing rules fall to satisfy the relevancy characteristic for most techniques because they do not appear to bear much relationship to benefits received. Existing rules also fall to satisfy the continuity

* Note that the Association Rule does not necessarily satisfy this characteristic because it applies to benefits at the margin. 
characteristic in that small changes in the proportion of local to national benefits that might result from changing techniques of abatement can result in major changes in local cost sharing because of the different cost composition among categories of cost that are shared differently. Existing rules must be labeled uncertain in that the actual percent of total costs bome by nonfederal groups will vary among techniques over time even when local benefits are the same ratio to total benefits for every technique. A difficult kind of uncertainty exists in that the eligibility of many nonplant techniques is not clear.

Relating the nonfederal percentage share of costs more closely to nonfederal benefits received would satisfy the characteristic of relevancy. Costsharing requirements can be made more continuous and certain by applying the same percentage to all techniques and cost categories. Local uncertainty in general could be further reduced if all technically viable alternatives for abatement were eligible for grants and if cligible project costs were always in practice awarded grants.

Redistribution of income, a second concept of equity, occurs in the cost sharing of pollution abatement when the benefits and costs of abatement are distributed to project interests in such a way as to change the prior distribution of income. Conflicts of interest over redistribution result when persons from whom benefits are withdrawn or on whom taxes are imposed consider such a redistribution to their personal disadvantage and perhaps also not in the national best interest.* For example, the Federal taxpayers that support through general taxes a Federal grant program that helps a community combat its wastewater problem, which is essentially local in nature, have their income redistributed to people in the recipient community. Equity in the redistributive sense defined here is not treated in this study.

*For a discussion of the relationship between cost sharing and redistribution, and of the implications of using cost sharing as a tool to effect various kinds of redistribution, see Marshall and Broussalian, Federal Cost-Sharing Policies for Water Resources, pp。216-224. 
1. Davis, Robert K. The Range of Choice in Water Management, A Study of Dissolved Oxygen in the Potomac Estuary. p. 125-126.

2. Raymond, Richard. The Impact of Federal Financing Provisions in the Federal Water Pollution Control Act Amendments of 1972. Public Policy. 22:109-110, Winter 1974 .

3. Water Policies for the Future. National Water Commission. Washington, D.C. U.S. Government Printing office. Final report to the President and to Congress of the United States. 1973. p. 77, 485-525.

4. Ibid., p. 78.

5. Ibid., p. 79.

6. Ibid.

7. Ibid., p. 80 .

8. Marshall, Harold E., The Relationships Between Local Cost-Sharing and Efficient Water-Resource Development (unpublished Ph.D. dissertation, The George Washington University, 1969), p. 56-89, has a more comprehensive survey of the literature on cost sharing.

9. Regan, Mark. Sharing Financial Responsibility of River Basin Development. In: Economics and Public Policy in Water Resources Development, Smith, S. C. and Castle, E. N. (eds.). Ames, Iowa State University Press, 1961. p. 215.

10. Renshaw, Edward F. Toward Responsible Government: An Economic Appraisal of Federal Investment in Water Resource Programs. Chicago, Idyia Press, 1957. p. 50.

11. Loughlin, James C. Cost-Sharing for Federal Water Resource Programs with Emphasis on Flood Protection. Water Resources Research. $\underline{6}(2): 377$, April 1970.

12. Marsha11, Harold E. Economic Efficlency Implications of Federal-Local Cost Sharing in Water Resource Development. Water Resources Research. $\underline{6}(3): 673-682$, June 1970 .

13. Ibid., p. 674-676.

14. Ib1d., p. 677-679.

15. Marshall, Harold E. and Vartkes L. Broussalian. Federal Cost-Sharing Policles for Water Resources. National Bureau of Standards. Springfield, Va., National Technical Information Service. No. PG-208304. National Water Commission. 1971. p. 201-214. 
16. Ibid., p. 121-128.

17. Rafuse, Robert W. Jr. and Michael D. Sherman. The Implications of the Net Fiscal Benefits Criterion for Cost Sharing in Flood Control

Projects. Mathematica Report. Washington, D.C. IWR Report 71-12. Institute for Water Resources, the Corps of Engineers. 1971. p. 11, 49-51.

18. Ibid., p. 51.

19. Ibid., p. i1.

20. Water Policies for the Future. National Water Commission. p. 485-525.

21. Ibid., p. 494.

22. Ibid., p. 495.

23. Marsha11, Harold E. Salinity Control and Cost Sharing. In: Proceedings of the Western Resources Conference, 1973. Boulder: University of Colorado, July 9 and 10, 1973. In press.

24. Marshall, Harold E. Cost Sharing as an Incentive to Attain the Objectives of Shoreline Protection. National Bureau of Standards. Washington, D.C. NBSIR 73-294. Corps of Engineers. December 1973. p. 21-23.

25. PL 92-500, Sec. 212(2)B.

26. Marshall, Harold E. Economic Efficiency Implications of Federal-Local Cost Sharing in Water Resources Development. p. 674-675.

27. U.S. Congress, Senate. Policies, Standards, and Procedures in the Formulation, Evaluation, and Review of Plans for Use and Development of Water and Related Land Resources, Sen, Doc. 97, 87th Congress, 2d sess., 1962, $\mathrm{V}(\mathrm{c})(2)$.

28. Marshall, Harold E. and Vartkes L. Broussalian. Federal Cost-Sharing Policles for Water Resources. p. 58-65, and Marsha11, Harold E. Economic Efficiency Implications of Federal-Local Cost Sharing in Water Resource Development. p. 675-677.

29. Shoup, Carl S. Public Finance. Chicago, Aldine Publishing Co., 1969. p. 23. 


\section{SECTION V}

EFFICIENCY IMPLICATIONS OF EXISTING

AND ALTERNATIVE COST-SHARING PROGRAMS

In this section we evaluate the existing and alternative cost-sharing programs with respect to the efficiency conditions outlined in Section IV. Some case examples are given of biases for particular techniques of abatement caused by existing cost-sharing rules.

\section{TECHNIQUES}

It was shown in Section IV that identical cost shares must apply to each technique considered for the purpose of abatement if the grant recipient is to be encouraged by cost sharing to select the nationally efficient combination of techniques under all conditions. Current rules for cost sharing pollution abatement, as described in Table 2, are not identical for all techniques. Thus communities may be biased towards nationally inefficient techniques for pollution abatement.

The hypothetical example in Table 5 illustrates how cost-sharing, unevenly applied among alternative techniques, can make the most costly technique to the nation become the least costly technique to the local community. The three techniques shown in the table are assumed to be equal in terms of benefits from abatement, but to differ greatly in total cost.* By comparing the last two columns, we can see that the ranking of techniques

*The assumption of equal benefits here is made to simplify the example. Benefit-cost analysis could be used to demonstrate bias effects even where benefits differ among techniques and where the local-Federal distribution of benefits differs by technique. 
In order of largest to smallest cost to the nation is techniques 1,2 , and 3; whereas, the ranking in order of largest to smallest cost to the local community is just the inverse, techniques 3,2 , and 1 . The potential local bias is even greater than Table 5 implies, however. The cost of technique 1, for which the Federal government pays $75 \%$, can be a maximum of four times as much as technique 3, for which there is no cost sharing, and still be preferred by the local community as the cheaper technique. The maximum biases among techniques are computed by dividing the nonfederal percentage cost share of one technique by that of another. Thus the bias of technique 1 over technique $3\left(B_{1: 3}\right)$ is calculated by dividing the nonfederal cost share of technique 3 by the nonfederal share for technique 1 . That 1s, $1.00 / .25$ equals 4. Similarly, technique 2 , with $50 \%$ cost sharing, can cost twice as much as technique 3, which is least-cost to the nation, and st111 be of lesser cost to the local community. That 1 , the $\mathrm{B}_{2: 3}$ is $1.00 / .5$ or $2 . *$

Table 5. IMPACT ON LOCAL PROJECT COST OF DIFFERENT COST-SHARING RULES: AN ILLUSTRATION

\begin{tabular}{|c|c|c|c|c|}
\hline Techniques & $\begin{array}{l}\text { Nonfederal } \\
\text { Cost Share } \\
\end{array}$ & $\begin{array}{l}\text { Federal } \\
\text { Cost Share } \\
\end{array}$ & $\begin{array}{l}\text { Total Project } \\
\text { Cost to the Nation } \\
\end{array}$ & $\begin{array}{c}\text { Total Project } \\
\text { Cost to the Local } \\
\text { Community } \\
\end{array}$ \\
\hline 1 & $25 \%$ & $75 \%$ & $\$ 50,000$ & $\$ 12,500$ \\
\hline 2 & $50 \%$ & $50 \%$ & $\$ 30,000$ & $\$ 15,000$ \\
\hline 3 & $100 \%$ & $0 \%$ & $\$ 20,000$ & $\$ 20,000$ \\
\hline
\end{tabular}

*Raymond has discussed the potential or maximum blas inherent in Federal cost-sharing rules in "The Impact of Federal Financing Provisions," pp. 5-6. 
The cost-sharing rule to eliminate these biases is to cost share each techulque in the same proportion. This rule will be effective no matter what actual percentage figure is chosen.

To encourage consideration of new technologies that might not be known at the time legislation is drawn up, the cost-sharing eligibility condition could be specified simply as all technically viable alternatives, thereby leaving room for expansion of eligible techniques. As long as the same percentage rule applies to all techniques, there will be no problem with choosing the nationally efficient technique(s), because the community will be seeking a technique that is simultaneously least costly to 1 t and to the nation.

A related problem that results from cost sharing all technically viable techniques is determining what part of that technique provides abatement per se, and consequently what part of the costs of that technique should be cost shared under the abatement program. For example, rehabilitation of the collection system to prevent infiltration is a technique that serves at least two purposes: expanded collection capacity and abatement benefits inherent in reduced infiltration. On efficiency grounds, only those costs that can properly be allocated to the purpose of abatement should be cost shared. Furthermore, the cost share applied to those allocated costs must equal the share applied to other techniques of abatement. A higher Federal subsidy would result in an overutilization of improvements in collection as an abatement technique, whereas providing no Federal subsidy would bias communities against improvements in collection as an abatement technique although in fact it might be the most efficient technique.

Allocating costs accurately between abatement and other purposes in a collection rehabilitation project that serves multiple purposes is a difficult task.* Because reaching a proper allocation of costs among purposes

*The theory and practice of cost allocation has not been undertaken in this study. For a description of three commonly used methods of allocating costs among multiple-purpose projects in water resource programs, see Marshall and Broussallan, Federal Cost-Sharing Policies for Water Resources, pp. 29-34 and pp. 251-253. 
Is difficult, two approaches that do not require cost allocation are consldered hore for encouraging efficient technique(s) in a multiplepurpose profect. One is to share the costs of a technique that satisfies multiple purposes, but at a lower rate than techniques that satisfy only the pollution abatement purpose. If designed properly, this rule would have the same impact of sharing equally all techniques where only those costs applicable to abatement are eligible. The problem still remains, however, of choosing the appropriate reduced cost share. A Federal share that is too high will encourage overutilization of the given technique for abatement, and a Federal share that is too low will encourage underutilization of that technique.

Another approach is to use benefits as an index to costs in determining either the cost allocation or the appropriate reduced cost-sharing rate for a technique satisfying multiple purposes. However, the distribution of benefits among purposes has no necessary relationship to the costs, and using benefits as an index is therefore not recommended.

Without in-depth Investigation Into this problem, the only concrete suggestion that can be made regarding the cost sharing of techniques serving more than one purpose is that, on the basis of an efflcient allocation of resources to abatement, a lower Federal cost share should be applied to techniques that provide benefits other than abatement than to techniques which provide abatement only, and that the cost share should decrease as the cost of providing these other benefits increases relative to the cost of providing abatement. Thus, existing practice which excludes collection systems in new communitles from grant eligiblitty appears compatible with this efficiency criteria. It would further appear that repairs to old collection facilities for the purpose of reducing infiltration be Federally shared to some extent, although not at as high a rate perhaps as a technique for treatment only.

Rehabilitation of collection works to prevent infiltration is just one example of a technique that serves more than one purpose. Other existing (and future) techniques for abatement might serve multiple purposes, and thus a reduced Federal cost share would properly be applied to them also. 
The previous discussion has dealt with eliminating blases by cost sharing al1 techniques for abatement equally. But to eliminate the bias from unequal cost sharing of techniques, it is not sufficient just to require that certain categories of costs be eligible for the same percentage cost share for all techniques. Blases to choose certain techniques still result when cost-sharing rules which do not cover equally all categories of costs (1.e., different percentage shares are provided for capital as compared to 0 \& $M$ or land costs) are applied to techniques with different cost composition (i.e., techniques with differing ratios of capital costs to $O \& M$ and land costs). Because $O \& M$ costs, for example, are not shared at all by the Federal government, while capital costs are (see Table 2), grant recipients will be biased towards capital-intensive techniques even though all techniques may be eligible for the same percentage share of capital cost. Likewise, grant recipients will try to avoid projects requiring expensive acquisition of lands for the project site. These responses occur because the effective nonfederal cost share is unequal among techniques (i.e., $c_{1} \neq c_{2}$ ).

Table 6 shows the impact on local costs of a cost-sharing rule which does not apply equally to all categories of cost. The cost figures in the table are actual estimates for three alternative treatment techniques evaluated for the Cleveland-Akron area. ${ }^{1}$ All techniques are purported to meet effectiveness standards, but they differ in the amount of total costs and in their relative proportions of capital, $0 \& \mathrm{M}$, and land costs. Construction costs (comprising capital and eligible land costs) of the land treatment technique account for about two-thirds of the total costs of that technique, and substantially less for the other two techniques. The land treatment technique has the highest cost to the nation $(\$ 183,200$ compared w1th $\$ 148,500$ and $\$ 144,600)$. The effect of the cost-sharing rule, however, is to make the land treatment technique the least costly to the local community $(\$ 92,525$ compared with $\$ 100,350$ and $\$ 106,725)$.

The maximum blases among the techniques are calculated from the local percentages of total national costs, as shown in the far right column of Table 6. The $B_{1: 3}$, for example, is $.74 / .51$ or 1.45 . This means that 


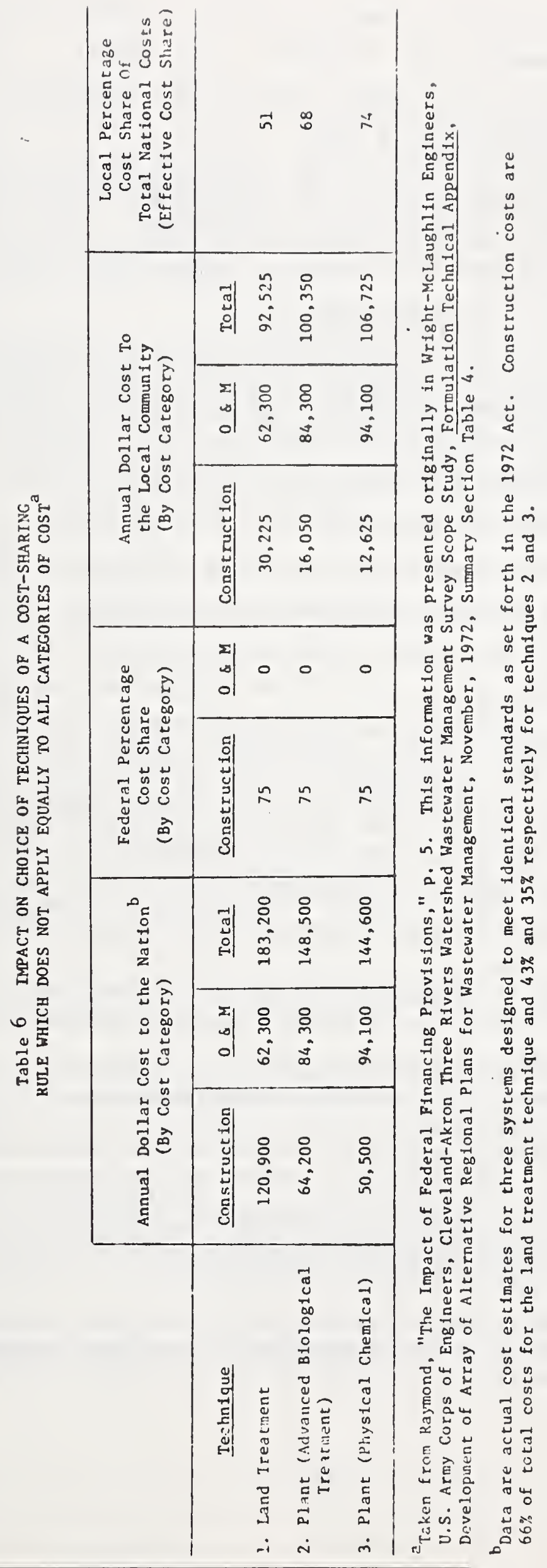


the land treatment described in Table 6 could cost nearly half again more than the physical-chemical plant technique, i.e., nearly $\$ 70,000$ dollars more, and still be the least costly to the community.* Similarly, The $\mathrm{B}_{1: 2}$ is 1.33 , and the $\mathrm{B}_{2: 3}$ is 1.09 .

The efficiency implication again is that local communities may select techniques that are not cost-effective to the nation. The cost-sharing rule to eliminate this bias is to share all categories of cost for all abatement techniques in the same proportion.

There are, however, alternative cost-sharing rules for arriving at the same (or nearly same) effective cost share for all techniques which may be used In lieu of applying the uniform rule across all cost categories. Some of these alternatives are discussed in the event that institutional or other constraints preclude application of the uniform rule.

The possible cost categories to share are land, capital, $0 \& M$, any combination of the three, or none. The "none" category can be dismissed as a plausible alternative because we are assuming that some grant program will be administered. Although, as we have seen above, applying a uniform percentage to all categories of costs would be optimal on efficiency grounds, let us suppose that for some reason only one category of cost could be Federally funded. As an example, let us assume that Federal grants can be made for capital expenses only. This assumption parallels actual Federal cost sharing practice in wastewater pollution abatement, wherein $0 \& M$ costs have traditionally not been shared.** Let us further assume,

* Note that Table 6 represents one particular case and is not intended to imply anything about the general cost relationship of the three techniques discussed.

**There are several reasons for sharing only capital. Practical financing problems face the Federal and nonfederal administrators of $0 \& M$ grants in that these grants would accrue to local communities over time and they would probably vary with growth conditions, inflation, and other uncontrollable variables. Operation and maintenance grants are entirely open-ended drains on grantors' budgets. Capital grants, on the other hand, are easier to administer because they are more precise in total amount and in the time of allocation. Given these and other considerations, it is not surprising that grantors would not want to share 0 \& $M$ costs.

It is recognized that, theoretically, 0 \& $M$ alone could be funded rather than capital with the rules to be developed. But since capital is most likely to be funded in practice, we focus on it in the examples. 
to keep the problem simple, that most of the costs are attributed to either capital or $0 \& M$. Thus nonfederal interests are biased against choosing techniques that are $0 \& M$ intensive.* Moreover, grant recipients might be expected to cut the quality and degree of $0 \& M$ below what might be attained with Federal aid.

To counteract these biases, several approaches might be considered. One is to award an add-on Federal capital subsidy for a project design that incorporates the appropriate level of $O \& M$ and another add-on capital subsidy over time based on the quality of performance of the grant recipient in the actual $0 \& M$ of the abatement project. These incentives might be criticized on the grounds that existing water quality standards require a certain quality of abatement and that extra capital subsidies are unnecessary for inducing good $0 \& M$ planning and performance. However, when no penalties are imposed for failure to comply with standards, the add-on subsidy becomes relevant.

Under a program of subsidizing capital only, another approach to eliminating the bias against techniques that are $0 \& M$ intensive is to vary the Federal capital grant among techniques so that the grant as a percentage of total projects costs, i.e., the effective grant, will be uniform across all techniques. It was shown in a hypothetical example in Table 6 that grant recipients would be biased towards technique 1 even with the same Federal capital share among all techniques, because the ratio of capital costs to other costs was higher for technique 1 than for techniques 2 and 3 . If the percentage of total costs could be equalized among techniques by making the Federal capital share vary among techniques, this bias could be eliminated.**

*Due to the compensation arrangement for architects/engineers that is based on construction costs (see Section III), a bias also exists for the contractor-planner to design capital-intensive abatement projects.

**Calculating the percentage cost shares for any particular project for different techniques would not be difficult in that project plans include costs by categories. 
With the unfform rule applied across all cost cateogires, any gIven percentage share of total costs would encourage communlty selection of the nat lonally efficient technique. However, with subsidization of capital only, the percentage figure would have to be transposed into an effective capital cost share that would vary with every change in the composition of cost categories. For example, to make the effective local total cost shares equal in Table 6 , let us say at $25 \%$, the local share for construction would have to be $38 \%$ for technique 1, 58\% for technique 2 , and $72 \%$ for technique 3 . Applying these different rules to construction for each technique would have the same effect as charging local interests $25 \%$ of all categories of costs.

Yet another approach to reducing the bias against 0 \& $M$ intensive techniques while sharing only capital costs is to restrict the effective Federal share for all techniques by some predetermined percentage. Such a constraint will prevent a capital-intensive technique under a capital cost-sharing program from receiving a much higher grant award than a less capital-intensive technique. Table 7 illustrates the determination of a percentage constraint and the biases among techniques with and without imposing that constraint.

As shown in rows 1 and 2 of the table, the three abatement techniques differ greatly in the relative composition of cost categories, ranging from practically all capital in the case of the collection and outfall systems, to only about one-third capital in the case of in-stream aeration. The third row of the table shows the computation of project cost to the local community under the existing grant program of a $75 \%$ Federal share for capital and a zero percent Federal share for $0 \& M$. The fourth and fifth rows give the percent of total costs borne by the local and Federal sectors respectively. The Federal share comprises $70 \%$ of the total cost of technique 1 , $49 \%$ of technique 2 , and $25 \%$ of technique 3 . The percentage Federal cost-sharing constraint which will be Just adequate to eliminate the bias is equal to the effective Federal cost share for that technique for which the Federal cost share is lowest. Accordingly, in this example, the constraint will be the lowest percentage in row 5 , i.e., $25 \%$. 


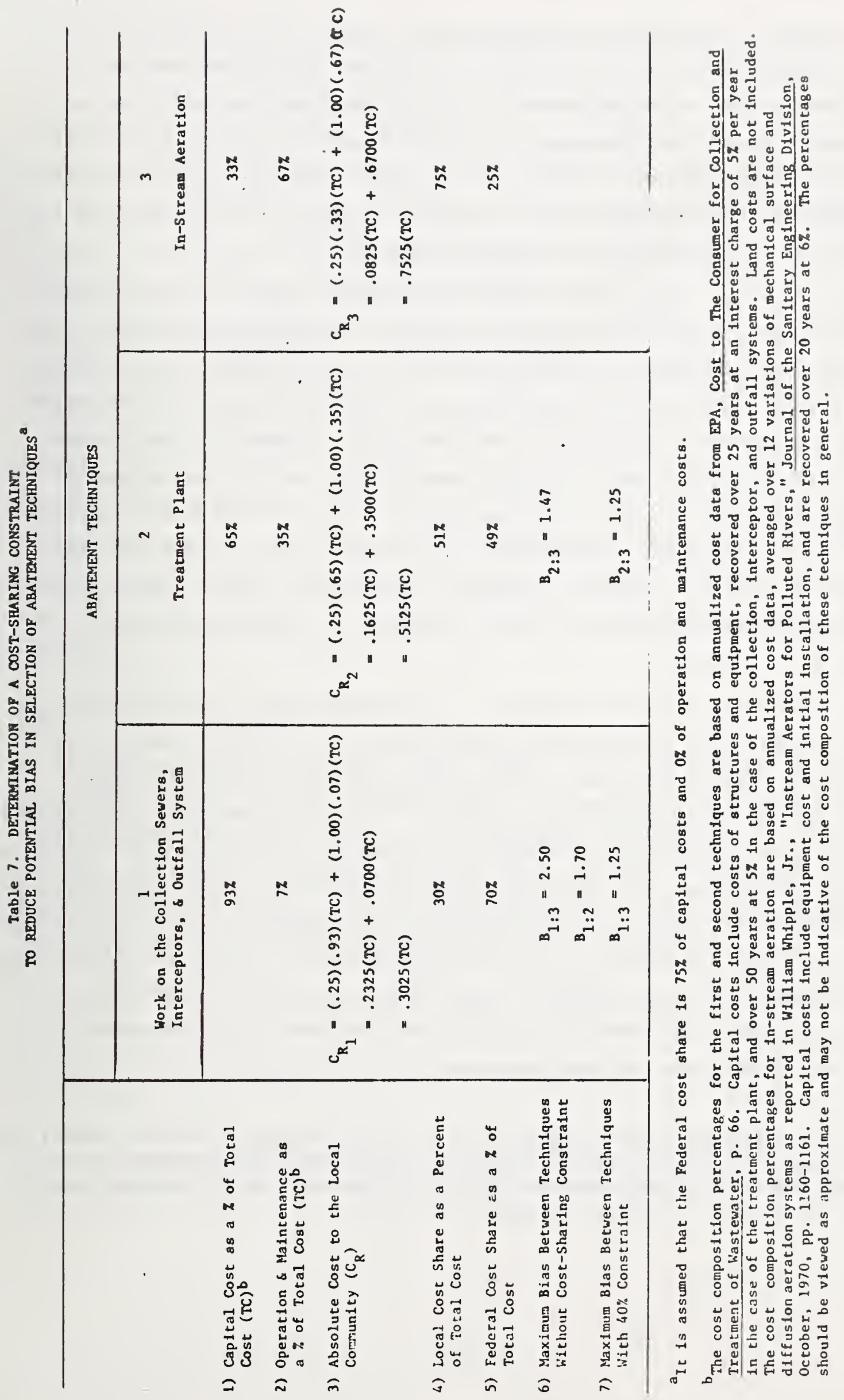


In the sixth row we calculate the maximum biases. Under the assumed rule of a $75 \%$ Federal capital cost share, the dollar cost to the nation of technique 1, the most capital-intensive project, could exceed by about two-and-one-half times the cost of the least capital-intensive project, technique 3, and still be favored by the local community.* That is, the maximum bias of technique 1 over technique $3\left(\mathrm{~B}_{1: 3}\right)$, is $.75 / .30$, or 2.5 . Simflarly, $B_{1: 2}$ and $B_{2: 3}$ are displayed in Table 7 .

Limiting Federal capital grant funds to an amount equal to $25 \%$ of total profect cost for all techniques is a constraint that would eliminate the bias towards techniques 1 and 2 as compared to technique 3 . The modified cost rule would be that the Federal grant program would pay $75 \%$ of capital costs and $0 \%$ of $0 \& M$ costs, but that the Federal share will not exceed $25 \%$ of total project costs. In the example, the cost to nonfederal interests is raised from $30 \%$ of total project costs to $75 \%$ for technique 1 , from $51 \%$ to $75 \%$ for technique 2 , and remains $75 \%$ for technique 3 . Thus the value of the bias between all three techniques becomes one, which means there is no cost-sharing advantage of one technique over another, when the constraint is imposed.

Note what occurs if the constraint on the Federal capital share is set above or below the maximum percentage required to eliminate the bias, in this case $25 \%$. If we assume a $40 \%$ Federal 1 imit, for example, row 7 shows that the $B_{1: 3}$ and the $B_{2: 3}$ would be 1.25 . Thus whenever the constraint is above the lowest effective Federal cost share, the biases will not be totally eliminated. If, on the other hand, we assume a lower constraint, say, in this example, $10 \%$, the local shares as a percentage of total costs would all be $90 \%$ and the blases 1 , $1 . e$. , there would be no cost-sharing advantage of one technique over another. In this case picking a constraint under $25 \%$ is in effect an "overki11" of the bias, because once it reaches $25 \%$ there is no more bias to be eliminated.

*For example, other things equal, a local community would be indifferent to a project utilizing technique 3 at a cost of $\$ 10,000$ as compared to a project utilizing technique 1 at a cost of $\$ 24,900$. This represents a potential national efficlency loss of $\$ 14,900$. 
Instead of estimating the approprlate funding constraint on a case by case basis, it could be expressed as a single percent to be applied to all projects and incorporated into the cost-sharing rule. Such a constraint would be somewhat arbitrary and would not necessarily eliminate all potential blases among techniques. However, if set sufficlently low, it would reduce the extremes of bias between techniques with very different cost composition, and would likely eliminate all blases between techniques that have a relatively high percent of costs of the type shared.

There are then approaches to the sharing of one category of cost that will encourage nationally efflcient decisions on the part of nonfederal interests even where techniques differ with respect to their cost composition. The constraint approach seems a practical one for at least reducing large biases among techniques. The constraint approach has the additional desirable feature of providing a percentage limit to Federal expenditures for any given project. If the decision were made to disburse a given Federal budget among more projects, setting the Federal constraint at a lower percentage would be an effective approach in accomplishing this objective.

\section{SCALE}

It was shown that the Association Rule (AR), i.e., charging grant recipients a cost share equal to their benefit share at the margin, would encourage local communtites to choose a scale of pollution abatement that is nationally efficient in terms of maximizing net national benefits. The scale implicatlons of alternative rules are consldered here to see how they rate according to the objective of maximizing net national benefits.*

The basic $25 \%$ nonfederal share for cap 1 tal and 1 and processes allowable under the existing rule appears lower than the likely share of total project benefits that would accrue to nonfederal interests at the margin. This

*It was pointed out earlier that EPA has no stated objective to maximize net national benefits in pollution abatement. If such an objective were to be established, however, it would be useful to see how existing rules rate. 
statement is based on the following rationale: Whereas many of the benefits from a community abatement profect are likely to accrue downstream from the community building that profect, generally most of the abatement benef 1 ts will accrue within a geographical area that may be identfied as a county, state, regional group of states, or as one or more of the 173 economic accounting areas that have been recommended by the Water Resources Councll for measuring reglonal development impacts. Because the nonfederal benefit share can be defined as all benefits that accrue at the municipal, state, and reglonal levels, and because most of the project benefits are likely to accrue within these boundaries, it seems reasonable to expect a high proportion of project benefits to be nonfederal.* The proportion of benefits in total and at the margin for nonfederal interests is therefore expected to be higher than the current cost share that is indicated by a $25 \%$ nonfederal capital share. It may be true that the community that recelves an abatement grant and that has to build the project may receive only a very small proportion of total nonfederal benefits, but the ratio of nonfederal to Federal benefits remains high. This situation may be indicative of the need for effective regional cost-sharing management systems, and not necessarily larger Federal grants to the community.

The existing Federal share of $75 \%$ seems high even for large cities and regions, where downstream and widespread users of water receive some benefits of abatement. It seems particularly high for small communities that might use septic tanks or spray irrigation and impact little on water quality in other areas. At the same time, existing Federal cost-sharing arrangements exclude from funding a technique such as low-flow augmentation that is 11 kely to have more direct downstream or widespread impacts than techniques such as community septic tanks, which are eligible for funding. This difference in eligibility seems in conflict with achievement of both efficiency and equity.

If the nonfederal share of benefits at the margin exceeds the cost share, then there will be an efficiency-in-scale bias for overdevelopment of abatement; i.e., nonfederal interests will be encouraged by the cost share to devote too many resources to pollution abatement, other things

*We do not deal here with the problem of collecting from the various project beneficlarles their portions of the nonfederal cost share. 
being equal. Yet there appears to be a deficit in pollution abatement activities, and few new plants for treatment are being built under the 1972 Act. This is true even where the state contributes extra money so that the community's cost share $1 \mathrm{~s}$ even further reduced (down to $12.5 \%$ for capital in New York communities). We feel that this discrepancy does not suggest that Federal cost sharing is necessarily too low, but rather that other factors may be limiting development. For examples, institutional constraints (see Section III) and uncertainty regarding ultimate allocation of Federal money may actually be more significant than cost--sharing rules in discouraging certain kinds and levels of abatement activities. Limited local funds and competing demands of alternative local investment opportunities ylelding greater local benefits might result in few funds available for abatement. Abatement projects might be particularly at a competitive disadvantage for scarce funds where communttles bear most of the nonfederal cost share but only receive a small proportion of the more widespread nonfederal benefits. In some cases communities responsible for abatement may be interested primarily in disposing of wastewater, rather than in abating pollution resulting from the wastewater. With this narrow view, the community sees its major wastewater problem as simply disposal, and therefore it is concerned with collection and transmission more than abatement. If communities percelve their benefits only from the standpoint of collection, then this might explain in part why even with availability of a $75 \%$ Federal capital grant, communities have not been induced to undertake many new projects for pollution abatement.

Effluent standards and other government regulations today make consideration of abatement activities mandatory for communities. So whether or not they perceive the benefits of pollution abatement accruing to them per se, they are faced with legal abatement requirements and penalties which may or may not be imposed for fallure to comply. Given this requirement, possible penalties, and a responsible attitude on the part of communities, it seems reasonable to assume that local communities will percelve some benefits from abatement, even if it is simply to meet improved standards. We assume, therefore, in the following discussion of scale, that communities do recelve some positive net benefits from abatement. 
Although the AR is the appropriate cost-sharing rule for eliminating any overbuilding or underbuilding bias in terms of the net benefits maximization criterion (see Section IV), there are practical drawbacks to this rule. Drawbacks are the fairly detalled information requirements on the incidence of benefits; the political acceptability of a rule that probably reduces drastically the Federal share and calls for a varying rather than fixed percentage rate among projects; and the relatively complex nature of the rule in practice. For this reason, we consider alternatives to the AR, as well as to the existing rules.*

We know that the level of cost-sharing, other things being equal, has some incentive effects on the pollution abatement that local communities w111 demand (see Section IV). We also know that an objective of the EPA grant program is to encourage abatement of wastewater pollution. A practical cost-sharing alternative then will involve the application of some positive Federal share to pollution abatement. In the following discussion we shall consider alternative cost-sharing rules in two ways: how they affect scale and how much they would have cost the Federal and nonfederal participants if they had been applied in meeting the historical abatement that has been sponsored by EPA.

Table 8 describes historical cost sharing for EPA and three of the four cost-sharing alternatives discussed in this section: (A) the current rule; (B) an equal percentage rule for all cost categories but costing the same amount of muney as $A$; and (C) the current rule imposed with a percentage constraint.** Each rule is examined in terms of how much it would have cost Federal and nonfederal participants had it been applied in meeting historical abatement

*For an evaluation of alternative cost-sharing rules for encouraging the selection of the nationally efficient scale, see Marshall and Broussalian, Federal Cost-Sharing Policies for Water Resources, pp . 173-240.

**The fourth rule discussed earlier was a varled cost share applied to different cost categorles such that the effective nonfederal share among techniques is equal. This rule was omitted from the table because of the lack of data necessary to illustrate $1 t$. 


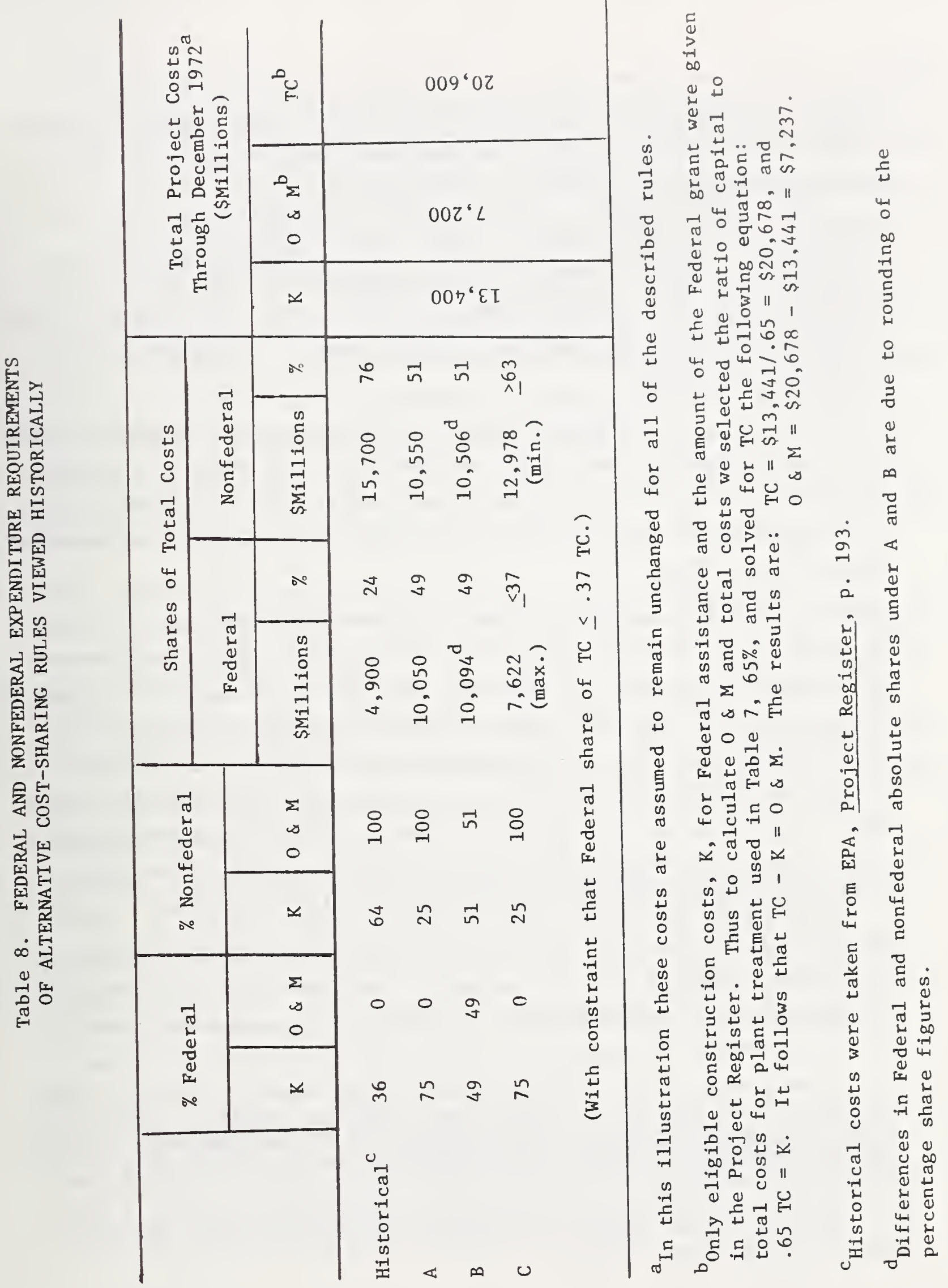


costs of profects sponsored by EPA through 1972. Total costs of abatement to which the rules are applied are $\$ 20,600$ million, of which $\$ 13,400$ is for construction and $\$ 7,200$ is for 0 \& M.*

Historically the Federal share of total costs is estimated to have averaged $24 \%$. This is based on average Federal shares of $36 \%$ for construction cost $(K)$, and zero percent for $0 \& M$ costs. The Federal absolute share was $\$ 4,900$ million and the nonfederal share is estimated to have been $\$ 15,700$ miliion.

Rule A is the current rule that applies only to construction costs. Given the $\$ 13,400$ million construction cost and the $\$ 7,200$ million estimated $0 \& M$ cost, the nonfederal share of total costs would be $\$ 10,550$ million. Thus a nonfederal share of $25 \%$ of capital would be equivalent to approximately $51 \%$ of total costs.

Rule $B$ is designed to cost nonfederal interests the same amount of money as was spent for Rule $A$, ** but with the local cost share equal across all categories of cost. Equilibrating the cost shares among cost categories demonstrates that any potential biases among techniques resulting from sharing cost categories differently could be eliminated without any change in the absolute nonfederal or Federal costs that are borne. In fact, by encouraging consideration of less capital-oriented techniques that may be less costly to the nation, nonfederal, Federal, and total costs of achieving a given level of abatement might be reduced.

Rule Capplies a constraint on the size of the Federal grant under the current cost-sharing rule. The purpose of the constraint is to ameliorate the blasing effect of unequal cost sharing of cost categories. The

*The capital costs of EPA profects through December 1972 were taken from U.S. Environmental Protection Agency, Project Register: Waste Water Treatment Construction Grants (Washington, D.C.: Environmental Protection Agency), December 31, 1972. The method of estimating total costs is described in Table 8 .

**Actual dollar amounts are slightly different due to rounding of the percentage share figures. 
percentage chosen here for 1llustration of the constraint is $37 \%$ * Apply 1 ng the $37 \%$ constraint against the current $75 \%$ Federal share for capital could reduce or leave unchanged Federal expenditures relative to Rule $A$, depending on the ratio of capital to total costs. That 1s, as the ratio of capital to total costs rises above the level where the constraint becomes effective, the Federal responsibllity becomes fixed for Rule $C$, whereas 1 continues to Increase for Rule A. A nonfederal absolute share of $\$ 12,978$ million becomes a minimum with Rule C. Had it applied historically, and assuming that abatement controls or standards did not compel communities to implement the level of abatement assumed in Table 8, we might expect that the actual expenditures in total and for each participating party would have been less with Rule C than with the other rules. Expenditures would probably have been less because some projects would have recelved less Federal funding and would have, therefore, been less attractive to nonfederal interests.

Also, some of the bias among techniques due to different compositions of cost categorles (see Table 7 and 1 ts explanation) would have been eliminated or reduced with Rule C because of the constraint. Given the techniques in Table 7, for example, imposition of a $37 \%$ constraint would eliminate the $B_{1: 2}$ and reduce the $B_{1: 3}$ and the $B_{2: 3^{\circ}}$ The lower the percentage constraint on the Federal cost share, the stronger would be the correction to the bias among techniques and the stronger would be the restraint on the scale of abatement demanded by the nonfederal interests.

Whichever of these approaches is taken, a percentage target must still be chosen. An effective Federal share of total costs less than the $49 \%$ implied by existing rules would probably tend to encourage more efficient scales of abatement. However, since avallable information regarding the incidence of abatement benefits is not comprehensive, further research is needed before some specific figure is selected.

*The $37 \%$ share is an average of $24 \%$, the Federal percentage of total costs paid on average from the inception of the EPA program to present (Table 3 ), and of $49 \%$, the Federal percentage of total costs implied in the current law and in the composition of capital versus $0 \& M$ assumed in Tables 7 and 8 . 
If cost sharing were to be used as a tool simply to encourage higher levels of abatement with no regard for the nationally efficient scale, then the appropriate direction of Federal cost sharing would be up rather than down. As shown in Section IV, local interests will tend to demand larger quantitites of abatement, other things equal, as the Federal cost share is ralsed. It is recognized, however, that allowing larger Federal contributions will result in funding fewer abatement projects with a given Federal budget.

Although no speciflc percentage is recommended here for cost sharing pollution abatement, the following general conclusions for encouragement of the least-cost technique(s) and the efficient scale are reached. Whatever percentage is selected, it should apply uniformly across all techniques and cost categories within techniques. If only one cost category can be shared, then the most efficient rule would be to vary the cost share of that category among techniques so that the effective nonfederal cost share by technique will be the same for a project or in general for all projects using those techniques. If the varlable cost share by cateogry were not acceptable on institutional grounds, then:a Federal percentage constralnt might be used to eliminate some of the biases resulting from different cost compositions.*

Cost sharing by the Federal, versus nonfederal, sector has been the exclusive focus here, and cost sharing by other groups has been ignored. If the nonfederal sector (state, for example) applies different rules in conjunction with a Federal agency that has implemented the rules outlined here, the implications for scale and techniques may vary from the above description. The principles out1ined for the Federal agency apply, however, equal1y as well to nonfederal participants. To assess the total impact of cost sharing, the cost-sharing rules of all participants would have to be considered.

*Because there are an infinite variety of rules that might be designed for sharing one type of cost or for constrained cost sharing, we do not attempt to make any general statement about how equitable they will be. 
1. Raymond, Richard. The Impact of Federal Financing Provisions in the Federal Water Pollution Control Act Amendments of 1972. p. 6. 


\section{SECTION VI}

\section{EFFECTS OF USER FEES ON COST SHARES*}

Legislated user fee arrangements appear to affect the efficlency of the present grant program in that they influence the effective cost shares of Federal and nonfederal interests, and thereby create biasing effects In the selection of abatement techniques and in decisions regarding scale. User fee arrangements also appear to have differential Impacts on residential as compared with Industrialized communttes.

This section is divided into four parts. The first part examines the legislative description of user charges. The second presents four alternative interpretations of the effects of user fees on cost shares, and assesses the validity of each. The third part critiques the current practice of excluding interest charges from Industrial user fees. The final part assesses the Impact of user fees on selection of abatement techniques, on selection of the scale of abatement facilities, and on subsidization of residential as compared with industrial communtties.

*User fees for pollution abatement are charges for waste disposal levied on users of sewerage removal and treatment services or on users of watercourses. Several reasons for imposing a fee in pollution abatement are the following: to obtain revenue to defray the costs of providing abatement; to encourage polluters to consider alternative and perhaps less costly techniques of waste disposal; and to ration efficlently the use of sewerage services.

In this study the focus is on cost sharing as it affects the cholce of a particular technique or level of abatement. Accordingly, user fees are discussed here in the context of their effect on abatement cost shares, rather than in the conventional sense of resource allocation and revenue generation, per se. 
LEGISLATED USER FEES

With respect to leglslative requirements for user fees, Section 204 (b)(1) of the 1972 Act states the following:

- . The Administrator [of EPA] sha11 not approve any grant for any treatment works . . . unless . . the Applicant has adopted or will adopt a system of charges to assure that each reclpient of waste treatment services within the applicant's Jurisdiction. . . will pay its proportionate share of the costs of operation and maintenance. . . .

In effect, this section provides for collection of user fees to repay 0 \& $M$ expenses from all recipients of services.

Section 204 (b)(1)(B) requires that the Administrator shall also have determined that the applicant has done the following:

- . made provision for the payment to such applicant by the industrial users of the treatment works, of that portion of the cost of construction of such treatment works (as determined by the Administrator) which is allocable to the treatment of such industrial wastes to the extent attributable to the Federal share of the cost of construction . . .

In other words, user fees will be collected from industrial users to pay that portion of the grant amount allocable to treatment of industrial waste.

It is further specified in Section 294 (b)(3) that the grantee do the following :

- . retain an amount of the revenues derived from the payment of costs by industrial users of waste treatment services, to the extent costs are attributable to the Federal share of eligible project costs pursuant to this title as determined by the Admistrator, equal to (A) the amount of the non-Federal cost of such project paid by the grantee plus (B) the amount, determined in accordance with regulations promulgated by the Administrator, necessary for future expansion and reconstruction of the project except that such retained amount sha11. not exceed 50 per centum of such revenues from such project.

In effect, this last section means that the grant reclpient will retain $50 \%$ of the amount recovered from industrial users against the Federal grant. The $50 \% 1$ imit is the effective rule for retention of users fees because the sum of the nonfederal capital cost and the amount necessary 
for future expansion and reconstruction will under normal circumstances exceed $50 \%$ of the amount recovered from industrial users. This may be demonstrated as follows: The above statement from Section 204 (b)(3) provides for retention of an amount equal to the sum of (1) the amount of nonfederal construction cost, which under the existing program $1825 \%$ of construction cost (K), and (2) an amount (E) for future expansion and replacement; $1 . e .$, a total amount equa 1 to $.25 \mathrm{~K}+\mathrm{E}$. The same Section further defines the 1 imit of retalned earnings as $50 \%$ of industrial user fees collected against the grant. This amount may be expressed as . 5(.75BK), where $B$ is the grant share allocable to industry, $K$ is the amount of eliglble construction costs, .75K is the amount of Federal grants and .75BK is the amount of industrial user fees collected against the Federal grant. Only in the case of a contraction in future costs of abatement facilities (such as might result from a drop in population, or from a technological breakthrough reducing the costs of abatement facilities, and/or from a decline in the general price level) would the amount necessary for future expansion and reconstruction (E) likely be less than the amount of current construction costs (K). A sizable contraction in future costs appears improbable, and the estimated future replacement cost alone would generally be at least equal to the current amount of construction cost, $1 . e$. , generally we would expect $\mathrm{E} \geq \mathrm{K}$.

Assuming $E=K$, and setting the two above expressions equal to one another, we may determine the condition whereby . $25 \mathrm{~K}+\mathrm{E}$ w111 not exceed the $50 \%$ 1 imit:

$$
\begin{aligned}
& .25 \mathrm{~K}+\mathrm{E}=.5(.75 \mathrm{~K}) \text {, where assuming no future expansion, } 1 . e ., E=\mathrm{K} \\
& 1.25 \mathrm{~K}=.375 \mathrm{KK} \text {. } \\
& B=3.33 \text {. }
\end{aligned}
$$

In other words, for $\beta<3.33, .25 K+E>.5(.75 \beta K)$. Since $\beta$, the Industrial share allocable to the grant, cannot by definition be more than the whole, i.e., $B \leq 1$, the condition under which $.25 \mathrm{~K}+\mathrm{E}$ will determine the amount of user fees is impossible under the assumed situation. 
It, however, $1 \mathrm{H}$ not necessary to assume that $\mathrm{E} \geq \mathrm{K}$ in order to demonstrate that the $50 \% 1 \mathrm{imlt}$ is the effective rule. It is necessary only that $\mathrm{E}>.125 \mathrm{~K}$, since for any $\mathrm{E}>.125 \mathrm{~K}$, .25K $+\mathrm{E}$ will exceed the $50 \% 1$ imit. In other words, even with a large contraction in future growth or a sharp decline in replacement costs, the $50 \%$ limit will still be the effective rule. Even for $\mathrm{E}=0$, as was assumed by Raymond in his ana1ysis, $150 \%$ is the effective rule as long as the percentage of the Federal grant allocable to industry does not exceed 67\%. Thus, that part of Section 204 (b) (3) which describes what user fees may be retained appears meaningless from the standpoint of specifying alternative allowable amounts. The real import of this Section of the 1972 Act was probably recognized in formulations of recent program rules and regulations, where it is simply stated that the grantee shall retain $50 \%$ of industrial user fees collected against the grant. ${ }^{2}$

\section{ALTERNATIVE INTERPRETATIONS}

Now that we have examined the legislative requirements for user charges, let us consider how user fee arrangements affect the Federal and nonfederal cost shares, and illustrate algebraically the impact of user fees on the cost shares. In assessing the effect of user fees on cost sharing we are concerned with actual user fee practice as it has been developed from administrative directives, and not solely the legislative requirements cited above. The complexity of existing arrangements, however, gives rise to alternative interpretations of the effects on cost shares. Since the total effects are not immediately obvious, we will build towards them by presenting four alternative interpretations (each identified by subscripts) based on successtve levels of information. In the process we point out the limitations of the first three interpretations and suggest why the fourth version presented (i.e., equations 30 and 31 ) appears to represent most closely current practice.

We begin by restating what cost shares appear to be, based on Section 202 (a) of the 1972 Act and ignoring user fee practice. According to this provision of the Act, the Federal grant for treatment works will be $75 \%$ of construction costs. Current interpretation of this provision, as we saw in Section III, 
is that $75 \%$ is a maximum, but not a minimum share of construction costs of a completed facility. Thus, based on the current interpretation of this basic legislation, the Federal agency will bear no more than $75 \%$ of construction costs, and the grant recipient no less than $25 \%$ of construction costs. Their effective percentage cost shares may be expressed respectively as:

$$
\mathrm{C}_{\mathrm{F}_{1}} \leq \frac{.75 \mathrm{~K}}{\mathrm{TC}}
$$

and

$$
C_{R_{1}} \geq \frac{.25 K+M+L}{T C}
$$

where $C_{F}=$ the Federal agency's share of abatement cost,

$C_{R}=$ the grant recipient's share of abatement cost,

$K=$ total costs of construction, i.e., capital and eligible land $\cos t$,

$M=$ present value of operation and maintenance costs over the life of the abatement facil1ty,

$L=$ land costs not eliglble for Federal cost sharing,

$\mathrm{TC}=$ present value of total costs of a completed abatement facility over its life.

Now we take into account the effect of the user fee provisions as they are set forth in the legislation. The first provision, 1.e., that user fees be collected from service recipients to repay their share of $0 \& M$, does not appear to affect the grant recipient's cost share.* The legislation merely specifles how the grantee shall cover one portion of its cost share. Thus the grantee bears the full cost of $0 \& M$ and covers, by Federal directive, these costs with user fees collected from recipients of abatement services.

*In this paper we investigate the relative cost shares borne by the Federal agency, and by the local government, focusing on the amount that each must ralse against its required share, rather than on who contributes to each share. 
The grantee's method(s) of generating revenue to cover 1 ts share of construction costs is not speclfied by the federal government. Thus, at its discretion, the grant reclplent may also collect user fees from the industrial and nonindustrial sectors of the community to defray the grantee's share of capital costs. None of these activities affects the grantee's cost share, merely its method of generating funds to pay its share.

The second provision, directing the grantee to collect user fees from industry equal to industry's share of construction grant funds and to retain half, does appear to affect the grantee and grantor's cost shares. Based on the information we have presented thus far, the effect appears to be to increase the effective Federal subsidy* by an amount equal to the retained user fees and, thereby, to reduce the grant recipient's cost share by a like amount. Accordingly, the Federal (grantor's) cost share and the grant recipient's cost share can now be expressed respectively as:

$$
\mathrm{C}_{2} \leq \frac{.75 \mathrm{~K}+.5(.75 \mathrm{BK})}{\mathrm{TC}}
$$

and

$$
C_{R_{2}} \geq \frac{M+L+.25 K-.5(.75 B K)}{T C}
$$

where $\beta=$ that percentage of construction costs allocable to treatment of industrial wastes.

The retained user fees constitute a subsidy even though they are drawn specifically from the industrial sector of the grantee's jurisdiction. They are viewed as additional subsidy beyond the original grant, because they comprise revenue ostensibly generated to cover the Federal cost share which is given instead to the grantee government.

Additional investigation of user fee arrangements, however, shows us that the real potential cost to the grant reciplent is changed somewhat further from equations (26) and (27), by Federal Regulations ${ }^{3}$ pursuant to the 1972 Act. Regulations stipulate that a minimum of $80 \%$ of the retained amounts, plus interest thereon, must be set aside in a reserve fund for future expansion and reconstruction. The amount retained in this fund each year

*As a payment by the Federal government to a local government, the grant constitutes a subsidy. By increasing the amount of payment by the Federal government to the local government, the retention of user fees raises the subsidy. 
is equal to $\frac{(.8)(.5)(.75 B K)}{n}=\frac{.3 \beta K}{n}$, where $n=$ the expected 11fe of the project, in years. Regulations allow the remaining $20 \%$ of retained user fees to be used as a discretionary fund by the grantee as he sees fit.* The amount of discretionary funds received each period is equal to $\frac{(.2)(.5)(.75 \mathrm{BK})}{\mathrm{n}}=\frac{.075 \mathrm{BK}}{\mathrm{n}}$. $* *$

The reserve fund can be used only for eligible project costs related to expansion and reconstruction of the original project and only with written approval of the Regional Administrator. The holder of a reserve fund may apply that fund to project costs for which a grant is requested or may use them for project costs apart from any grant request. However, if a grant is forthcoming, it is required that the amount in the reserve fund be deducted from eligible project costs for purpose of determining the size

* No clear rationale for the $80 / 20$ percentage split of retained revenue between reserve funds and discretionary funds was found.

**User fees to recover the industrial share of the grant are collected over the life of the treatment works in annual payments equal to . $375 \mathrm{BK}$ divided by the number of years of expected life, and not including an interest component. To correctly assess their value, it is necessary to discount to the present the amount of both the discretionary funds and reserve funds. Discounting is necessary because the retained user fees are recelved in increments over time and there is a time preference for their receipt. The present values of the discretionary funds $\left(P V_{D}\right)$ and of reserve funds $\left(P V_{R}\right)$ are as follows:

$$
\begin{aligned}
& P V_{D}=\sum_{j=1}^{n} \frac{.075 \beta K}{n(1+1)} j=\frac{.075 \beta K\left[(1+1)^{n}-1\right]}{n i(1+1)^{n}} \\
& P V_{R}=\sum_{j=1}^{n} \frac{.3 \beta K}{n(1+1)}=\frac{.3 \beta K\left[(1+1)^{n}-1\right]}{n i(1+1)^{n}}
\end{aligned}
$$

where $n=$ the number of recovery periods over the life of a project,

1 = the discount rate,

$I=$ the number of periods before the fund is spent, during which user fees have been collected from industry. and

$\frac{(1+1)^{n}-1}{1(1+1)^{n}}$ is the unfform present worth discount formula to convert a stream of annual payments to a present value. 
of the grant.* Thus, whenever a grant is recelved, the reserve-fund-holder has no cholce but to apply the amount then in the fund to that project, and have the amount of the grant thereby reduced; he need not, however, have held the fund unt 11 a grant was forthcoming.

Since on $1 y 20 \%$ of the retained amount is discretionary, and the remaining reserve portion reduces the amount of future grants, it may appear that the grantee's cost is reduced by just the present value of the discretionary fund rather than by the full amount of the retained revenue as is shown in equation (27). This was the view expressed by some EPA grant officials. According to this third interpretation, the cost shares of the grantor and the grantee would be expressed as:

$$
\mathrm{C}_{\mathrm{F}_{3}} \leq \frac{.75 \mathrm{~K}+\mathrm{D}}{\mathrm{TC}}
$$

and

$$
C_{R_{3}} \geq \frac{M+L+.25 K-D}{T C}
$$

where $D=$ the present value of the discretionary portion of retained user fees.

The grantee's cost share as expressed above by equation (29) is greater than that expressed by equation (27), which deducts the full amount of retained fees from the grantee's cost; nevertheless, it is lower than the grantee's cost share without retention of any user fees as denoted by equation (25).

Let us now examine the effect of the reserve portion of retained earnings (the reserve fund) more carefully. This leads to the fourth, and we believe most realistic, interpretation of the effect of user fees on cost shares.

*In connection with determining grants, Section 35.927-17 of the Grant Program Regulations provides the following.

allowable project costs (are to be) reduced by an amount equal to the unexpended balance of the amounts retained by the applicant for future reconstruction and expansion... . together with Interest earned thereon. 
The reserve fund increases the Federal contribution and reduces the grantee's effective cost share, despite the fact that it may reduce the nominal amount of the formal grant. That is, the net effect of the reserve fund is to reduce further the grantee's cost share beyond the reduction rendered by the discretionary funds alone. The grantee's cost share is further reduced because the amount accumulated in the reserve fund is applied to eligible construction costs without an equal reduction in the amount of grant recelved. Specifically, the reserve fund Impacts upon cost shares in the following several ways: (1) it reduces the total amount of eligible project costs by the amount of the fund, (2) it reduces the amount of the formal grant by $75 \%$ of the amount of the fund, and (3) It reduces slightly the amount of future retained user fees which are based on the current grant. We shall consider further each of these effects - the first one reducing the grantee's cost share, the second two increasing it, but the three effects in net reducing the grantee's cost share.

Since the reserve fund ( $R$ ) was originally collected against the Federal share, reduction of eligible project costs by the amount in the reserve fund results, in itself, in a Federal contribution of $R$ to abatement. After reduction by the reserve fund, $K$ - $R$ of eligible costs are left uncovered. Since the formal grant is provided for $75 \%$ of the remaining eligible costs, 1.e., .75(K - R) the effective formal grant is lowered by $.75 \mathrm{R}$, as a result of the reserve fund. Thus, the effect of the reserve fund is first to raise the Federal contribution by an amount $R$ and then lower 1 t by an amount .75R, amounting in net to an increase of . 25R. Reduction of project costs by $R$ means that only $25 \%$ of $K-R$ in eligible costs remain to the community government, rather than the ful1 $25 \%$ of $K$. Hence, the effect of $R$ observed here is to reduce the community's effective costs by $.25 R$.

Now we complete our assessment of the reserve fund's impact by taking into account the third effect noted above -- the reduction in the grantee's future receipts of user fees. The reserve fund reduces the future recelpt of user fees because the amount of the grant upon which these funds are partly based is lowerad by .75R. Hore, however, we include in the cost share expression the fmpact of the reserve fund only on future receipts of discretionary funds 
and not on future receipts of reserve funds. The reason is that in our interpretation of cost shares, we have chosen to evaluate the reserve fund as a function of past grants, and the discretionary funds as a function of the current grant. The assessment of the reserve fund as an accumulated sum based on past grants means that any reductions in the amount which might have resulted from previous reserve funds is already taken into account. Expanding the cost share expression to include also the present value of future reserve funds based on the current grant would result in over-counting the reserve fund.*

Without the reserve fund, the present value of the future receipts of discretionary funds is equal to $\sum_{j=1} \frac{.075 \beta K}{n(1+1) j}$. But when accumulated reserve funds are taken into account, the present value of discretionary funds is equal to $\sum_{j=1}^{n} \frac{.075 B(K-R)}{n(1+i)^{j}}$. As $R$ becomes larger and is deducted from $K$, the present value of the discretionary fund becomes smaller. Consequently, the reduction in the grantee's effective costs becomes less.

Therefore, the reserve fund increases the effective subsidy on current projects, while at the same time diminishing it on future projects by reducing the amount of future discretionary funds. However, the increasing effects of the reserve fund on the Federal subsidy substantially outweigh the decreasing effects, thereby resulting in a net reduction in the grantee's cost share.

By combining the observed effects of the reserve portion of retained user fees with that of the discretionary portion (as shown in the third interpretation), we have the fourth, and we belleve, most complete, interpretation of cost shares under existing user fee arrangements:

$$
\mathrm{C}_{\mathrm{F}_{4}} \leq \frac{.75(\mathrm{~K}-\mathrm{R})+\mathrm{R}+\mathrm{D}_{\mathrm{R}}}{\mathrm{TC}}
$$

and

$$
C_{R_{4}} \geq \frac{M+L+.25(K-R)-D_{R}}{T C}
$$

*An alternative interpretation of cost shares would evaluate both the discretionary and reserve funds in terms of the present value of future recelpts based on the current grant. 
where $C_{F_{4}}$ and $C_{R_{4}}=$ the real effective cost shares of the grantor and grantee, respectively, of a completed abatement works, as determined by Federal legislation, regulatIons, and current practices of the grant program office,

$R=$ the present value of the reserve portion of retalned user fees which have been collected from industry against its share of past Federal grants,

$D_{R}=$ the present value of future discretionary funds taking into account the effect of the accumulated reserve fund.

Table 9 shows a grantee's abatement costs for a hypothetical project with and without the retention of user fees. In this example, the grantee's share of construction cost is reduced from $25 \%$ to $12 \%$, and his share of total cost from $78 \%$ to $73 \%$ as a result of retalning user fees collected against the Federal grant.

In addition to the user fee effect described above, there appear to be other, more subtle effects of user fee arrangements on cost shares. For one thing, existing arrangements appear to provide incentive to the fund manager to spend the reserve fund on eligible costs of projects accorded high priority by the community, but low priority in the grant approval process. (Likely examples of such projects are sewage collection-related, as opposed to more treatment-related projects.) By applying the $R$ to costs of projects which it wishes to undertake, but for which it is unlikely to be successful in recelving a formal grant, the community can reduce by $R$ the amount of costs it otherwise would incur, without reducing its overall recelpt of grant funds. By exhausting the fund prior to application for a grant which 1 t does expect to recelve, the community will avoid having the fund reduce the amount of the grant. With this approach the community government could, over time, realize a Federal contribution to abatement costs equal to $.75 K+R+D$, rather than the $.75 K+.25 R+D_{R}$ contribution shown by equation (30). That is, it could in this way reduce its costs by an additional $75 \% \mathrm{R}$, plus the value of the excess* of $\mathrm{D}$ over

*D represents the present value of the discretionary fund; $D_{R}$ represents the present value of the discretlonary fund, taking into account the reducing effect of the accumulated reserve fund; therefore $D \geq D_{R}$. 


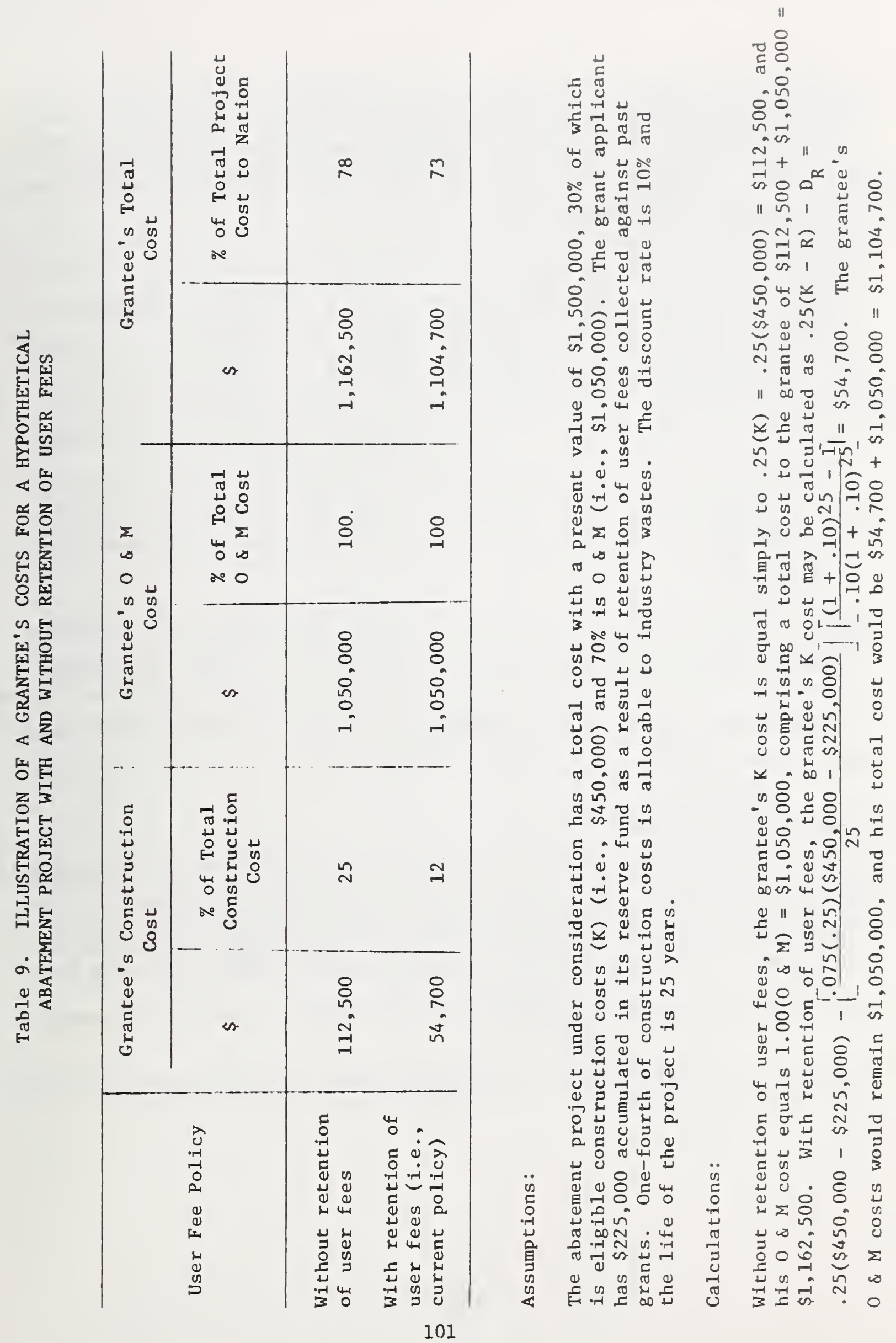


$D_{R}$, beyond the reduction achleved by applying $R$ to costs for which grants are avallable. This, however, represents a special case which would hold true only if the reserve fund is applied to costs which the community would have otherwise incurred in full.

Another possible impact of the reserve fund not heretofore noted is its effect of increasing the reserve-fund-holder's prospects of obtaining additional formal grants. The grant office may accord higher priority to the grant application of an applicant having such a fund than applicants without a fund, due to the possibility of bringing forth a relatively larger total profect with a relatively smaller additional Federal grant. This characteristic may provide conflicting incentives to that observed above, Insomuch as it may encourage the community to apply its fund to partial payment of major profects for which it is actively seeking grant assistance.

In any case, the retention of user fees appears to ralse the effective Federal subsidy above $75 \%$ of construction costs, and reduce the grantee's share below $25 \%$ of construction costs. As we have seen, part of the increased subsidy results from the discretionary portion of retained user fees and part is attributable to the reserve fund.

\section{INTEREST CHARGES ON USER FEES}

Existing program regulations require that user fees collected from industrial users not include an interest charge. 4 User fees are collected in fixed annual payments collected over the life of the facllity or over 30 years, whichever is less. The present value of the total amount collected from industry is equal to $\sum_{j=1}^{n} \frac{.75 B K}{n(1+1)}$, and the amount retained by grantees is equal to $\sum_{j=1}^{n} \frac{.375 \beta K}{n(1+1)} j$. The user fee revenue earns interest only after 
It is collected and placed in an interest-bearing account or securities. As a result of the omission of an interest charge, the present value of the amount collected from industry is less than the amount of Federal funds spent for industrial abatement facllities. Consequently, industry receives a Federal subsidy. In 1ess it were the intent of the law to provide costsharing assistance to industry, as well as to the nonindustrial sectors of communities, interest charges are needed to compensate for the time preference of money. If industry provided its own abatement facilities, it would forgo the use of the investment funds for other purposes. Similarly, the Federal government forgoes the use for other purposes of funds expended for industrial abatement facilities.

To see the substantial subsidy to industry which results from falling to charge interest, consider the following example. Assume that under existing arrangements a $\$ 100,000$ construction grant allocable to treatment of industrial wastes would be recovered from industry over approximately 30 years, in yearly payments of $\$ 3,333$. With a $10 \%$ nominal discount rate, the present value of the $\$ 100,000$ collected in this manner is, however, only $\$ 31,420$ (1.e., $\left.\$ 3,333\left[\frac{(1+.10)^{30}-1}{.10(1+.10)^{30}}\right]=\$ 31,420\right)$. With a $10 \%$ nominal discount rate, the annual user fee collected from industry should be $\$ 10,610$, rather than $\$ 3,333$ (1.e., $\$ 100,000\left[\frac{.10(1+.10)^{30}}{(1+.10)^{30}-1} \mid=\$ 10,610\right.$, which is $\$ 100,000$ amortized over 30 years at $10 \%$ ). Thus, in this 1llustrative example the annual user fees are less than one-third what they would be if the time value of money were considered. 
Omission of Interest charges from user fees has at least two consequences: (1) User fee revenue forthcoming to the Federal and community governments Is much less than $1 t$ would be $1 f$ industry fully pald its share of construction costs. (2) Industry recelves an additional Federal contribution towards provision of 1 ts abatement facllities, which, other things equal, w111 encourage it to tie into municlpal abatement systems.

\section{USER FEE IMPLICATIONS}

Now that we have shown quantitatively the effect of user fees on cost shares under varlous interpretations of the user fee policy, let us consider the potential consequences of these effects.

A number of problems appear to result from the effects of user fees examined above. A potential efficlency problem arfses in that retention of user fees collected against the Federal grant reduces the grantee's real cost share and therefore encourages the grantee to select a larger scale of abatement facllitles. If the local community's share of costs $1 \mathrm{~s}$ brought below 1 ts share of benefits from abatement at the margin, there will be a tendency towards overbullding of facilities.

Another efficlency problem is that retention of user fees collected against the Federal grant gives Incentive to communities to provide capital-intensive or eligible land-Intensive profects for purpose of treating industrial wastes. The blas towards techniques with a high proportion of eligible construction cost results because retention ralses the potential Federal contribution to capital and elfgible land costs, but does not change the Federal contribution to 0 \& $M$. The biasing effect is similar to that which would result from explicitly ralsing the Federal percentage cost share for construction costs relative to other cost categorles, and we saw earlier that the more unequal the cost sharing of different categorles of costs, the greater the incentive to the grantee to choose techniques with costs which are Federally shared over techniques with costs which are not Federally shared. 
The incentive to treat industrial wastes results from the fact that the grantee can actually improve his net revenue position by increasing construction costs attributable to treatment of industrial wastes. This may be demonstrated as follows:

For simplicitly assume that we begin with a community which at the outset provides no industrial waste treatment, $1 . e ., \beta=0$; we can now calculate the change in the net revenue position of the community $(\Delta N)$ which may result from a change in construction $(\Delta K)$, in ineligible land $(\Delta L)$, and in $0 \& M$ cost $(\Delta M)$, attributable entirely to inclusion of industry in the community sewerage system. To indicate the possible impacts, we examine the change in net revenue under alternative assumptions regarding management of the reserve fund and collection of user fees to recover the community government's share of cost.

Let us begin by assuming that the retained user fees collected against the industrial share of the grant are used in such a way that they do not reduce the recelpt of grant funds. This could be the case if the reserve fund were applied to eligible costs of projects with high community priority, but low grant priority, such that the fund reduced the community's cost by $R$, without reducing the amount of subsequent grants. (This case is explained in the second part of this section.)

We further assume that the $\Delta M$ attributable to industry is exactly covered by user fees collected from industry for those costs, as required in Federal legislation. Hence, apart from possible economies or diseconomies of scale, the net revenue position of the grantee (and of the non-industrial community) is unaffected by changes in $0 \& M$ costs necessitated by industry, $1 . e ., 0 \& M$ costs incurred are just offset by user fees received. With respect to the resulting $\Delta \mathrm{K}$ and $\Delta \mathrm{L}$, we may make either of two assumptions: (a) that the community government charges industrial users for industry's part of construction and land costs not covered by a Federal grant -- which it may do at its discretion, or (b) that the community government does not charge industrial users for their share of these costs -- which it may also do. 
Flrst we examine the change in net revenue to the communfty government under assumption (a). In this case, the 0 \& $M$, construction, and land costs incurred by the community government are just offset by industry user fees, and $\Delta \mathrm{M}, \Delta \mathrm{L}$, and $\Delta \mathrm{K}$ cancel out of the equation. The recelpt of user fees collected against the grant, however, are unmatched by costs incurred by the community government and the amount of these fees retained constitutes a net revenue gain by the community government.

$$
\Delta N_{1}=\frac{+.375 \Delta K}{n}\left|\frac{(1+1)^{n}-\overline{1}}{1(1+1)^{n}}\right|
$$

where

$\Delta N_{1}=$ the summation of costs incurred (negative effect) and revenue received (positive effect) by the communfty government due to provision of an abatement facllity for Industrlal wastewater. (Subscripts 1, 2, and 3 designate cases examined under alternative assumptions.)

$\Delta \mathrm{K}=$ the change in construction cost attributable to provision of service to industry,

$\frac{(1+1)^{n}-1}{1(1+1)^{n}}=$ the present worth formula used to convert a stream of annual payments to a present value, where $n$ is the $\frac{.375 \Delta K}{n}\left[\frac{(1+1)^{n}-1}{1(1+1)^{n}}\right]$ number of interest periods and $i$ is the discount rate, and $=$ the present value of retalned user fees under the assumptions for this case.

From equation (32) we can see the net improvement in the revenue position of the community government. Thus, in this case, the community government has incentlve to provide facllities with large eligible construction costs to treat industry wastes.

For the second case let us continue to malntain all the above assumptions, with the exception that we now assume the community government does not recover revenue from industry to repay its share of construction costs not covered by the grant. The other costs incurred by the community 
government are again just offset by user fees, but construction costs are not offset by user fees. The outcome in terms of the community government's revenue position is less clear.

$$
\Delta N_{2}=-.25 \Delta K+\frac{.375 \Delta K}{n}\left[\frac{(1+1)^{n}-1}{1(1+1)^{n}}\right] \text {. }
$$

Here the provision of services to industry may or may not result in an advantage to the community government, depending upon the time over which the user fees are to be collected and the size of the discount rate. For short time horizons and low discount rates, the value of the retained user fees could even in this case exceed the additional capital costs incurred by the community government.

For a third case, we assume that the community government recovers from Industrial users their share of local construction and other costs, but we now assume that it applies the reserve fund to a future project for which a grant could be recelved. That is, the reserve fund is used in such a way that it reduces the future receipt of grant money. Again, the expendltures for $0 \& M$, land, and capital costs are assumed just offset by receipts of user fees, thereby canceling $\Delta \mathrm{M}, \Delta \mathrm{L}$, and $\Delta \mathrm{K}$ from the equation. In this case the change in the community government's net revenue position resulting from treatment of industrial wastes will be less positive than in the first case shown above, but nevertheless positive.

$$
\begin{aligned}
\Delta N_{3} & \left.=+.25^{[\cdot 3 \Delta K}\right]\left[\frac{(1+1)^{n}-1}{n}\right]+\frac{.075 \Delta K}{n}\left[\frac{\left.(1+1)^{n}-1\right]}{1(1+1)^{n}}\right] \\
& =\frac{+.150 \Delta K}{n}\left[\frac{(1+1)^{n}-1}{1(1+1)^{n}}\right] .
\end{aligned}
$$

Thus, in this case, too, it is possible for the local community government to improve its net revenue position by increasing construction cost attributable to industry.

We can summarize the financlal effects arising from provision of industrial abatement facilities, on the various parties involved, as follows: The Federal government pays $75 \%$ of construction costs and recoups an amount 
equal to $37.5 \%$ of construction costs in user fees. The community government pays $25 \%$ of construction costs and recovers an amount equal to as much as $62.5 \%$ of construction costs in industrial user fees; it pays $100 \%$ of other costs and may recelve a like amount in user fees. The industrial sector of the community at the most pays $100 \%$ of total costs, less interest costs; It recelves $100 \%$ of abatement services resulting from the total expenditures. The net revenue recelved by the community government, which may amount to as much as $37.5 \%$ of construction costs, may be used for the benefit of both the nonindustrial and industrial sectors. As inducement to industry to connect to the municipal system, the community government could reduce somewhat its user charges to industry for locally-incurred costs, such that Industry would In effect pay less than $100 \%$ of costs less interest. Other things equal, this effect would be expected to give some incentive to municipalities to provide capital-intensive and/or eligible land-intensive facilities for treatment of industrial wastewater, since by so doing the community at large would benefit.

With respect to other problems arising from existing user fee arrangements, there may be inefficlent, and possibly conflicting, incentives provided as to the use of the retained amounts. On the one hand, we have seen a possible incentive for the community to spend the reserve fund for eligible costs of projects which are accorded low priority or considered of marginal Importance by grant program administrators but which are given high priority by the community, such that the fund 1 s not used on projects where the likelihood of recelving a grant is high. With this approach, the local community deducts the reserve fund from its costs without having the amount of 1 ts grants correspondingly reduced. On the other hand, the community may have incentive to accumulate the fund for use as a lever In obtalning future grants.

Another implication of existing Federal user fee arrangements is that they appear to favor industrialized communities over residential communities. That is, even though benefits recelved for two communities may be the same, the real nonfederal cost shares will vary according to the proportion of 
treatment relegated to industry needs. Construction costs to a residential community are equal to $.25 \mathrm{~K}$, and the subsidy amounts to $75 \%$ of construction cost. But for an industrialized community, the subsidy amounts to $75 \%$ of total construction cost plus $25 \%$ to $100 \%$ of the present value of the reserve fund plus the present value of the discretionary fund, and the local share of cost is less than. 25K. Thus the communities servicing industry are glven an additional Federal contribution beyond the $75 \%$ of construction costs, which other communities do not receive.*

In general, industrialized communities may benefit from the reserve fund. The reserve fund provides a sure source of money which, with the approval of the reglonal EPA Administrator, may be used for eligible abatement costs at any time. The approval process is separate from the usual grant application procedure and does not require a priority rating. Thus the grantee-trust-fund holder has a ready source of construction funds for which it need not compete with other communities. The reserve fund may also give the grantee an advantage in obtaining additional grarits because, as was explained above, the Federal granting agency will be able to generate more abatement per Federal grant dollar where the reserve fund is applied.

A further problem with the existing user fee arrangements is that there is no guarantee that the municipality will choose to use the discretionary fund for wastewater abatement. Hence, a portion of the Federal subsidy may not contribute to the grant program's objective of providing incentive to municipalities to construct treatment works.

A final implication of the current user fee program, perhaps obvious at this point, is that $1 \mathrm{t}$ obscures the effective Federal and local cost shares. As may be seen by comparing equations (25) and (31), the actual cost to the grant recipient may differ substantially from the $25 \%$ of capital plus $100 \%$ of $0 \& M$ implied by the main cost-share provision (Sec. 202(a)) of

*Beyond the revenue advantage gained by retention of user fees, the local community would also benefit if economies of scale resulted from inclusion of industry. 
the 1972 Act. The legislation and regulations pertaining to user fees are difficult to understand in prose and logic. As a result, community governments' Interpretations of the law, and, consequently, their ultimate cost shares, may differ from what was intended by the legislation. Communit1es whose managers are skilled in the grant process may be able to ut1lize the obscure provisions of existing arrangements to reduce their effective cost share, whereas communities with less sophisticated management may recelve less Federal contribution.

In summary, exlsting user fee arrangements are characterized by the following:

(1) Retention of user fees produces a potential blas towards overbullding;

(2) retention of user fees encourages municipalities to provide abatement services to industry; (3) retention of user fees biases municipalities towards selection of capital-intensive and eliglble land-intensive techniques to treat Industrlal wastewater; (4) omfssion of an interest charge from Industry user fees is a subsidy to industry and reduces user fee revenue; (5) retention of user fees results in unequal treatment of residential communities as compared with industrialized communities; and (6) existing arrangements obscure real cost shares.

A rationale for the pollcy permitting municipalities to retaln user fees is to provide the municipality with a source of future funds whereby 1 t might become self-supporting in abatement activites. And, the retention of user fees does appear to provide a source of funds for future needs. But the practice has efficlency and other effects which might be regarded as problems. Returning these retained user fees to the Construction Grant Program for redistribution among grant applicants through the regular grant procedures would appear to eliminate the problems described above, without reducing the amount of total funds avallable to municlpalities. 
1. Raymond, Richard. The Impact of Federal Financing Provisions in the Federal Water Pollution Control Act Amendments of 1972. p. 7.

2. Final Construction Grant Regulations, Construction Grants for Waste Treatment Works. p. 5263.

3. Ib1d., P. 5263-4.

4. Ib1d., p. 5263 . 


\section{SECTION VII}

SUMMARY, FINDINGS, AND

SUGGESTIONS FOR FURTHER RESEARCH

\section{SUMMARY}

The Environmental Protection Agency (EPA) administers the Construction Grant Program for the abatement of wastewater pollution. The Federal Water Pollution Control Act Amendments of 1972 (1972 Act) describe to some extent the eligibility requirements for a community to apply for EPA grants and the percentage Federal cost shares that can be awarded for community abatement projects. The construction Grant Program, as enacted by the 1972 Act and administered by EPA, has been criticized for being ineficient in that it encourages a misallocation of resources in wastewater pollution abatement.

The purpose of this study is to evaluate alternative cost-sharing programs with respect to carefully defined efficiency and equity criteria. The emphasis is on efficiency. Findings of the study are presented describing efficiency and equity implications of alternative cost-sharing rules and of institutional changes affecting cost sharing.

The focus of this study is on the local incentive effects of Federal cost sharing; that is, how Federal grants might encourage local communities to pick one kind or size of abatement technique over another.

The existing cost-sharing program as described in the 1972 Act and implemented by Agency regulations is discussed in Section III. The eligibility for grants, that is, what costs are allowable and unallowable under the Construction Grant Program, is demonstrated to differ when examined from the standpoint of legislation and what occurs in practice. Eligibility for Federal grants 
Is also shown to vary among the different abatement techniques. Cost shares awarded by EPA are shown to have averaged $36 \%$ of eligible construction costs up to 1972 , as compared to the $75 \%$ maximum share now allowed for by the 1972 Act. Institutional constraints other than cost-sharing eligibility are identified that may bias communities against nationally efficient choices in pollution abatement. For examples, such constraints as minimum treatment standards, training and education biases toward plants on the part of decision-making engineers, small areas of abatement jurisdiction, and use of sewerage systems as growth management tools appear to play a significant role in affecting what techniques are chosen by communities seeking assistance in pollution abatement.

The theoretical relationships between cost sharing and the selection of nationally efficient techniques (plant or nonplant) for abatement are discussed in Section IV. A selective survey of the literature presents the background of work done in evaluating efficiency and equity of cost sharing in the water resources area. The local demand for pollution abatement is shown to be inversely related to the local cost share. The effect of abatement standards on the demand for abatement is also explored, both for the case where standards are enforced and for the case where standards are not enforced. The optimal cost sharing rules are then derived for encouraging communities to select (1) the least-cost techniques for abatement and (2) the nationally efficient scale of abatement. Existing cost-sharing rules are found to be inequitable in terms of certain characteristics of equity that are defined in the study.

In evaluating efficlency implications of existing and alternative cost-sharing programs in Section $V$, a number of problems concerning community selection of abatement were identified in the existing program. Case examples 111 ustrate the bias effects on communities of current rules that apply different cost-sharing percentages to different techniques and to different cost categoires. Local communities under existing rules have a cost-sharing bias to pick techniques with the minimum local financial commitments, and these are not necessarily the least-cost techniques to the nation. Alter- 
native practical cost-sharing rules are proposed that do not entirely meet the efficiency conditions derived in the study, but that more nearly satisfy those conditions than existing rules.

\section{FINDINGS}

(1) Same Percentage Cost Share

for Al1 Techniques

Application of the same percentage cost share to all plant and nonplant techniques for the purpose of abating wastewater pollution w111 encourage nonfederal interests to simultaneously select the combination of techniques which is least costly for the nation as well as for themselves. This rule applies both to the case where communities seek to maximize net benefits from abatement with a budget constraint and to the case where a given standard of abatement is enforced.* Applying the same share (regardless of what that share 1s) across all techniques w111 eliminate the potential cost-sharing blas for some techniques over others (e.g., for plant over nonplant techniques) that appears to exist under the current rules. (See Sections IV and V.)

To encourage consideration of new technologles that might not be known at the time legislation is drawn up, the cost-sharing eligibility condition could be specified simply as all technically viable alternatives. Nonfederal interests would have an economic incentive to apply for grants for techniques that are cost effective.

A related problem that results from sharing all technically viable techniques is determining what part of an activity is abatement, and consequently what part of that activity should be cost shared. For example, rehab111tation of sewers is a multiple-purpose profect that provides benefits through abatement as well as through wastewater collection. By cost

*It is recognized that global efficiency in the sense of the efficient allocation of resources among all national programs is not necessarily reached by equilibrating cost shares for techniques only in pollution abatement programs. 
sharing only those costs under the Construction Grant Program that can properly be allocated to abatement per se, the nationally efficient scale of abatement w111 be encouraged. Thus, a lower Federal cost share would be applied to techniques that provide benefits other than abatement, and the cost share would decrease as the cost of providing those other benefits increases relative to the cost of abatement.

(2) Same Percentage Cost Shares

for A11 Cost Categories

Application of the same percentage cost share to all cost categories of al1 techniques for abating wastewater pollution will encourage community selection of the nationally least-cost technique(s) of providing abatement. All categories of project costs would include capital; 1and for both site and process; operation and malntenance; and planning.

A bias to choose certain techniques results when different cost-sharing percentages for the different categories of cost are applied to techniques having different cost composition, 1.e., different ratios of cost categories. Because operation and maintenance costs, for example, are not currently shared at all by the Federal government, while capital costs are shared, grant reciplents are blased towards capital-intensive techniques even though all techniques may be eligible for the same percentage share of capital cost. (See Sections IV and V.)

Assuming there are reasons why all categorles of costs could not be shared, two alternatives for encouraging local selection of the least-cost technique(s) might be considered in 1 leu of the same percentage for all categories. The first alternative satisfles the necessary condition for encouraging the selection of the least-cost technique(s), and the second can satisfy it under certain situations. The first approach is to vary the share of the single cost category to be subsidized, let us say capital as an example, so that the local share as a percentage of total project costs (1.e., the effective cost share) will be uniform across all techniques. A second approach, st111 providing a Federal share for one category on $1 y$, would impose a constraint on the percentage of total costs that the Federal agency could bear. The cost-sharing bias will be reduced to a degree dependent on how low the constraint is and in some cases will be eliminated. (See Section V.) 
Findings 1 and 2, if implemented, would enhance equity in comparison to existing cost-sharing rules in that grant recipients would be more certain over time of what they will receive for any given total project cost regardless of the technique chosen or the composition of cost categories. (See Section IV.)

\section{(3) Consideration of a Reduced Federal}

\section{Cost Share}

Nationally efficient scales of abatement would be encouraged by reducing the effective Federal cost share. The legislation governing the Construction Grant Program does not specify nationally efficient scales of abatement (1.e., the maximization of national net benefits) as an objective of the program (see Section IV). However, the Association Rule (see Section IV) could meet such an objective by encouraging grant recipients to choose a scale of abatement that is nationally as well as locally efficient. For most projects, existing Federal cost shares probably exceed those that would be obtained from applying the Association Rule (see Section V). Lower Federal shares could be large enough to provide some incentive for communities to expand their abatement activities and still tend to encourage more efficient scales. Since available information regarding the incidence of abatement benefits is not comprehensive, further research is needed before specific percentage cost shares can be selected.

\section{(4) Same Percentage Cost Shares for}

Communities of All Sizes

Varying cost shares in proportion to community size, other things being equal, may lead to inefficient scales of development.

Over some range of abatement levels, the average cost of abatement (i.e., the cost per unit of abatement) will fall as a result of economies of scale. Assuming that this range of decreasing average cost extends to large scales of abatement, big citles with large demands for abatement would be expected to have lower average costs than small cities with less demand for abatement.

One way of encouraging small cities to demand higher levels of abatement and thereby profit from economies of scale is to raise the percentage cost share for small cities above that of big cities. (There may also 
be nonefficlency reasons for giving small clties preferential cost shares.) The imnlication of the preferential cost share, however, may be a less rather than more efficient allocation of resources to abatement. That is, the efficient scale of abatement for a small city may be much less than that scale at which average costs are minimized (see Section IV).

Thus, if preferential Federal cost shares are offered to small cities to encourage them to take advantage of economies of scale, the result may be an oversized project from the standpoint of maximizing net benefits from abatement.

Achieving efficient levels of abatement is not necessarily incompatible with taking advantage of economies of scale. For example, it might be advantageous to individual cities as well as the nation for cities to foin in the construction of regional treatment plants that would lower the average cost of abatement to all while at the same time providing the efficient level of abatement. Cost sharing is one of many incentives that could be used to encourage a regional approach to abatement.

(5) User Fees Returned to

Construction Grant Program

The problems arising from the grantee's retention of half the industrial user fees collected against the Federal grant could be eliminated without reducing the total amount of Federal funding by returning the full amount to EPA for redistribution through the regular grant process.

Existing Federal user fee arrangements, which allow the grant recipient to retain part of the user fees collected from industry to repay industry's share of the Federal grant, increase the Federal contribution to abatement and reduce the effective cost share of the grantee. The grantee is free to use $20 \%$ of the amount retained in any way he chooses. This $20 \%$, the discretionary portion, of retained user fees increases the Federal contribution by its full amount. The grantee must hold the remaining $80 \%$ of retained user fees in a reserve fund for use only for eligible project costs. Claims to the contrary notwithstanding, the reserve portion of retained revenue also results in an increase in the Federal contribution to abatement and 
reduces the grantee's cost share. The reserve fund will usually raise the Federal subsidy by an amount equal to $25 \%$ of the present value of the fund although the reciplent may use tho regerve fund in such a way as to reduce his costs by the full present value of the fund. The amount of retained revenue and hence the size of the Federal and local cost shares, depends upon the percentage of construction costs allocable to treatment of Industrial wastes.

Efficiency problems which appear to result from existing user fee arrangements are the following: (1) Retention of user fees collected against the Federal grant provides incentive to municipalities to provide abatement facilities for treatment of industrlal wastes which are capital-intensive and eligible land-intensive in nature. Municlpalities are encouraged to treat industrial wastes because they may improve their net revenue position by so dolng; they are blased towards provision of capital-intensive and eligible land-intensive techniques because capital and eligible land expenditures enlarge the potentlal Federal subsidy, while expenditures for $O \& M$ do not. (2) Retention may increase the grantee's tendency to select an excessive scale of abatement by increasing further the differential between the grantee's share of benefits from abatement and its share of costs. (3) Part of the additional subsidy may not further the objectives of the grant program since the grantee may choose not to use the discretionary portion of retalned revenue for wastewater abatement.

In addition, under existing user fee arrangements industrialized communities recelve a larger percentage Federal cost share than do communities which are primarily residential even though nonfederal benefits as a proportion of national benefits may be essentlally the same for both types of communities. The additional Federal subsidy to the grantee resulting from retained user fees increases as the Industrial component of wastewater increases, such that the more Industrialized the community, the lower the effective nonfederal cost share.

Exlsting arrangements also appear to give rise to incentive effects which may not be appropriate to the program or necessarily intended under the law. The existing program, for example, may give conflicting incentives 
to grantees regarding use of their reserve fund. On the one hand, the community has the incentive to spend its reserve fund for items for which it has strong demand but for which the prospects of receiving grant funds are low. This may lead to use of the fund for purposes which are regarded as relatively less important and therefore accorded low priority by grant administrators. On the other hand, possession of the fund may improve the chances of a community's recelving an additional Federal grant, and may thereby provide an incentive to hold the fund for use in applying for grants for large projects.*

The retention of user fees may be criticized in general on grounds that it obscures the true Federal and local cost shares. Difficulty in interpreting the law and regulations may contribute to different ultimate cost shares among grant applicants. (See Section VI.)

\section{(6) Interest Charge to Industrial Users}

Inclusion of interest charges in industrial user fees would make industry charges more reflective of the economic cost of providing abatement service to industry, and would increase the amount of revenue available to the Federal and community governments.

Existing program regulations require that industrial user fees not include an interest charge. When the payments for industry's share of construction costs are collected over a long period, without an interest charge, industrial users tend to be substantially undercharged. As a result, industry recelves a substantial subsidy and, thereby, an incentive to connect to the municipal abatement system, while potential public revenue 1 s foregone. (See Section VI.)

\section{(7) Elimination of Legal and Other Institutional Constraints}

There are a number of possible institutional obstacles which may discourage selection of certain techniques even if they are the cost-effective choices.

*As noted above, the existing user fee arrangements also provide incentive to communities to treat industrial wastewater in the municipal system. The desirability of this incentive effect was not investigated. 
If, for Instance, State and EPA design standards, guidelines, and technology transfer manuals are very conservative and emphasize the well-established processes, they may blas municipalities towards treatment plant processes. Examination of these documents for blas and inclusion of necessary revisions will help to encourage selection of cost-effective techniques.

The training and experience of many state and EPA offlctals who review applications are geared towards traditional plant/engineering solutions. Educational and promotional efforts to encourage planners to consider nonplant techniques might lead towards more comprehensive evaluation of alternatives during the initial planning stages.

Architects'/engineers' fees for design of a facillty traditionally have been based upon the amount of capital costs -- a practice which may bias designs for abatement facilities towards capital-intensive and away from nonplant and/or low capital techniques. Basing the fees on 0 \& M costs, as well as capital costs, might avold this bias.

Another institutional problem is that small jurisdictions may not be in a position to implement certain kinds of abatement techniques, to organize collective facllities, or to integrate use of multiple techniques; hence, they may not be able to adopt the cost-effective approach to abatement. Further development of reglonal management systems are needed to overcome this problem.

Emphasis in the law, the regulations, and the program of some techniques more than others may lead to preferences for these techniques by grant applicants who perceive them as "favored" in the grant approval process. Uniform treatment of abatement techniques would avold this blas. (See Section III.)

If the seven findings that are identified above were to be acted upon and appropriate changes Implemented in the Construction Grant Program, the following results could be expected: the local cost-sharing bias for capital-intensive and eligible land-intensive techniques would be reduced; the local cost-sharing blas for some plant over nonplant techniques would 
be reduced; Federal and nonfederal expenditures on nonplant techniques would increase relative to plant techniques; the commuity demand for nonplant techniques would Increase; and the degree of abatement per national dollar spent would increase.

SUGGESTIONS FOR FURTHER RESEARCH

The research evaluation undertaken for this report uncovered additional areas of research that might be of value to EPA in meeting its objectives of encouraging efficiency in abatement and of treating cost-sharing parties equitably.

One type of research needed is the investigation of incentive effects of institutional requirements (i.e., minimum treatment standards, minimum levels of discharge, etc.) on communities' selections of techniques of abatement. It might be demonstrated, for example, that institutional requirements as well as cost sharing represent critical elements in biasing nonfederal interests in favor of certain kinds of abatement techniques.

A second research problem of relevance to this study is the determination of the optimal points in time at which to reduce or eliminate Federal abatement grants. For example, given an objective of meeting a certain level of discharge by a certain date, grant officials would like to know at what times and by what percentages grants could be reduced to meet the discharge level and get the abatement programonaself-sustaining basis as soon as possible.

A third potential area for useful research is the analysis of the link between levels of local performance in abatement and rewards or grants based on good performance. Some states, such as New York, for example, share up to one-third of the costs of operation and maintenance with cities that manage their plants well. Variable Federal grants based on local performance is one way of encouraging good performance. A loan which makes the amount paid back inversely related to the performance of an abatement project might be another promising incentive for good local performance. 
A fourth topic of additional research is the determination of community objective functions in pollution abatement. If communitles do in fact regard collection and disposal as their primary wastewater goals rather than abatement, then the optimal approach to encouraging nationally efficlent behavior on the part of communities would have to be altered accordingly. Incentives cannot be formulated unt1l the objectives of the parties to be affected are known.

A fifth area of research is the sensitivity of communitles to having their costs varled for certain techniques. Th1s cost-sharing elasticity, 1.e., the percentage change in the demand for abatement relative to a percentage change in the local cost share, would enable decision makers to estimate more accurately the impact on nonfederal demands for abatement of changing cost-sharing rules. 


\section{APPENDIX}

\section{DESCRIPTION OF WASTEWATER ABATEMENT TECHNIQUES}

The pollution abatement techniques discussed in the report and listed in Exhib1t 1 are here further described. The purpose is to give the reader a better understanding of the techniques and perspective of how they might be applied to particular wastewater abatement problems.

Table 10 shows four major problems faced by many municipal waste treatment systems. The table gives the typical cause of the problems from a technical standpoint and possible solutions to the problems, including use of both plant and nonplant treatment, prevention, and control techniques. For example, a major problem is pollution from wastewater overflowing the collection system; the Immedlate cause is usually insufficient flow capacity of the sewers; and possible techniques to solve the problem include separation of storm and wastewater sewers, temporary storage of storm and wastewater for later transmission to the plant for treatment, treatment of overflows, Increasing the rate of transmission to the plant, etc. From the table 1 t may be seen which techniques appear more applicable to each of the particular problems.

It should be noted that all of the techniques listed are not necessarily technically viable in all situations. For instance, some techniques such as low-flow augmentation may be site-dependent. Techniques may be applicable only in certain cases. For example, rerouting wastewater to a larger body of water or dividing discharge among waterways to reduce the burden on the receiving waterway obviously is a viable technique only if alternative receiving waters are available. Also tradition and legal constraints may restrict the use of a technique to specific circumstances. 


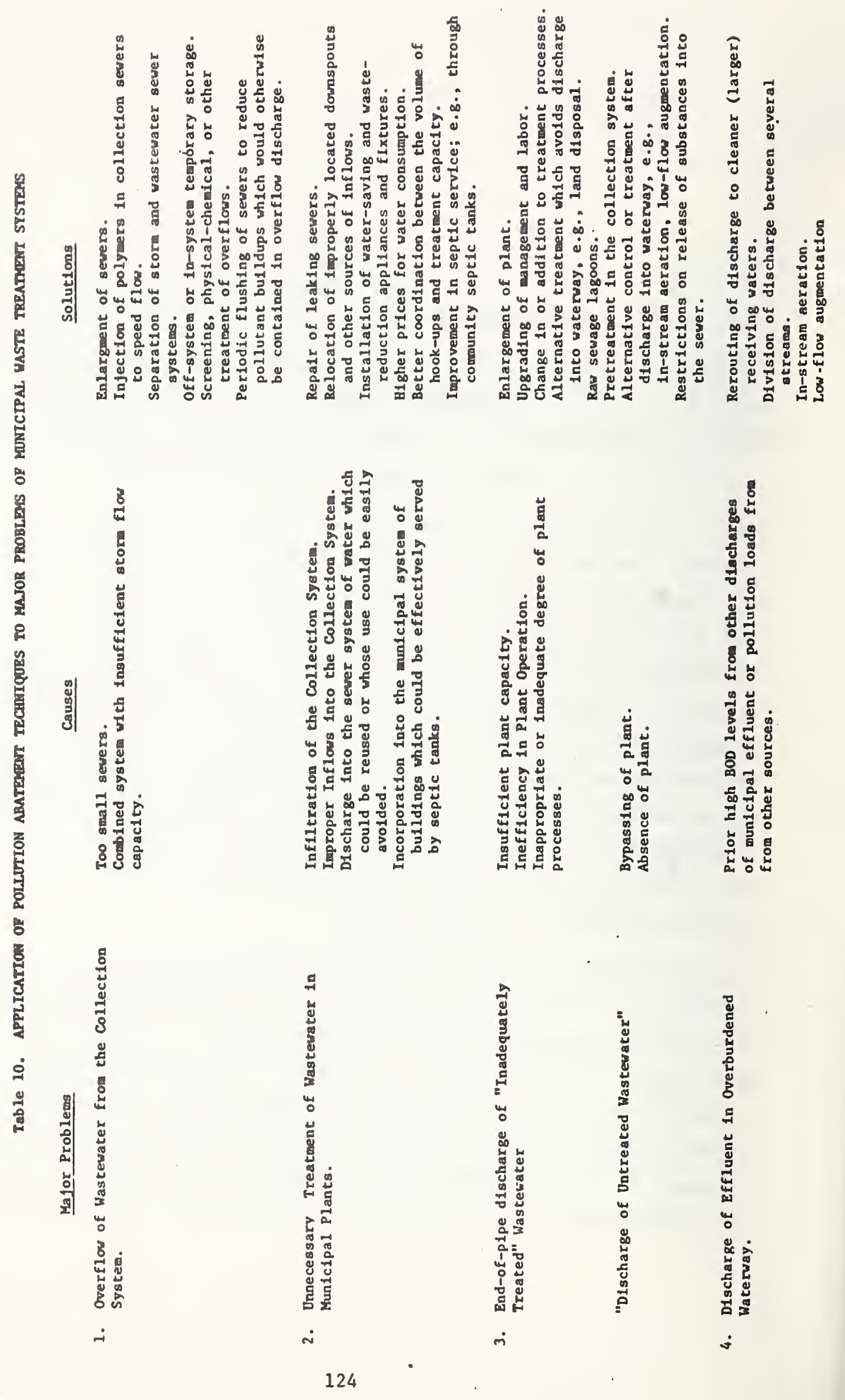


For example, in-stream aeration has been generally regarded as sultable for special problems only, such as restoration of a polluted area of a waterway for which raising the general water quality through advanced treatment of wastewater inflows would be a slow and costly approach. The technique has generally not been regarded as a substitute for plant treatment per se. Following are descriptions of each technique:

Water Use Reduction Programs are measures undertaken by public agencies to reduce the volume of water used by households and industry. Since most water when used becomes wastewater in the sewerage system, a reduction in water consumption lessens the burden on sewage disposal facilities. (Note that increasing the volume of water in the sewer system has the negative effect of Increasing the volume of wastewater which must be collected, treated, and disposed, while increasing the quantity of receiving water into which effluent or wastewater is discharged has the positive effect of diluting the concentration of wastes.) Some measures which might be undertaken by public agencles to reduce water use are (1) education programs to teach the public water-saving practices; (2) use of water pricing to decrease the demand for water by increasing its cost; and (3) tax, subsidy, or regulatory programs to encourage installation of low water-use devices and appliances, such as reduced-flow toilets and faucets, level control and water retention devices on automatic washers, and recycle/reuse systems which treat and reuse bath and laundry washwater for tollet flushing and lawn irrigation.

Active Control of the Sewer Collection System is using the sewer collection system to reduce, control, or treat wastewater prior to 1 ts entering the treatment plant. Active control of the collection system affects what can and should be done in the treatment system. Four of the techniques whereby the collection system can be used to accomplish wastewater control, reduction, or treatment are the following techniques:

(1) Injection of High Molecular Weight Polymers into the Collection System reduces the flow resistance of wastewater and thereby increases the transmission of wastewater through the collection system. In effect, the technique is a substitute for enlargement of the collection pipe, in that both techniques increase the load capability of the collection system. 
(2) Controlled Flow in the Collection System is the selective retention and release of wastewater from the collection system to the treatment system for the purposes of (a) increasing efficiency in plant operations by achieving more uniform inflows of wastewater to the plant, and of (b) preventing overflows of untreated wastewater from the collection system into waterways when inflows into the system exceed transmission and/or treatment capability. (Retention to prevent overflows may require the addition of storage facilities to the collection system.)

(3) Pretreatment in the Collection System is any treatment action taken in the collection system to improve transmission to the plant or to reduce later processing requirements; e.g., grit removal may be done in the collection channel, wastes may be ground and wastewater may be preaerated in order to satisfy immediate BOD, decrease odor, or improve later processing.

(4) Controlled Flushing of Sewers is the deliberate washing out of combined sewer systems perlodically in order to capture for treatment the pollutants which accumulate in the pipes during dry periods and which otherwise would worsen the contamination problem from storm overflow. Methods of flushing sewers include (1) the quick discharge of sewage from tanks located in manholes, and (2) the blocking of the lower end of laterals with quickrelease, inflatable barriers.

This study is concerned with those aspects of Enhancement and Rehabilitation of Collection Sewers which contribute to abatement of wastewater pollution. Th1s would include improvement in design or construction of the collection system which enables the system better to transmit wastewater which requires treatment and to exclude intake of water not requiring treatment. Innovative features may be initially incorporated in new collection systems; existing systems may be rebuilt or repaired to include improvements. Following are some specific measures which may be taken to improve pollution abatement by use of the collection system. 
(1) Enlargement of Sewers refers to Increasing the size of the sewer pipes to Increase transmission of wastewater through them. Undersized sewers may cause wastewater to be discharged before it reaches the plant.

(2) Separation of Storm and Wastewater Collection means the provision of two separate, parallel systems of pipes; one for carrying storm runoff from buildings and land and one for carrying sewage -in contrast to a combined sewer system which carries both sewage and storm water runoff in the same pipes. Separate systems require a much larger construction cost than combined systems because of the duplication of sewer 11 nes required. Separate systems, however, offer the advantage of reducing pollution from sewer overflow during wet periods. Overflow is a serious problem associated with combined systems. Combined sewers are generally designed to accommodate a maximum volume in excess of dry-weather flow, but during storms the capacity may be exceeded, resulting in the discharge of a mixture of storm water and raw sewage directly into recelving waters. Separation of the systems usually overcomes the problem of overflows, but does not prevent the problem of pollution from wastes present in the storm water, e.g., oily, salty runoff from streets.

Separation of sewers is not the only means of overcoming the problem of comblned sewer overflow. Possible alternative approaches include structural alterations ,to the interceptor systems; separation of santtary and storm water within the combined system by means of a pressure or vacuum sanitary sewer suspended within existing combined sewers; increase in transmission through the plpes and/or expansion of treatment capability (see Enlargement of Sewers and Injection of Polymers); storage of excess wastewater for later transmission (see Selective Retention); treatment of overflows (see Treatment of Overflows); selective placement of overflows (see Selective Routing of Effluent Discharge); reduction 
of contaminants in overflowing water by such things as pre-storm sewer flushing (see Controlled Flushing of Sewers), storage of Inttlal overflow with higher pollutant load, and more frequent cleaning of streets during dry periods.

(3) Construction, Repalrs, and Corrective Measures to Prevent Inf11tration and Inflows refers to efforts to prevent the entrance of ground water into a sewer through breaks, porous walls, or defective joints, or of the entrance of surface water resulting, for example, from improper location or connection of roof drains. Reduction in the amount of wastewater unnecessarily entering the plant conserves treatment resources.

Control of and Restrictions on Release of Certain Substances into the Sewer System means limitations or bans imposed by public authorities on the release of substances into the sewer system, either by households or Industries, for the purposes of reducing treatment cost or preventing untreatable waste from entering the system. For example, households might be restricted in their use of detergents containing phosphates; industries might be required to extract certain industrial chemicals from their wastes prior to discharge into a municipal system; and industries, for the purpose of reducing wastewater volume, mlght be banned from releasing water which could be reused by them without treatment (e.g., cooling water).

Influencing Declsions of Households and Industry to Connect or Not to Connect to a Municlpal Sewer System is a way public agencies may affect the volume and/or composition of wastewater flowing into the municipal sewerage system for treatment. One direct constraint is the imposition of a sewer moratorium which prohlbits tie-1ns. Pricing policy for connection of bulldings to the sewer system is another, though much less powerful, method of Influencing declsions. There are other approaches which may be undertaken by public agencles which are perhaps less obvious and less certain in effect than the two above. For example, an industry which ties into a municipal system generally is charged a user charge to offset the costs which 1t imposes upon the system. In pract1ce, however, the user 
charge may not fully cover 1ndustry's share of cost, or, by like token, 1t might be excessive. Hence the user charge may blas industry's choice. [Though not likely an instrument of policy, the relative efficiency of a municipal system may also attract (or repel) industries to (or from) a tie-in because of the posslbilities of sharing in economies of scale (or operational inefficiences).] There are other public policles and practices which through subsidization may influence industry's decision. For example, an industry which is charged a user fee equal to the nominal cost attributable to its wastewater disposal may nevertheless receive subsidies, in so much as there is (a) no sales tax on equipment installed, (b) no local property tax on the treatment facility, and (c) debt financing with long-term, low interest, tax-exempt bonds. Yet another factor in an Industry's decision to treat its own wastes and discharge directly into a waterway, or to discharge into a municipal system, is the degree of legal accountability associated with each choice. Without sophisticated monitoring devices, industry may reduce its accountability by mixing its sewage with other sewage in the municipal system. Lack of accountability also impedes the development by public authorities of an equitable user fee schedule. Public agencies may also influence industry's decisions by increasing the desirability of internal (1n-industry) wastewater reduction or treatment per se. This might be done by raising the cost of clean water, thereby increasing the attractiveness of wastewater recycling and reuse. Another strategy would be to call public attention to desired and undesired behavior by industry, relying on their concern for public image to influence decisions. As demonstrated in Section VI, existing Federal user fee policy, which allows grant recipients to retain half of the user fees collected from industrial users against the Federal grant, appears to give incentive both to municipalities to encourage industry to tie-in to the municipal system and to industry to choose to connect.

The objective of Discharge Flow Routing and Outfall Location is to place the effluent discharge into receiving waters so as to reduce the amount of wastes per unit of water, and thereby, improve water quality. Given a level of effluent, one method of controlling the ratio of waste to receiving water is to divide the discharge of effluent among several streams. 
Another method is to extend outfall systems to larger bodies of water where assimilative capacity is greater.

Low-Flow Augmentation of Recelving Waters is the supplementation of stream flow during periods of low natural flow by release of water, usually Impounded during times of excess flow, for purpose of reducing the concentration of pollutants in the waterway. By increasing the flow of water relative to waste material entering the waterway, the waste concentration is diluted (1.e., the ratio of wastes per unit of water is reduced) and the assimilative capacity of the water is increased. Generally low-flow augmentation is used to guarantee that water pollution will not rise above some maximum concentration. The technique is usually accomplished by daming waterways upstream of the area to be diluted and storing water in reservolrs prior to planned release. However, it may also be accomplished by the prevention of or reduction in upstream diversions of water during critical periods.

A Waste Treatment Plant is a series of tanks, screens, filters, lagoons, and other process units, which are arranged in close proximity to one another and generally involve buildings, facilities and a central organization. The treatment plant is the part of a sewerage system which comes after the sewer collection system and before the outfall, or discharge, system. The conventional waste treatment plant may combine any of a number of processes which together provide primary and secondary treatment, 1.e., removal of suspended solids, blodegradable organics, and microorganisms from wastewater piped to it. The advanced waste treatment plant typically adds to the conventional in-plant processes some additional (1.e., tertiary) blological-physical-chemical treatment techniques which enable reclamation of high quality water from wastewater. Table 11 indicates the large array of processes which could be employed in a waste treatment facility.

Land Treatment of Wastewater is the application of wastewater to land for purposes of treatment and disposal. This technique goes beyond the practice of land disposal of sludge, the solid matter remaining after plant treatment of wastewater, in that both the liquid and solid wastes may be disposed in 


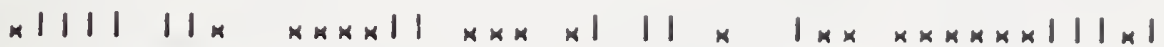

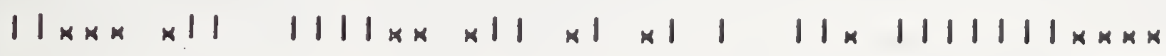


this manner, and the land application is itself used as a total or partial treatment process. The technique may be carried out in several ways: (1) The untreated wastewater, consisting of solids and 11quid, may be spread directly onto the 1and. (2) The untreated solld and 11quid components of wastewater may be separated, and the liquid sprayed by an Irrigation-type system on the land, and the solld part elther applied separately to the land or disposed of in some other way. (3) The wastewater may be partially treated, for instance by a perfod of storage in an oxidation pond or sewage lagoon, prior to land application by elther of the above methods. Objectives in land disposal of wastewater may include land fertilization, In addition to restoration of water quality which occurs as the water filters through natural solls. When the latter 1s the sole objective, marginal land unused for other purposes may be used. When the former objective $1 \mathrm{~s}$ present, the wastewater may be applied to farmland, woodland, and land under reclamation. Additional possible sites for disposal which might benefit from fertilization, as well as provide sultable disposal land in areas where adequate farmland and woodland are unavallable, are parks and highway medians and shoulders.

Community Sept1c Tanks are rural sewerage systems which provide wastewater disposal for a group of bulldings. They present an alternative to the conventional one-septic-tank-for-each-house arrangement now prevalent in rural areas not reached by municipal sewer 11nes. There are three main approaches to community disposal of wastewater in rural areas. The flrst 1s the plping of waste from a group of bulldings to a large septic tank, normally located on public land. Aside from 1ts large size, more extensive collection system, and location, the community septic tank is identical to the conventional single-bullding septic tank. It consists of a large, watertight contalner, usually made of concrete or steel and burled underground. In the tank, naturally occurring microorganisms in the sewage decompose 1t. The sludge settles on the bottom of the tank, from which 1t must be removed perlodically, and the clear effluent flows out of the tank through a system of distributing tiles or pipes into the ground, where It $1 \mathrm{~s}$ absorbed and becomes part of the ground water supply. A second approach is the perlodic collection by truck of wastes from individual 
holding or storage facilities located at rural buildings, and the transportation to a disposal area or facility. Th1s second approach may be necessary in areas where absorption of effluent into the ground from septic tanks is impeded, such as in areas of heavy rainfall, or where soll properties provide poor percolation, or where an excessive number of septic tanks overload absorption capacity of the surrounding ground. A third approach involves an arrangement by which a designated public authority assumes ownership and maintenance responsibility of individual septic tanks located on private property. As used in this report, the term "community septic tank" encompasses all of the above approaches to joint disposal of rural wastewater.

A Raw Sewage Lagoon is a pond for recelving and impounding raw sewage while the interaction of sunlight, oxygen, bacterla, and algae decompose the waste and restore the water to a purer state. Both gravity separation and blological reduction are accomplished in the lagoon. Though lagoons are more often used in confunction with conventional treatment plants to provide "polish treatment," raw sewage lagoons have been used successfully alone to provide treatment. They may be particularly sultable for smaller communitles where needed land is avallable at reasonable costs and wastewater loads are of manageable proportions, for treatment of certain kinds of industrial wastes, and as initial treatment facilities in newly developing areas prior to dense settlement. In the latter case, they may be used to provide polishing treatment if a plant 18 later added. The raw sewage lagoon may also be used in confunction with land disposal techniques, such as spray irrigation, to provide preliminary treatment. Aeration of Recelving Waters (In-Stream Aeration) is the introduction of afr or molecular oxygen, by artifical means, into a waterway for the purpose of raising the level of dissolved oxygen (DO), a key determinant of water quality. If natural sources of oxygen--primarily reaeration at the surface-are not sufficient to meet the biochemical oxygen demand (BOD) Imposed upon it (1.e., the amount of DO required for aeroblc decomposition of organic matter present in the water), the level of water quality deteriorates. Raising the level of DO Increases the waste assimilative 
capac1ty of the waterway and is one means of Improving water quality. There are a number of different types of systems or processes by which aeration of rivers, streams, lakes, and ponds may be accomplished. Some systems are site dependent, such as techniques which rely on weirs or dams. Other systems are more flexible with respect to site, such as (1) mechanical surface aerators which transfer oxygen by breaking the water into droplets and inducing turbulent mixing, (2) diffusion systems which introduce air or molecular oxygen directly into the water through perforated tubing, nozzles, or jets installed below the water surface, and (3) the side stream pressurlzation system in which a small percentage of the flow volume of river water is drawn off, mixed with oxygen under pressure and the supersaturated mixture is diffused back into the river.

Treatment of Overflow refers to the application of treatment processes to untreated wastewater dischaged from a sewer system into recelving waters when flow exceeds the system's transmission and storage capacity. Generally, overflows occur in a comblned sewer system during large inflows of storm water and consist of a mixture of storm water and raw sewage. Normal sewage treatment processes could be used, such as screening and straining and chlorination. Some processes may be applied to overflows at the rate at whlch they occur; others require storage of overflow for treatment. 


\section{B IBLIOGRAPHY}

Costs of Construction of Publicly-Owned Wastewater Treatment Works:

1973 Needs Survey. Environmental Protection Agency,

Washington, D.C., November 1973.

Cost to the Consumer for Collection and Treatment of Wastewater. Environmental Protection Agency, Washington, D.C., Government Printing Office. Water Pollution Research Series, No. 17090. July 1970. Table 24.

Davis, Robert K. The Range of Choice in Water Management, A Study of Dissolved Oxygen in the Potomac Estuary. Baltimore, The Johns Hopkins Press, 1968. p. 124-126.

Environmental News. Environmental Protection Agency, January 10, 1974, p. 2.

"Fairfax Sewage Plan Set," The Washington Post, March 27, 1974, p. C-1, Col. 1 .

Federal Assistance Programs of the Environmental Protection Agency.

Reprinted from the Catalog of Federal Domestic Assistance, Washington, D.C. June 1973, Sec. 66.015 .

Federal Grants for the Construction of Municipal Waste Water Treatment Facilities. Environmental Protection Agency, Washington, D.C.

Federal Water Pollution Control Act Amendments of 1972, PL 92-500, 92nd Congress, S.2770, October 18, 1972.

Fina1 Construction Grant Regulations, Construction Grants for Waste Treatment Works. Federa1 Register, XXXIX, No. 29, February 11, 1974.

Kneese, Allen and Bla1r Bower. Managing Water Qual1ty: Economics, Technology, Institutions. Baltimore, The Johns Hopkins Press, 1968. p. 97-179.

Lough11n, James C. Cost-Sharing for Federal Water Resource Programs with Emphas1s on Flood Protection. Water Resources Research. 6(2):377, Apri1 1970.

Marglin, Stephen A. Objectives of Water-Resource Development: A General Statement. In: Deslgn of Water Resource Systems, Maass, et. a1. Cambridge, Harvard University Press, 1962. p. 31-36.

Marshall, Harold E. Cost Sharing as an Incentive to Attain the Objectives of Shoreline Protection. National Bureau of Standards. Washington, D.C. NBSIR 73-294. Corps of Engineers. December 1973. p. 21-23.

Marsha11, Harold E. Economic Efficiency Implications of Federal-Local Cost Sharing in Water Resource Development. Water Resources Research. 6(3):673-682, June 1970 . 
Marshal1, Harold E. Salinity Control and Cost Sharing. In: Proceedings of the Western Resources Conference, 1973. Boulder: University of Colorado, July 9 and 10, 1973. In press.

Marsha11, Harold E. The Relationships Between Local Cost-Sharing and Efficient Water-Resource Development (unpublished $\mathrm{Ph} . \mathrm{D}$. dissertation, The George Washington University, 1969), p. 56-89.

Marsha11, Harold E. and Vartkes L. Broussallan. Federa1 Cost Sharing Policies for Water Resources. National Bureau of Standards. Springfield, Va., National Technical Information Service. No. PB-208-304. National Water Commission. 1971. p. 121-128 and 201-214.

Methods for Financing Water Pollution Abatement from Point Sources. Urban Systems Research and Engineering, Inc. Prepared for the Water Quality Office of the Environmental Protection Agency. August 1971. p. 39.

Musgrave, Richard. The Theory of Public Finance. New York, McGraw-H111, 1959. $628 \mathrm{p}$.

"Prince William Tables Funds for Sewer Plant," The Washington Post, February 5, 1974, Sec. C.

Project Register: Waste Water Treatment Construction Grants. Environmental Protection Agency, Washington, D.C. December 31, 1972.

Rafuse, Robert W. Jr. and Michael D. Sherman. The Implications of the Net Fiscal Benefits Criterion for Cost Sharing in Flood Control Projects. Mathematica Report. Washington, D.C. IWR Report 71-12. Institute for Water Resources, the Corps of Engineers. 1971. p. 11, 49-51.

Raymond, Richard. The Impact of Federal Financing Provisions in the Federal Water Pollution Control Act Amendments of 1972. Public Policy. 22:109-110, Winter 1974.

Regan, Mark. Sharing Financial Responsibility of River Basin Development. In: Economics and Public Policy in Water Resources Development, Smith, S. C. and Castle, E. N. (eds.). Ames, Iowa State University Press, 1961. p. 215.

Renshaw, Edward F. Toward Responsible Government: An Economic Appraisal of Federal Investment in Water Resource Programs. Chicago, Idyia Press, 1957. p. 50.

Research and Demonstration Program to Achieve Water Quality Goals: What the Federal Government Needs to Do. General Accounting Office. Washington, D.C., Government Printing Office. Volume 1, No. B-166506. Report to Congress. January 1974. p. 44-45. 
"Rivers Cleanup Aid Cut," The Washington Post, January 11, 1974, pp. A-1, A-4.

"Sewage Plant Work Halt Sought," Washington Star-News, January 27, 1974, P. B-4, Col. 3 .

Shoup, Carl S. Public Finance. Chicago, Aldine Publishing Co., 1969, p. 23.

The Federal Water Pollution Control Act Amendments of 1972, Highlights. Environmental Protection Agency, December 1972.

U.S. Congress, Senate. Policies, Standards and Procedures in the Formulation, Evaluation, and Review of Plans for Use and Development of Water and Related Land Resources, Sen. Doc. 97, 87th Congress, 2d sess., 1962, $\mathrm{V}(\mathrm{c})(2)$.

Waste Treatment Fund Allocations. Senate Committee on Public Works. 93rd Congress, 1st Session, Calendar No. 604, Report No. 93-630, December 13, 1973. p. 6 .

Water Policies for the Future. National Water Commission. Washington, D.C., U.S. Government Printing Office. Final report to the President and to the Congress of the United States. 1973. p. 77, 485-525.

Whipple, W1111am Jr. Instream Aerators for Polluted Rivers. Journal of the Sanitary Engineering Division. p. 1160-1161, October 1970. 
NBS.114A (FEV. 7.73 )

\begin{tabular}{|c|c|c|c|}
\hline $\begin{array}{l}\text { U.S. OEPT. OF COMM. } \\
\text { BIBLIOGRAPHIC DATA } \\
\text { SHEET }\end{array}$ & $\begin{array}{l}\text { 1. '1.IHIK ATION OR Rl:P(ORT NO. } \\
74-479\end{array}$ & $\begin{array}{l}\text { 2. Gov't Accression } \\
\text { No. }\end{array}$ & 3. Recipient's Accession No. \\
\hline \multicolumn{3}{|l|}{ 4. $1111.1:$ ANI) S1/BTITI.1: } & 5. Publication Date \\
\hline \multicolumn{3}{|c|}{$\begin{array}{l}\text { ANALYSIS OF COST SHARING PROGRAMS FOR POLLUTION } \\
\text { ABATEMENT OF MUNICIPAL WASTEWATER }\end{array}$} & 6. Performing Organization Code \\
\hline \multicolumn{3}{|c|}{$\begin{array}{l}\text { 7. AlllioR(S) } \\
\text { Dr. Harold E. Marshall and Rosalie T. Ruegg }\end{array}$} & 8. Performing Organ. Report No. \\
\hline \multirow{2}{*}{\multicolumn{3}{|c|}{$\begin{array}{l}\text { 9. 1'1:RI-ORMINC ORGANIZATION NAME AND ADDRESS } \\
\text { NATIONAL BUREAU OF STANDARDS } \\
\text { DEPARTMENT OF COMMERCE } \\
\text { WASHINGTON, D.C. } 20234\end{array}$}} & $\begin{array}{l}\text { 10. Project/Task/Work Unit No. } \\
4637430\end{array}$ \\
\hline & & & 11. Contract/Grant No. \\
\hline \multirow{2}{*}{\multicolumn{3}{|c|}{$\begin{array}{l}\text { 12. Simuling (Irpunization Name and Complete Address (Street, City, State, ZIP) } \\
\text { Office of Research and Monitoring } \\
\text { U.S. Environmenta1 Protection Agency } \\
\text { Washington, D.C. } 20460\end{array}$}} & $\begin{array}{l}\text { 13. Type of Report \& Period } \\
\text { Covered } \\
\text { Final }\end{array}$ \\
\hline & & & 14. Sponsoring Agency Code \\
\hline
\end{tabular}

15. SIIP'I.I:MI:NTARY NOTES

16. ABSTRACT (A 200.word or less factual summary of most significant information. If document includes a significant bibliography or literature survey, mention it here.)

This study evaluates existing cost-sharing programs for wastewater pollution abatement as described in the Federal Water Pollution Control Act Amendments of 1972 , describes alternative cost-sharing programs that provide improvements in terms of national efficiency and equity criteria as defined herein, and suggests related areas for further research. Emphasis is on how Federal cost sharing biases communities in favor of certain kinds of techniques. The approach is to describe the current costsharing programs for both plant and nonplant techniques; to examine cost-sharing, legal, and other institutional biases against certain techniques; to analyze efficiency and equity effects of alternative cost-sharing programs; and to describe the incentive effects of cost sharing on nonfederal interests with respect to their choices among abatement techniques. Findings of the study are that more efficient abatement will result if the same percentage cost share applies to all plant and nonplant techniques of abatement; the same percentage also applies to all categories of cost (e.g., capltal, land, operation and maintenance) for a given technique; the same percentage applies to large and small communities; institutional constraints on the selection of nonplant techniques are removed; and if the program provides for Federal cost sharing of every abatement technique that is technically viable.

17. KLY WORDS (six to twelve entries; alphabetical order; capitalize only the first letter of the first key word unless a proper nami: separated by semicolons)

Cost sharing; efficiency; equity; financing; nonplant treatment; sewage treatment; user fees; water pollution

18. AVAII.ABII.ITY [X Unlisnited

For Official Distribution. Do Not Release to NTIS

Opder Prom Sup. of Doc., U.S. Government Printing Office Washington, D.C. 20402, si) Cat. No. C 13

X Order lirom National Technical Information Service (N'IS springfield, Visginia 22151

\begin{tabular}{|l|c|}
\hline $\begin{array}{l}\text { 19. SECURITY CLASS } \\
\text { (THIS REPURT) }\end{array}$ & 137 \\
UNCL. ASSIFIED & 21. NO. OF PAGES \\
\hline $\begin{array}{l}\text { 20. SE(UURITY CLASS } \\
\text { (THIS PAGE) } \\
\text { UNCLASSIFIED }\end{array}$ & 22. Price \\
\hline
\end{tabular}




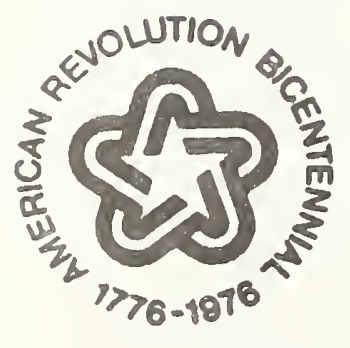

